\title{
Advances in Membrane Distillation for Water Desalination and Purification Applications
}

\author{
Lucy Mar Camacho ${ }^{1, *}$, Ludovic Dumée ${ }^{2,3}$, Jianhua Zhang ${ }^{3}$, Jun-de Li $^{4}$, Mikel Duke ${ }^{3}$, \\ Juan Gomez ${ }^{5}$ and Stephen Gray ${ }^{3, *}$
}

1 Center for Inland Desalination Systems, University of Texas at E1 Paso, 500 West University Avenue, E1 Paso, TX 79968, USA

2 Institute for Frontier Materials, Deakin University, Waurn Ponds Campus, Victoria 3216, Australia; E-Mail: ludovic.dumee@deakin.edu.au

3 Institute for Sustainability and Innovation, Victoria University, P.O. Box 14428, Melbourne, Victoria 8001, Australia; E-Mails: jianhua.zhang@vu.edu.au (J.Z.); mikel.duke@vu.edu.au (M.D.)

4 School of Engineering and Science, Victoria University, P.O. Box 14428, Melbourne, Victoria 8001, Australia; E-Mail: jun-de.li@vu.edu.au

5 Texas Sustainable Energy Research Institute, University of Texas at San Antonio, 1 UTSA Circle, San Antonio, TX 78249, USA; E-Mail: juan.gomez@utsa.edu

* Authors to whom correspondence should be addressed; E-Mails: 1camacho3@utep.edu (L.M.C.); stephen.gray@vu.edu.au (S.G.); Tel.: +1-915-747-5766 (L.M.C.); +61-3-9919-8097 (S.G.); Fax: +1-915-747-5145 (L.M.C); +61-3-9919-7696 (S.G.).

Received: 23 November 2012; in revised form: 14 December 2012 / Accepted: 25 December 2012 / Published: 25 January 2013

\begin{abstract}
Membrane distillation is a process that utilizes differences in vapor pressure to permeate water through a macro-porous membrane and reject other non-volatile constituents present in the influent water. This review considers the fundamental heat and mass transfer processes in membrane distillation, recent advances in membrane technology, module configurations, and the applications and economics of membrane distillation, and identifies areas that may lead to technological improvements in membrane distillation as well as the application characteristics required for commercial deployment.
\end{abstract}

Keywords: membrane distillation; heat transfer; mass transfer; module configurations; water desalination and purification 


\section{Nomenclature}

a exponent coefficient

$A_{\text {contact }}$ surface area of exchange $\left(\mathrm{m}^{2}\right)$

$A_{\mathrm{n}} \quad$ area calculated as the projection of the object on a plane normal to the main direction of the surface $\left(\mathrm{m}^{2}\right)$

$A_{\mathrm{m}} \quad$ surface area measured by any experimental adsorption technique $\left(\mathrm{m}^{2}\right)$

$b \quad$ membrane thickness (m)

$B \quad$ pore size morphology constant

$B_{0} \quad$ membrane characteristic

$C_{\text {membrane }}$ membrane mass transfer coefficient $\left(\mathrm{L} \mathrm{m}^{-2} \mathrm{~h}^{-1}\right)$

$C_{\mathrm{P}} \quad$ specific heat of water $(4.18 \mathrm{~kJ} / \mathrm{kg} / \mathrm{K})$

$d$ mean pore diameter of the membrane $(\mathrm{m})$

$d_{\mathrm{f}} \quad$ diameter of a single spacer fibre

$D \quad$ carbon nanotube diameter (m)

$E_{\text {elec,std }}$ electrical energy consumed per $\mathrm{m}^{3}$ of permeate $\left(\mathrm{kWh} / \mathrm{m}^{3}\right)$

$f \quad$ the permeance of the membrane

$F \quad$ single pass recovery

$g$ gravitational acceleration $\left(9.81 \mathrm{~m} / \mathrm{s}^{2}\right)$

$G^{\text {DCMD }}$ global heat transfer coefficient across the membrane in DCMD $\left(\mathrm{kW} \mathrm{m}^{-2}\right)$

$h_{\mathrm{f}} \quad$ feed boundary layer heat transfer coefficient $\left(\mathrm{kW} \mathrm{m}^{-2}\right)$

$h_{\mathrm{p}} \quad$ permeate boundary layer heat transfer coefficient $\left(\mathrm{kW} \mathrm{m}^{-2}\right)$

$h_{\mathrm{m}} \quad$ membrane heat transfer coefficient $\left(\mathrm{kW} \mathrm{m}^{-2}\right)$

$h_{\mathrm{sp}} \quad$ height of the spacer $(\mathrm{m})$

$H_{\mathrm{g}} \quad$ enthalpy of the vapor $(\mathrm{kJ} / \mathrm{kg})$

$\Delta H_{\mathrm{v}} \quad$ variation of enthalpy $(\mathrm{kJ} / \mathrm{kg})$

$\Delta H_{\text {vap }}$ latent heat of vaporisation $(\mathrm{kJ} / \mathrm{kg})$

$J_{\mathrm{w}} \quad$ water flux across the membrane $\left(\mathrm{kg} \mathrm{m}^{-2} \mathrm{~s}^{-1}\right)$

$K \quad$ membrane permeability $\left(\mathrm{kg} \mathrm{m}^{-1} \mathrm{~s}^{-1}\right)$

$k_{\mathrm{B}} \quad$ Boltzman constant $\left(1.381 \times 10^{-23} \mathrm{~J} / \mathrm{K}\right)$

$K_{\mathrm{i}, \mathrm{T}, \mathrm{P}} \quad$ a function of temperature, vapor pressure, and of the gas molecular mass

$K_{0} \quad$ membrane characteristic defined by Equation (9)

Kn Knudsen number

$K(T) \quad$ a function of temperature and molecular weight of the gas

$l \quad$ mean free path of the molecules

$l_{\mathrm{m}} \quad$ distance between parallel spacer fibres (m)

LEP Limit Entry Pressure $(\mathrm{kPa})$

$M \quad$ molecular mass $(\mathrm{g} / \mathrm{mol})$

$M_{w} \quad$ molecular weights of water $(\mathrm{g} / \mathrm{mol})$

$M_{a} \quad$ molecular weights of air $(\mathrm{g} / \mathrm{mol})$

$n \quad$ number of CNTs per unit cross section in bucky-paper

$P \quad$ pressure in the air gap $(\mathrm{kPa})$ 
$P_{\mathrm{A}} \quad$ atmospheric pressure $(\mathrm{kPa})$

$P_{\mathrm{T} 1} \quad$ vapor pressure at the hot stream temperature $(\mathrm{kPa})$

$P_{\mathrm{T} 2} \quad$ vapor pressure at the cold stream temperature $(\mathrm{kPa})$

$P_{\mathrm{Kn}} \quad$ ratio of the main membrane geometrical parameters ruling permeation

$P_{\text {Process }}$ liquid pressure on either side of the membrane $(\mathrm{kPa})$

$P_{\text {Pore }} \quad$ air pressure in the pore $(\mathrm{kPa})$

$P_{F} \quad$ MD module feed pressure $(\mathrm{kPa})$

$Q_{1} \quad$ total heat flux from the hot side to the cold side $\left(\mathrm{kW} \cdot \mathrm{m}^{-2}\right)$

$Q_{2} \quad$ total heat transfer from the bulk feed to the membrane interface $\left(\mathrm{kW} \cdot \mathrm{m}^{-2}\right)$

$R \quad$ the universal gas constant (taken as $8.3144 \mathrm{~m}^{2} \mathrm{~kg} \mathrm{~s}^{-2} \mathrm{~K}^{-1} \mathrm{~mol}^{-1}$ )

$\mathrm{r} \quad$ average radius of the pores $(\mathrm{m})$

$r_{\max } \quad$ maximum pore radius $(\mathrm{m})$

$t_{1 / 2} \quad$ half time to reach the maximum intensity-laser flash technique (s)

$t$ proportion of conductive heat (balance due to evaporative heat) loss through the membrane

$T \quad$ mean temperature in the pores $(\mathrm{K})$

$T_{\mathrm{mf}} \quad$ temperature of the membrane surface on the feed side (K) (also defined as $T_{1}$ )

$T_{\mathrm{mp}} \quad$ temperature of the membrane surface on the permeate side (K) (also defined as $T_{2}$ )

$T_{\mathrm{f}} \quad$ bulk feed temperature $(\mathrm{K})$

$T_{\mathrm{F}} \quad$ feed temperature of the brine (feed) stream $\left(\mathrm{K}\right.$ or $\left.{ }^{\circ} \mathrm{C}\right)$

$T_{\mathrm{E}} \quad$ exit temperature of the brine (feed) stream $\left(\mathrm{K}\right.$ or $\left.{ }^{\circ} \mathrm{C}\right)$

$T_{\mathrm{P}} \quad$ temperature polarization coefficient

$w \quad$ thermal diffusivity $\left(\mathrm{m} \mathrm{s}^{-1}\right)$

$\left(\frac{d T}{d y}\right)_{\text {boundary }}$ temperature gradient in the thermal boundary layer of the feed $(\mathrm{K} / \mathrm{m})$

\section{Greek Letters}

$\alpha \quad$ convective heat transfer coefficient on the hot side $\left(\mathrm{kW} / \mathrm{m}^{2}\right)$

$\beta \quad$ exponential value that varies with the ratio of the mean free path, $l$, to the average pore size of the membrane

$\varepsilon \quad$ membrane porosity (\%)

$\gamma_{\mathrm{L}} \quad$ surface tension of the liquid on the membrane surface $\left(\right.$ dyn $\left.\mathrm{cm}^{-1}\right)$

$\kappa \quad$ surface roughness

$\lambda \quad$ is the thermal conductivity of the membrane $(\mathrm{kW} / \mathrm{m})$

$\lambda_{\text {th }} \quad$ thermal conductivity $\left(\mathrm{W} \mathrm{m}^{-1}\right)$

$\mu \quad$ viscosity $(\mathrm{N} / \mathrm{m})$

$\eta \quad$ pump efficiency

$\Pi \quad$ power input of the conductivity meter (W)

$\tau \quad$ tortuosity of the membrane

$\theta \quad$ contact angle $\left({ }^{\circ}\right)$

$\theta_{\mathrm{f}} \quad$ angle between spacer fibres in the flow direction $\left(^{\circ}\right)$

$\sigma_{\mathrm{w}} \quad$ collision diameters for water vapor $\left(2.641 \times 10^{-10} \mathrm{~m}\right)$ 
$\sigma_{\mathrm{a}} \quad$ collision diameters for air $\left(3.711 \times 10^{-10} \mathrm{~m}\right)$

\section{Introduction}

Membrane distillation (MD) is a thermal, membrane-based separation process [1,2]. The driving force for the MD processes is quite different from other membrane processes, being the vapor pressure difference across the membrane rather than an applied absolute pressure difference, a concentration gradient or an electrical potential gradient, which drives mass transfer through a membrane [1,3].

Membrane distillation was introduced in the late 1960s [4,5]. However, it was not commercialised at that time for desalination purposes. There were two major factors hindering its development [6]: (1) Membranes with adequate characteristics and at reasonable cost were not available; and (2) the economics of the process were not favourable compared to reverse osmosis (RO) [7]. The comparative economics were based on typical data from those membranes and systems which were far from optimal and the finding that the temperature polarization coefficient was low (estimated by Schofield et al. [8] to be 0.32). Hence, for this system, when the temperature difference between the bulk temperature of the hot and cold channels was $10{ }^{\circ} \mathrm{C}$, the actual temperature difference across the membrane was only $3.2{ }^{\circ} \mathrm{C}$. In the $1980 \mathrm{~s}$, with the availability of new membranes, more research focused on membrane distillation and many novel MD modules were designed based on improved understanding of the mass and heat transfer principles of MD [9,10]. Furthermore, new applications for membrane distillation [11,12] were considered in environmental protection and wastewater treatment.

The MD process was defined in the "Round Table" at the "Workshop on Membrane Distillation" in Rome on 5 May 1986. According to the Terminology for Membrane Distillation [13], the MD process should have the following characteristics:

- The membrane should be porous;

- The membrane should not be wetted by process liquids;

- No capillary condensation should take place inside the pores of the membranes;

- Only vapor should be transported through the pores of the membrane;

- The membrane must not alter the vapor equilibrium of the different components in the process liquids;

- At least one side of the membrane should be in direct contact with the process liquid; and

- For each component, the driving force of the membrane operation is a partial pressure gradient in the vapor phase.

According to previous research [14], there are two major factors hindering the application of membrane distillation: One is suitable membranes for MD and the other is energy efficiency.

\subsection{Configurations of Membrane Distillation}

Figure 1 illustrates four configurations of the MD system, which differ based on the nature of the cold side processing of the permeate $[6,14]$ : 
- Direct Contact Membrane Distillation (DCMD), in which the membrane is in direct contact with liquid phases. This is the simplest configuration capable of producing reasonably high flux. It is best suited for applications such as desalination and concentration of aqueous solutions (e.g., juice concentrates) [1,15-19].

- Air Gap Membrane Distillation (AGMD), in which an air gap is interposed between the membrane and a condensation surface. The configuration has the highest energy efficiency, but the flux obtained is generally low. The air gap configuration can be widely employed for most membrane distillation applications [20], particularly where energy availability is low.

- Vacuum Membrane Distillation (VMD), in which the permeate side is vapor or air under reduced pressure, and if needed, permeate is condensed in a separate device. This configuration is useful when volatiles are being removed from an aqueous solution [21,22].

- Sweep Gas Membrane Distillation (SGMD), in which stripping gas is used as a carrier for the produced vapor. It is used when volatiles are removed from an aqueous solution [23-27].

Figure 1. Membrane distillation configurations: (a) Direct Contact Membrane Distillation (DCMD); (b) Gore-tex membrane distillation; (c) Vacuum Membrane Distillation (VMD);

(d) Sweep Gas Membrane Distillation (SGMD).

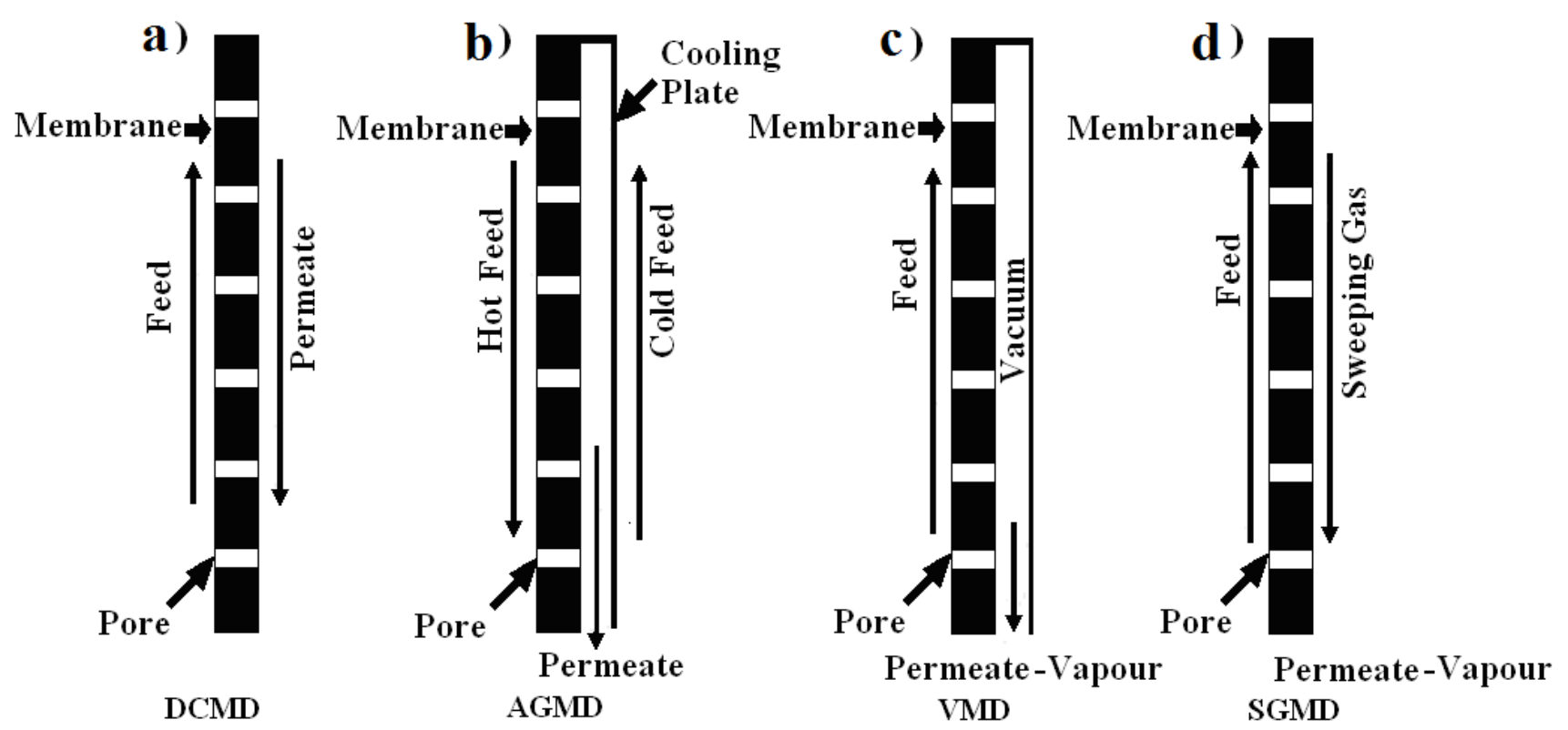

Due to its simple structure and high flux relative to AGMD and SGMD, laboratory-scale DCMD has been widely studied [2]. The main disadvantage for DCMD in commercial applications is its low energy efficiency. Although polymeric membranes generally have low thermal conductivity, the driving force (temperature difference between the feed and permeate sides) for mass transfer will also lead to significant conductive heat transfer through the membrane due to the small membrane thickness, so only part of the supplied heat energy is used for production. Of the four configurations, DCMD has the highest heat conduction loss because of the higher heat transfer coefficient on the permeate side for this configuration, which results in relatively low thermal efficiency $[28,29]$.

In AGMD, the air gap is usually the controlling factor for the mass and heat transfers [30] because of its greater thermal and mass transfer resistances. In comparison with the thickness $(40-250 \mu \mathrm{m})$ and 
conductivity of the membrane, the air gap is much thicker (general 2000-10,000 $\mu \mathrm{m}$ ) [31,32] and has lower thermal conductivity. Therefore, more heat energy in AGMD will be used for water evaporation than in DCMD. Additionally, if a low temperature feed is used as the cooling stream in this configuration, the latent heat can be recovered through the condensation of the vapor on the cooling plate. However, AGMD typically has a low flux, due to the low temperature difference $[6,20,32]$ across the membrane and therefore larger surface areas are required.

In SGMD, the vapor is stripped from the hot feed by a gas stream, and then condensed in an external condenser. It has higher mass transfer rates than AGMD, due to the greater driving force originating from the reduced vapor pressure on the permeate side of the membrane, and has less heat loss through the membrane than DCMD. However, an external condenser and an air blower or compressed air are needed to maintain operation of this configuration, which will cause an increase in investment [25], energy use and running costs.

In VMD, the vapor permeate is removed continuously from the vacuum chamber to form a vapor pressure difference across the membrane. Theoretically, this configuration can provide the greatest driving force at the same feed temperature, because the vapor pressure on the cold side can be reduced to almost zero. An external condenser is required as for AGMD, if the liquid permeate is the product.

Of the four configurations, DCMD is the most popular for MD laboratory research, with more than half of the published references for membrane distillation based on DCMD [1,2,6,33]. However, AGMD is more popular in commercial applications, because of its high energy efficiency and capability for latent heat recovery [34,35].

\subsection{Configurations of MD Modules}

There are two major MD module configurations [2], which are the tubular module and the plate and frame module. Both of these modules have been used in pilot plant trials [35-37].

Figure 2a shows a schematic diagram of a hollow fiber tubular module, in which hollow fiber membranes are glued into a housing. This configuration can have a very high packing density $\left(3000 \mathrm{~m}^{2} / \mathrm{m}^{3}\right)[33,37]$. The feed is introduced into the shell side or into lumen side of the hollow fibers, and cooling fluid, sweeping gas, or negative pressure can be applied on the other side to form VMD, SGMD, or DCMD. Because of its large active area combined with a small footprint, hollow fiber modules have great potential in commercial applications [33]. Although broken hollow fibers cannot be replaced, they can be detected by the liquid decay test (LDT) [38-40] and pinned to remove broken fibers from service. Good flow distribution on the shell side can be difficult to achieve, with subsequent high degrees of temperature polarization. Cross-flow modules have been developed to reduce this effect for hollow fiber modules [41].

Figure $2 b$ shows the structure of the plate and frame module. This module is suitable for flat sheet membranes and can be used for DCMD, AGMD, VMD, and SGMD. In this configuration, the packing density is about $100-400 \mathrm{~m}^{2} / \mathrm{m}^{3}$ [10,33]. Although this configuration has a relatively smaller effective area for the same volume when compared to the tubular modules, it is easy to construct and multiple layers of flat sheet MD membranes can be used to increase the effective area. As shown in Figure 2b, it is easy to change damaged membranes from this configuration. Thus, this module is widely employed in laboratory experiments for testing the influence of membrane properties and process parameters on 
the flux or energy efficiency of membrane distillation [33]. Also the flow dynamics can be improved by the use of spacers that increase turbulence and reduce temperature polarization.

Figure 2. Membrane distillation (MD) Modules: (a) Tubular module for hollow fiber; (b) Plate and frame module for flat sheet membrane.

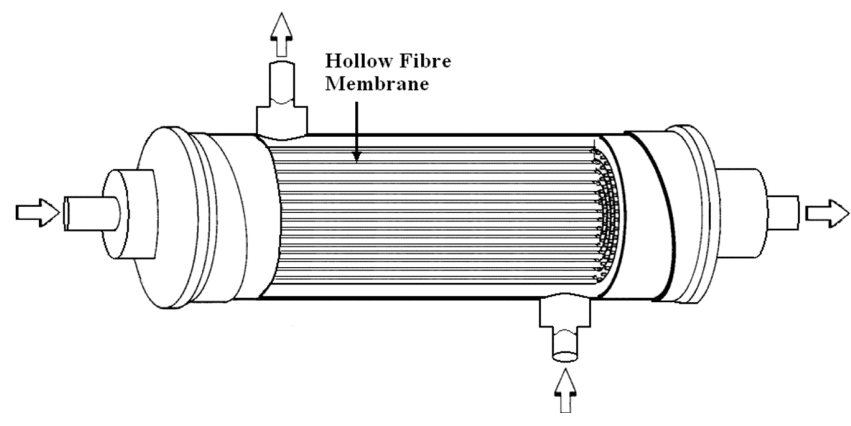

(a)

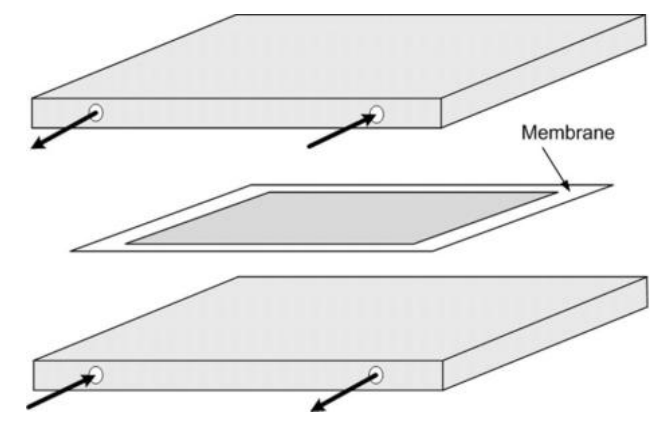

(b)

To meet the requirement of commercial applications, other configurations with large specific areas were also developed, i.e., spiral-wound modules mainly employed for air/permeate gap membrane distillation $[40,42,43]$ have a much more compact structure than the conventional plate and frame AGMD.

\subsection{Membranes for Membrane Distillation Applications}

There are two common types of membrane configurations shown in Figure 3:

- Hollow fiber membrane mainly prepared from PP, PVDF, and PVDF-PTFE composite material $[44,45]$; and

- Flat sheet membrane mainly prepared from PP, PTFE, and PVDF.

Compared with flat sheet membranes, hollow fiber membranes have relatively large specific surface areas [46], but the main impediment of the hollow fiber module is its typically low flux (generally 1-4 $\mathrm{L} \mathrm{m}^{-2} \mathrm{~h}^{-1}$ at $40-60{ }^{\circ} \mathrm{C}$ ) [47-49]. The low flux is related to its poor flow dynamics and the resultant high degree of temperature polarization. However, high-flux hollow fiber membranes with different features suitable for membrane distillation have been developed recently, such as dual-layer hydrophilic-hydrophobic fibers with a very thin effective hydrophobic PVDF layer $(50 \mu \mathrm{m})$, and hollow fiber membranes with a sponge-like structure and thin walls [45,47,50,51], which have flux of about $50-70 \mathrm{~kg} \mathrm{~m}^{-2} \mathrm{~h}^{-1}$ at about $80-90^{\circ} \mathrm{C}$. This flux is as high as that from flat sheet membrane.

Figure 3. Schematics of (a) hollow fiber and (b) flat sheet membranes.

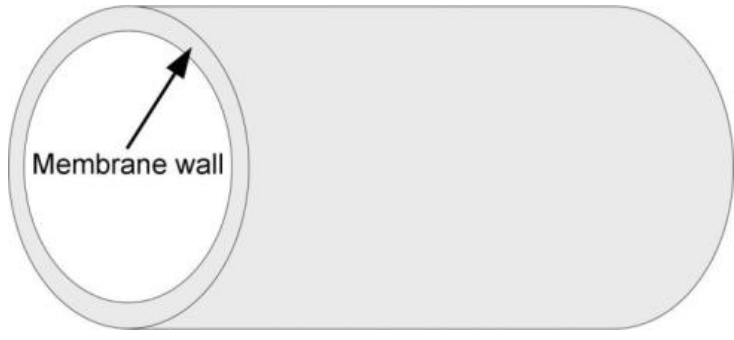

(a)

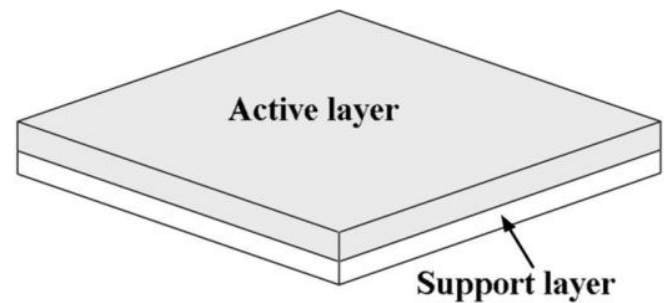

(b) 
The reported flux from flat sheet membranes is typically $20-30 \mathrm{~L} \mathrm{~m}^{-2} \mathrm{~h}^{-1}$ [6] at inlet temperatures of hot $60{ }^{\circ} \mathrm{C}$ and cold $20^{\circ} \mathrm{C}$. In general, the polymeric membrane shown in Figure $3 \mathrm{~b}$ is composed of a thin active layer and a porous support layer. This structure is able to provide sufficient mechanical strength for the membrane to enable the active layer to be manufactured as thin as possible, which reduces the mass transfer resistance.

As the flux from membrane distillation is related to the membrane length, it is more appropriate to compare membrane performance with the mass transfer coefficient rather than the flux [52]. However, it is difficult to calculate the mass transfer coefficients from published works, because typically there is insufficient provision of data. Therefore, the flux provided here is only used as an approximate indication of performance.

\subsubsection{Membrane Materials}

The most common materials used for MD membranes are poly(tetrafluoroethylene) (PTFE), poly(propylene) (PP) and poly(vinylidenefluoride) (PVDF) [53]. The porosity of the membranes used is in the range of 0.60 to 0.95 , the pore size is in the range of 0.2 to $1.0 \mu \mathrm{m}$, and the thickness is in the range of 0.04 to $0.25 \mathrm{~mm}[6,52]$. The surface energies and thermal conductivities of these materials are listed in Table 1.

Of these materials, PTFE has the highest hydrophobicity (largest contact angle with water), good chemical and thermal stability and oxidation resistance, but it has the highest conductivity which will cause greater heat transfer through PTFE membranes. PVDF has good hydrophobicity, thermal resistance and mechanical strength and can be easily prepared into membranes with versatile pore structures by different methods. PP also exhibits good thermal and chemical resistance [33]. Recently, new membrane materials, such as carbon nanotubes, fluorinated copolymer materials and surface modified PES [51,54-56], have been developed to make MD membranes with good mechanical strength and high hydrophobicity and porosity.

Sintering, stretching, and phase inversion are some of the methods to fabricate MD membranes from these materials [57-59].

Table 1. Reported surface energy and thermal conductivity of most popular materials used in MD [33,57-59].

\begin{tabular}{ccc}
\hline Membrane Material & Surface Energy $\left(\times \mathbf{1 0}^{-\mathbf{3}} \mathbf{N} / \mathbf{m}\right)$ & Thermal Conductivity $\left(\mathbf{W ~ m}^{-\mathbf{1}} \mathbf{K}^{\mathbf{- 1}}\right)$ \\
\hline PTFE & $9-20$ & $\sim 0.25$ \\
PP & 30.0 & $\sim 0.17$ \\
PVDF & 30.3 & $\sim 0.19$ \\
\hline
\end{tabular}

\subsubsection{Characteristics of MD Membrane}

In membrane distillation, membranes on the basis of their selective properties are not involved in the mass transport phenomena, but are involved in heat transport from the hot side to the cold side. Therefore, compounds transferred across the membrane in gas phase are driven by vapor pressure differences based on vapor-liquid equilibrium, and the macro-porous polymeric or inorganic membrane employed between the permeate and feed sides acts as a physical barrier providing the 
interfaces where heat and mass are simultaneously exchanged. Thus, the properties of membranes suitable for membrane distillation should include [13,60-64]:

- An adequate thickness, based on a compromise between increased membrane permeability (tend to increase flux) and decreased thermal resistance (tend to reduce heat efficiency or interface temperature difference) as the membrane becomes thinner;

- Reasonably large pore size and narrow pore size distribution, limited by the minimum Liquid Entry Pressure (LEP) of the membrane. In MD, the hydrostatic pressure must be lower than LEP to avoid membrane wetting. This can be quantified by the Laplace (Cantor) Equation [6] as following Equation (1):

$$
L E P=\frac{-2 B \gamma_{l}}{r_{\max }} \cos \theta<P_{\text {process }}-P_{\text {pore }}
$$

where $B$ is a geometric factor, $\gamma_{l}$ is the surface tension of the solution, $\theta$ is the contact angle between the solution and the membrane surface which depends on the hydrophobicity of the membrane, $r_{\max }$ is the largest pore size, $P_{\text {process }}$ is the liquid pressure on either side of the membrane, and $P_{\text {pore }}$ is the air pressure in the membrane pore.

- Low surface energy, equivalent to high hydrophobicity. Based on Equation (1), material with higher hydrophobicity can be made into membranes with larger pore sizes, or membranes made from more hydrophobic material will be applicable under higher pressures for a given pore size;

- Low thermal conductivity. High thermal conductivities increases sensible heat transfer and reduce vapor flux due to reduced interface temperature difference; and

- High porosity. High porosity increases both the thermal resistance and the permeability of MD membranes, so both the heat efficiency and flux are increased. However, high porosity membranes have low mechanical strength and tend to crack or compress under mild pressure, which results in the loss of membrane performance.

The sintering method can be used to prepare PTFE membranes. In the sintering process, polymeric powder is pressed into a film or plate and sintered just below the melting point. The porosity of the membranes made in this manner is in the range of $10 \%-40 \%$ and typical pore sizes are in the range of 0.2 to $20 \mu \mathrm{m}$.

Stretching technology can be used to make PP and PTFE membranes. In this process, films are formed by extrusion from a polymeric powder at temperatures close to the melting point coupled with a rapid draw-down. The membranes made have pore sizes in the range of $0.2-20 \mu \mathrm{m}$ and porosity of about $90 \%[33,53,65]$.

Phase inversion can be used to produce PVDF membranes. In this process, the polymer is dissolved in an appropriate solvent $[66,67]$ and spread as a 20-200 $\mu \mathrm{m}$ thick film on supports, such as nonwoven polyester, PP backing material or PP scrim backing [53,67], and an appropriate precipitant (typically water) is added to split the homogeneous solution film into two phases (a solid polymer rich phase and a liquid rich phase). The prepared membrane has a pore size in the range of 0.2 to $20 \mu \mathrm{m}$, and porosity of approximately $80 \%$ [45]. 
Most of the polymeric materials for membrane fabrication are flexible and deformable under force, and the porosity of the MD membranes is generally greater than $80 \%$. Therefore, it can be speculated that the membrane will be compressed under the hydrodynamic pressure incurred from the flowing feed and/or permeate flowing. As a result, the properties of the membrane, such as pore size, porosity, membrane thickness and thermal conductivity will be altered. These phenomena will become significant when the process is scaled up and longer membranes are employed. A flux reduction of 15\%-39\% was observed when the pressure in DCMD was increased from $1 \mathrm{kPa}$ to $45 \mathrm{kPa}$ by Zhang et al. [68,69]. DCMD Modelling identified that while compression increased the membrane permeability, it also led to increased thermal conductivity of the membranes, and overall membrane distillation performance decreased [69].

\subsubsection{Membrane Fouling and Wetting}

Membrane fouling is a major obstacle in the application of membrane technologies [70,71], as it causes flux to decline. The foulant, e.g., bio-film, precipitations of organic and inorganic matter, can reduce the permeability of a membrane by clogging the membrane surface and/or pores. Although membrane distillation is more resistant to fouling than conventional thermal processes, dosing of anti-scalants can be used to control scaling [72-74]. Dow et al. [75] also showed that lower feed temperatures can substantially reduce the influence of fouling in DCMD.

Since the hydrophobic MD membrane is the barrier between the feed and permeate, membrane wetting will reduce the rejection of the non-volatiles. Membrane wetting can occur under the following conditions:

- The hydraulic pressure applied on the surface of the membrane is greater than the LEP;

- The foulant depositing on the membrane surface can effectively reduce the hydrophobicity of the membrane [36,76], which was generally found in a long-term operation or in treating high-concentration feeds such as for brine crystallisation; and

- In the presence of high organic content or surfactant in the feed, which can lower the surface tension of feed solution and/or reduce the hydrophobicity of the membrane via adsorption and lead to membrane wetting [77].

\subsection{Heat Transfer and Mass Transfer Phenomena in MD}

In MD processes, heat and mass transfers are coupled together in the same direction from the hot side to the cold side [78]. Figure 4 illustrates these processes in DCMD, which is typical for MD configurations. The feed temperature, $T_{\mathrm{f}}$, drops across the feed side boundary layer to $T_{1}$ at the membrane surface. Some water evaporates and is transported through the membrane. Simultaneously, heat is conducted through the membrane to the cold (permeate) side. The cold flow temperature $T_{\mathrm{p}}$ increases across the permeate boundary layer to $T_{2}$ at the membrane surface on the cold side as water vapor condenses into the fresh water stream and gains heat from the feed side. The driving force is, therefore, the vapor pressure difference between $T_{1}$ and $T_{2}$, which is less than the vapor pressure difference between $T_{\mathrm{f}}$ and $T_{\mathrm{p}}$. This phenomenon is called temperature polarization. The temperature polarization coefficient is defined by Schofield et al. [8] as follows: 


$$
\mathrm{TP}=\frac{T_{1}-T_{2}}{T_{f}-T_{p}}
$$

Figure 4. DCMD heat transfer and mass transfer through membrane.

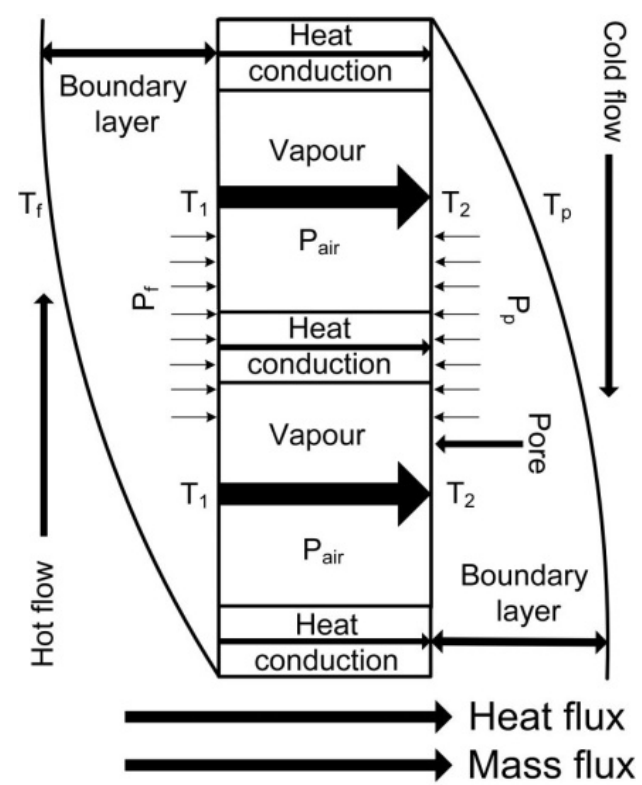

\subsubsection{Heat Transfer}

Heat transfer from the feed side to the permeate side involves two steps [2]: First, the heat transfers from the hot side to the cold side across the membrane as sensible heat and latent heat, so as to form the temperature difference between boundary layer and bulk flow; second, the heat transfers from the bulk flow of the feed to the boundary layer via heat convection, due to the temperature difference arising from the first step. In the first step, as shown in Figure 4, the sensible heat is conducted through the membrane to the cold side, and the latent heat is carried by the water vapor, which is evaporated at the interface between the hot stream and membrane pores and is condensed at the interface between the pores and cold stream for DCMD [16].

According to the two heat transfer processes, the heat balance of the feed stream can be described by [78-80] with the following Equations (3-5):

$$
\begin{gathered}
Q_{1}=\frac{\lambda}{b}\left(T_{1}-T_{2}\right)+J H_{g} \\
\lambda=\lambda_{\text {air }} \varepsilon+\lambda_{\text {solid }}(1-\varepsilon) \\
Q_{2}=\alpha\left(T_{f}-T_{1}\right)
\end{gathered}
$$

because $Q_{1}=Q_{2}$, then

$$
\alpha\left(T_{f}-T_{1}\right)=\frac{\lambda}{b}\left(T_{1}-T_{2}\right)+J H_{g}
$$

where $Q_{1}$ or $Q_{2}$ are the total heat flux from the hot side to the cold side, $\lambda$ is the thermal conductivity of the membrane, $b$ is the membrane thickness, $\varepsilon$ is the membrane porosity, $\alpha$ is the convective heat transfer coefficient on the hot side, $J$ is the permeate flux, and $H_{\mathrm{g}}$ is the enthalpy of the vapor. 
As Equation (4) calculates the thermal conductivity assuming parallel heat flow through air and membrane material, it is appropriate for estimating the thermal conductivity as the tortuosity approaches 1. PTFE membranes have been estimated to have tortuosity's of 1.1 [68], and hence this approach to estimating thermal conductivity is appropriate for these membranes.

In Equation (6), $(\lambda / b)\left(T_{1}-T_{2}\right)$ is the sensible heat loss through the membrane and $J H_{\mathrm{g}}$ is the total enthalpy carried by the permeate. In AGMD, an air gap is interposed between the membrane and the cooling plate, and the percentage of sensible heat loss is less than that in DCMD [81,82], but the stagnant air gap also increases the resistance to the mass transfer. Instead of the stagnant air gap, a striping gas is used in SGMD, which boosts the mass transfer and provides good resistance to sensible heat transfer, but there is more energy consumption from the blower and/or condenser if the permeate is the product $[23,26,27]$. In VMD, the sensible heat loss can even be neglected, if a very low vacuum is employed in the permeate chamber, but it would not be as competitive as DCMD and AGMD if the thermal energy cannot be recovered from the external condenser.

\subsubsection{Mass Transfer}

Mass transfer in the DCMD process includes three steps: firstly the hot feed vaporizes from the liquid/gas interface, secondly the vapor is driven by the vapor pressure difference and crosses from the hot interface to the cold interface through the pores, and thirdly the vapor condenses into the cold side stream [52]. Therefore, there are two major factors controlling the mass transfer: one is the vapor pressure difference, and the other is the permeability of the membrane.

If the fluid dynamics conditions on both sides of the membrane could be considered good, mass transfer through the membrane may be the limiting step for mass transfer in MD [83]. The influence of the physical properties on membrane permeability includes:

(1) The effective area for mass transfer is less than the total membrane area because the membrane is not $100 \%$ porous;

(2) For most practical membranes, the membrane pores do not go straight through the membrane and the path for vapor transport is greater than the thickness of the membrane; and

(3) The inside walls of the pores increase the resistance to diffusion by decreasing the momentum of the vapor molecules.

The mass transport mechanism in the membrane pores is governed by three basic mechanisms known as Knudsen-diffusion $(K)$, Poiseuille-flow $(P)$ and Molecular-diffusion $(M)$ or a combination between these known as the transition mechanism [2,84]. The Knudsen number $(K n)$ is used to indicate the dominant mass transfer mechanism in the pores:

$$
K n=l / d
$$

where $d$ is the mean pore size of the membrane; and $l$ is the mean free path of the molecules defined by Kuhn and Forstering [85] and Albert and Silbey [86] as:

$$
l=\frac{k_{B} T}{\pi\left(\left(\sigma_{w}+\sigma_{a}\right) / 2\right)^{2} P_{\text {pore }}} \frac{1}{\sqrt{1+\left(m M_{w} / m M_{a}\right)}}
$$


where $k_{\mathrm{B}}$ is the Boltzman constant $\left(1.381 \times 10^{-23} \mathrm{~J} / \mathrm{K}\right), \sigma_{\mathrm{w}}$ and $\sigma_{\mathrm{a}}$ the collision diameters for water vapor $\left(2.641 \times 10^{-10} \mathrm{~m}\right)$ and air $\left(3.711 \times 10^{-10} \mathrm{~m}\right)[87,88], T$ is the mean temperature in the pores, and $M_{\mathrm{w}}$ and $M_{\mathrm{a}}$ are the molecular weights of water and air. At a typical membrane temperature of $60{ }^{\circ} \mathrm{C}$, the mean free path of the water vapor in the membrane pores is $0.11 \mu \mathrm{m}$. The pore sizes of the membranes used for membrane distillation are in the range of 0.2 to $1.0 \mu \mathrm{m}$, so $K n$ will be in the range of 0.5 to 0.1 . Table 2 shows the dominating mass transfer mechanism based on the $K n$ [83] for different configurations.

Table 2. Dominating mass transfer mechanism in different MD configurations.

\begin{tabular}{|c|c|c|c|c|}
\hline Configurations & $\begin{array}{c}\text { Component in } \\
\text { pores }\end{array}$ & $\begin{array}{c}\text { Vapor Pressure } \\
\text { difference across pores }\end{array}$ & Driving force & $\begin{array}{c}\text { Mass transfer mechanism } \\
(0.01<K n<1) \\
\end{array}$ \\
\hline DCMD & $\begin{array}{l}\text { Vapor-air } \\
\text { mixture }\end{array}$ & $\Delta P=0$ & $\begin{array}{c}\text { Partial vapor } \\
\text { pressure difference }\end{array}$ & $\mathrm{M}-\mathrm{K}$ transition \\
\hline AGMD & $\begin{array}{l}\text { Vapor-air } \\
\text { mixture }\end{array}$ & $\Delta P=0$ & $\begin{array}{c}\text { Partial vapor } \\
\text { pressure difference }\end{array}$ & $\mathrm{M}-\mathrm{K}$ transition \\
\hline SGMD & $\begin{array}{l}\text { Vapor-air } \\
\text { mixture }\end{array}$ & $\Delta P=0$ & $\begin{array}{c}\text { Partial vapor } \\
\text { pressure difference }\end{array}$ & $\mathrm{M}-\mathrm{K}$ transition \\
\hline VMD & Vapor & $\Delta P \neq 0$ & $\begin{array}{c}\text { Partial vapor } \\
\text { pressure difference }\end{array}$ & $\mathrm{P}-\mathrm{K}$ transition \\
\hline
\end{tabular}

There are also two other popular mass transfer models for membrane distillation, which are Schofield's model [79,88] and the dusty-gas model for DCMD [89,90]. In the "Dusty-Gas" model [89,91], the porous membrane is assumed to be an array of dust particles held stationary in space, and the dust particles in terms of the classical kinetic theory of gases are supposed to be giant molecules in the interactions between gas and surface. Based on this model, a general flux equation for a gas that permeates through a porous media in the Knudsen-viscous transition region can be described as:

$$
J=-\frac{M}{R T}\left[\left(K_{0} \bar{v}+\frac{B_{0} P_{\text {pore }}}{\mu}\right) \frac{\left(P_{T 1}-P_{T 2}\right)}{b}\right]
$$

in which

$$
K_{0}=\frac{d \varepsilon}{3 t} \text { and } B_{0}=\frac{\varepsilon d^{2}}{32 t}
$$

These equations of different mass transfer models can all be simplified to [52]:

$$
J=C_{\text {membrane }}\left(P_{T 1}-P_{T 2}\right)
$$

in which

$$
C_{\text {membrane }} \propto \frac{d^{a} \varepsilon}{t b}
$$

where $a$ is an exponent coefficient in the range of $1-2$.

From Equation (10b), it can be concluded that the flux for MD can be increased by increasing pore sizes and porosity and by reducing the tortuosity and thickness of the membrane. However, according to Equation (6), reducing the thickness of the membrane also increases the sensible heat loss from the hot side to the cold side, which leads to a reduction of water flux due to decreased interfacial 
temperature differences (vapor pressure difference). Therefore, there is an optimum membrane thickness for membrane distillation efficiency.

To minimize the sensible heat loss, the heat transfer coefficient $(\lambda / \mathrm{b})$ of the membrane can be reduced by increasing the membrane porosity. This will also reduce the sensible heat transfer as according to Equation (4), the average thermal conductivity of the membrane will be reduced since the thermal conductivity of the air is in general one order of magnitude less than that of the membrane materials.

\subsection{Operating Parameters Affecting MD Performance}

\subsubsection{Parameters to Reducing Temperature Polarization}

To maximise flux, it is necessary to increase the vapor pressure difference across the membrane or to reduce temperature polarization $[92,93]$. Therefore, it is necessary to improve the convective heat transfer coefficient for the purpose of producing more flux according to Equations (3), (5) and (6). The convective heat transfer coefficient can be expressed as Equation (11) according [94]:

$$
\alpha_{f}=-\frac{\lambda_{f}}{T_{f}-T_{1}}\left(\frac{d T}{d y}\right)_{\text {boundary }}
$$

where $\lambda_{\mathrm{f}}$ is thermal conductivity of the feed, and $\left(\frac{d T}{d y}\right)_{\text {boundary }}$ is the temperature gradient in the thermal boundary layer of the feed. From Equation (10b), it can be seen that the convective heat transfer coefficient can be improved effectively by reducing the thickness of the thermal boundary layer. As the thickness of the thermal boundary layer can be reduced by enhancing the stream turbulence, increasing flow rate can effectively improve the flux. However, the hydrodynamic pressure has a square relationship to the flow rate [95], and the increased pressure will diminish the effect of increasing turbulence if the membrane is compressible $[68,69]$.

The presence of turbulence promoters, e.g., net-like spacers or zigzag spacers shown schematically in Figure $5[96,97]$ can effectively reduce the thickness of the thermal boundary layer and improve $\alpha_{\mathrm{f}}$ [98]. It is also important that high heat transfer rates are achieved with a low pressure drop in the channels where the feed solution and cooling liquid are flowing [28,92,93,96,99].

Figure 5. Spacer structure.

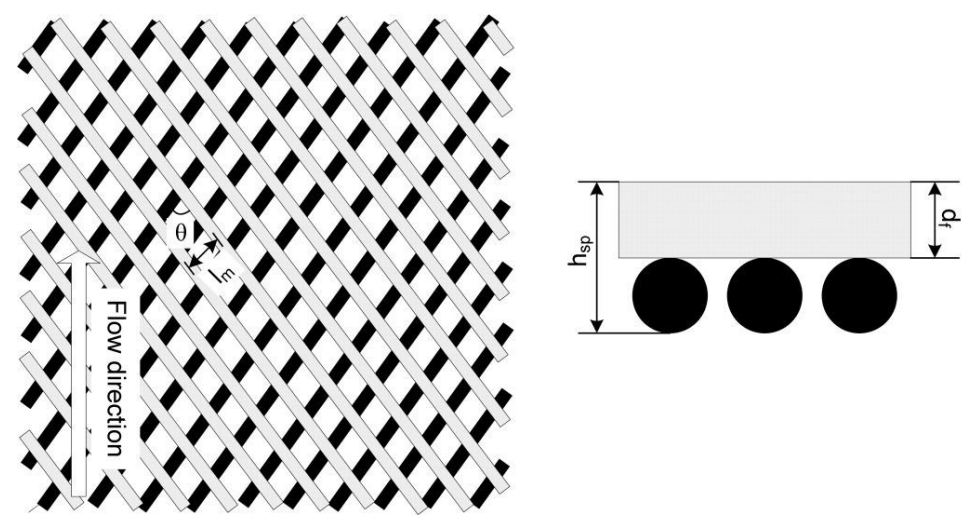

Notes: $\theta_{f}$ is the angle between spacer fibres in the flow direction; $l_{m}$ is the distance between parallel spacer fibres; $h_{s p}$ is the height of the spacer and $d_{f}$ is the diameter of a single spacer fibre. 
From reported data [92], it is found that the temperature polarization coefficient of spacer-filled channels falls in the range of 0.9-0.97, in comparison with a temperature polarization coefficient 0.57-0.76 for flowing channels without spacers. The effect of Reynolds number on heat transfer for the spacer-filled flat channels is presented and discussed in $[92,96,100]$. It is also noticed that the influence of turbulence on flux becomes less at higher turbulence levels. Therefore, it is necessary to control turbulence within an adequate range to reduce the energy cost associated with pumping.

\subsubsection{Feed Temperature}

As MD is driven by vapor pressures which vary exponentially with the stream temperature [52], the flux is affected greatly by the feed temperature. Furthermore, since the heat loss through themal conduction is linear to the temperature difference across the membrane as according to Equation (3), the proportion of energy used for evaporation will increase as the feed temperature increases [52]. However, an increase of temperature polarization due to the high flux and greater heat and mass transfer was also observed with rising temperature $[52,53,69]$, but this can be reduced by using turbulence promotors such as spacers.

\subsection{Modelling Aspects of Membrane Distillation}

Mass transfer in MD is acompanioned by heat transfer, so MD Modelling is more complex than that for heat exchangers. The parameters or data that should be considered during Modelling include [2]:

- Membrane characteristics, such as membrane thickness, pore size, tortuosity and porosity, which can be aquired by gas permeation experiment, scanning electron microscopy and image analysis $[68,101]$;

- Thermal conductivity of the membrane is measurable in some cases [102] or can be calculated with Equation (4) $[14,51,68]$;

- Convective heat transfer coefficient of the feed and/or permeate streams, which can be calculated by semi-emperical equations based on Nusselt numbers and by including factors such as the structure of the spacer or module, flow velocities, properties of feed and permeate, the operation temperature, etc. and

- An important assumption adopted in Modelling MD is that the kinetic effects at the vapor-liquid interface are negligible. According to this assumption, vapor-liquid equilibrium equations can be applied to determine the partial vapor pressures of each component at each side of the membrane.

\subsection{Applications of Membrane Distillation}

Although MD is currently studied mostly at the laboratory scale, membrane distillation has potentially distinctive advantages in some particular areas [6,33]. There are several pilot plants currently undergoing field trials: for treating wastewater from a power plant (in Singapore) [35], wastewater in a chemical plant (The Netherlands) by Memstill ${ }^{\circledR}$, and other wastewaters are currently being investigated at laboratory stage, i.e., the RO concentrate treatment, ground water treatment and solar heat utilisation $[75,103,104]$. 
Producing high-purity water from salty water is one of the many MD applications. Since 1982, Gore [105] proposed MD membrane modules for desalting $\mathrm{NaCl}$ aqueous solutions. Papers related to MD research in desalination processes increased dramatically in the following years [7,10,24,106]. Different types of hydrophobic membranes and configurations [107,108] were studied for desalination purposes. Coupling membrane distillation with solar energy was studied and has demonstrated the feasibility of solar powered MD in which $60 \%-80 \%$ of the energy was recovered [109-111]. Membrane distillation may also be integrated with reverse osmosis processes to increase the water recovery in the desalination plants $[109,112]$ by treating the brine. Lawson and Llyod [81] stated that membrane distillation can be a viable process for desalination, while Schneider et al. [82] have argued that small, portable desalination units utilising waste heat are more feasible for application of MD.

Membrane distillation also can be used for water treatment, such as removing heavy metals from wastewater [113], recovering $\mathrm{HCl}$ from cleaning solution in electroplating [114], concentrating sulphuric acid to recover lanthanide compounds in apatite phosphogypsum extraction process [115], eliminating radioisotopes, reducing the waste volume from nuclear industry [116] and removing volatile organic components from dilute aqueous solutions [21,22,117,118].

Due to the low feed temperature, MD can also be used for concentrating solutions in the food industry. It has been widely tested for the concentration of many juices including orange juice [18], apple juice [119] and sugarcane juice [120].

MD was also employed for selective extraction of volatile solutes and solvents for applications in the health and fermentation industries. Blood and plasma were treated by MD in order to promote a solute-free extraction of water from biomedical solutions without loss in quality [121,122]. Membrane distillation has also been suggested as an innovative tool to ameliorate treatment of uraemia by allowing purification of the blood ultrafiltrate and the re-injection of the purified water to the patients [123]. MD was also combined with a bioreactor to promote the reaction rate of ethanol fermentation by selectively removing ethanol [124].

Further discussion of applications is contained in Section 3.

\section{Advances on MD Processes and Modules for Water Purification}

Even though membrane distillation was patented in the 1960s [125], is has not been commercialised because of the success of competing technologies. However in just the last few years, MD has emerged with numerous commercially oriented devices and novel process integrations. This section focuses on the current process arrangements and commercially available MD systems.

\subsection{Stand-Alone Systems}

A module to house a membrane and perform MD is not complicated but requires more complexity in its connections as compared to pressurised membrane systems (micro, ultra and nanofiltration as well as reverse osmosis). As shown in Figure 6, we see the simplest form of DCMD configuration which will desalinate a saline water feed to a very high quality permeate. 
Figure 6. Standard MD setup to desalinate water in direct contact mode.

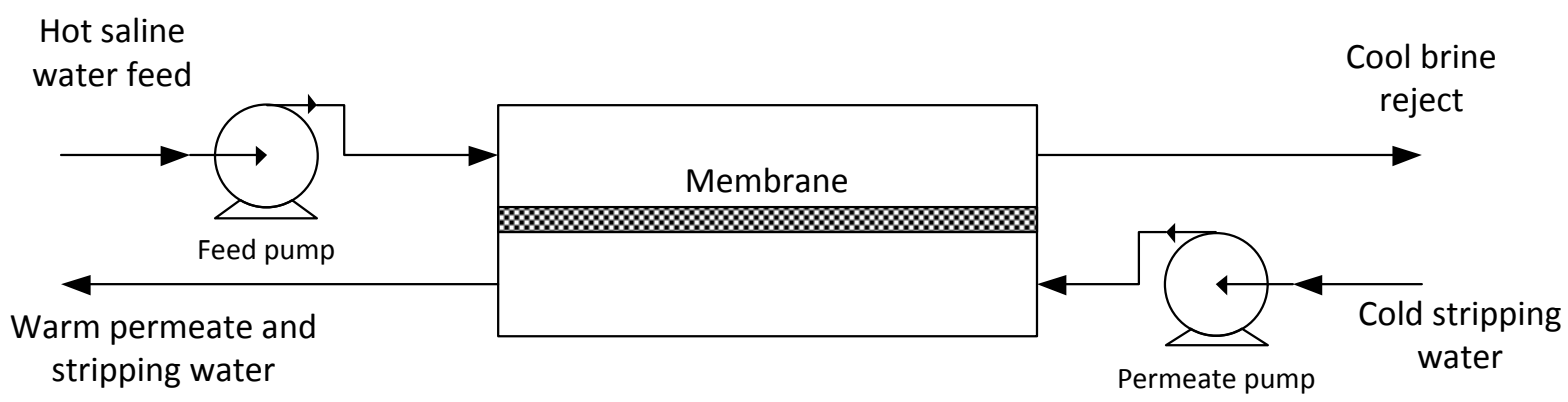

However, the simplest form suffers drawbacks which must be overcome to make MD practically useful. The three key drawbacks under standard process configuration are:

- Water recovery limit: The flux of the membrane draws a significant amount of energy purely through the evaporation of the feed, which is deposited into the permeate. The limiting amount of water permeated as a fraction of water fed, $F$, (i.e., single pass recovery) is presented according to [126] as Equation (12):

$$
F=(1-t) \frac{C_{P}\left(T_{F}-T_{E}\right)}{\Delta H_{\text {vap }}}
$$

where $T_{F}$ and $T_{E}$ are the feed and exit temperatures, respectively $\left(\mathrm{K}\right.$ or $\left.{ }^{\circ} \mathrm{C}\right), C_{P}$ is the specific heat of water $(4.18 \mathrm{~kJ} / \mathrm{kg} / \mathrm{K}), t$ is the proportion of conductive heat (balance due to evaporative heat) loss through the membrane, and $\Delta H_{\text {vap }}$ is the latent heat of vaporisation $(\mathrm{kJ} / \mathrm{kg})$. For example, if the feed water is supplied at $80{ }^{\circ} \mathrm{C}$, no more than $7.7 \mathrm{wt} \%$ of this desalinated water will evaporate to the permeate (i.e., $F$ ) by the time this temperature is reduced to $20{ }^{\circ} \mathrm{C}$ (assuming $t=0.3$ ). This is typically managed by reheating the cool brine reject and sending it back to the feed. In DCMD, this recirculation is likewise done on the permeate side. Both pumps will now be larger, by at least an order of magnitude, in order to achieve useful recoveries exceeding $50 \%$.

- Electrical energy constraints: The thermodynamics of the simple MD setup in turn constrains the electrical consumption. Each pump in Figure 6 will consume electrical energy per unit water permeated, $E_{\text {elec,std }}\left(\mathrm{kWh} / \mathrm{m}^{3}\right)$, according to:

$$
E_{\text {elec,std }}=\frac{P_{F}}{\eta F} \frac{1}{3600}
$$

where $P_{\mathrm{F}}$ is the MD module feed pressure $(\mathrm{kPa})$, and $\eta$ is pump efficiency. If we assume $P_{\mathrm{F}}=20 \mathrm{kPa}$, and pump efficiency of 0.6 , each pump consumes $0.12 \mathrm{kWh} / \mathrm{m}^{3}$ of electricity. Both pumps consume $0.23 \mathrm{kWh} / \mathrm{m}^{3}$. Clearly achieving low pressure drops along the module will have an impact on the electrical energy requirement of MD systems. This minimum is related to the point above, where $F$ equates to around $7.7 \mathrm{wt} \%$; and

- Thermal energy constraints: Water evaporation energy per unit mass, $\Delta H_{\text {vap }}$, is $2260 \mathrm{~kJ} / \mathrm{kg}$, or $628 \mathrm{kWh} / \mathrm{m}^{3}$. This energy is in the form of thermal energy, which is the standard thermal energy required to operate the MD system in Figure 6. This value equates to a performance ratio (PR), or gain output ratio (GOR) of 1 , being the mass ratio of water produced to the amount of steam energy (i.e., latent heat) fed to the process. 
With state-of-the-art reverse osmosis requiring as little as $2 \mathrm{kWh} / \mathrm{m}^{3}$ of electric energy and no thermal energy, we see that standard MD by thermodynamics uses an order of magnitude less electricity, and nearly 300 fold the thermal energy to desalinate the same amount of water. State-of-the-art MD systems feature refinement of the system proposed in Figure 6, or its variants VMD, SGMD and AGMD, primarily to reduce the thermal energy required, and more recently, the electrical energy.

\subsection{State of the Art MD Research and Systems}

The principal research activities on $\mathrm{MD}$ can be divided broadly into two categories: fouling/performance testing, and energy efficient process design. With fouling/performance design, fundamental understandings of the diffusion mechanisms coupled with heat and mass transfer has unlocked the critical science needed to select optimal operating conditions, membrane materials and module designs that ultimately give better flux performance for the same operational conditions [52,53,127]. Fouling of membranes has explored scaling issues for the classic applications in brine concentration [72,128], and the more novel application in dairy processing [129]. While this research progresses to uncover further fundamental improvements, the focus here is on the novel process configurations that address the performance limitations defined in Section 2.1. The most notable organisations specialising in MD modules or high efficiency systems are:

- Fraunhofer ISE (AGMD);

- Memstill and Aquastill (AGMD);

- Scarab (AGMD);

- Memsys (vacuum enhanced multi effect AGMD).

\subsubsection{Fraunhofer ISE}

One of the earlier MD modules to appear was an AGMD module from Fraunhofer Institute for Solar Energy System (ISE), Germany. The innovative aspect of their design was a spiral wound AGMD system as shown in Figure 7. AGMD has the advantage in that the module itself features internal heat recycling to minimise the loss of latent heat, thus greatly reducing the thermal energy requirement. They propose to have achieved thermal energy consumptions of 140 to $200 \mathrm{kWh} / \mathrm{m}^{3}$ in their 2003 device [130], or greater than 4 fold improvement in the latent heat required to evaporate the same amount of water (GOR up to 4.5).

With their latest design, shown in Figure 7, they can build between 5 and $14 \mathrm{~m}^{2}$ of membrane area into a single unit. Under certain conditions, thermal energy requirements can be as low as $130 \mathrm{kWh} / \mathrm{m}^{3}$ as reported in 2011 [42], representing a GOR of 4.8. 
Figure 7. (a) Section of Fraunhofer ISE's spiral wound AGMD module: (1) condenser inlet, (2) condenser outlet, (3) evaporator inlet, (4) evaporator outlet, (5) distillate outlet, (6) condenser channel, (7) evaporator channel, (8) condenser foil, (9) distillate channel and (10) hydrophobic membrane; (b) Picture of the modules [42].

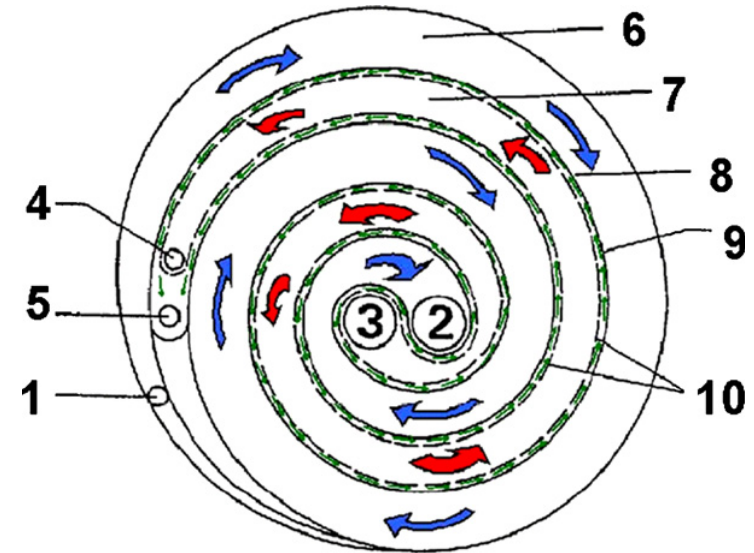

(a)

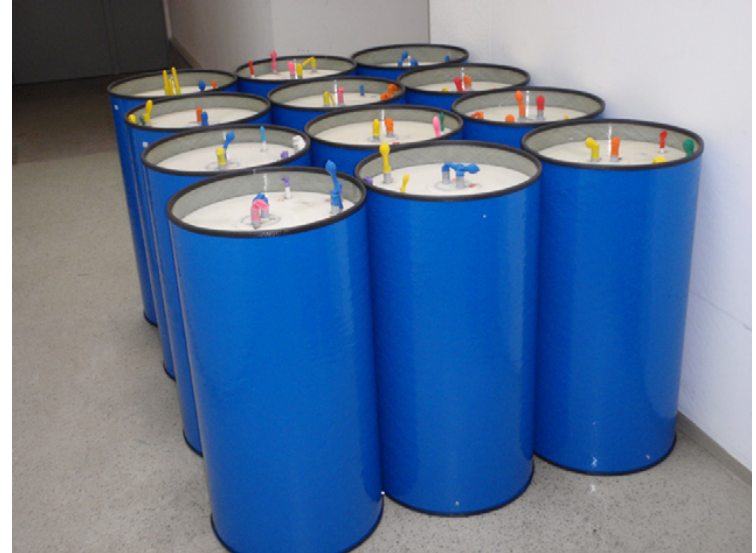

(b)

\subsubsection{Memstill and Aquastill}

The Memstill system started development in 1999 by TNO (Netherlands Organisation for Applied Scientific Research) and emerged around 2006. Memstill was also based on the energy efficient AGMD concept (see Figure 8) and is probably one of the longest running projects trialling MD [34]. Memstill was developed by a consortium consisting of TNO and Keppel Seghers Belgium N.V. A costing based on Memstill's system revealed that desalination by MD can reduce desalinated water costs to within the range of $\$ 0.26$ to $\$ 0.50$ per $\mathrm{m}^{3}$ water treated depending on the cost of the thermal energy provided [29]. The principle reason for this observed saving was cheaper plant materials to build their module in comparison to RO (RO uses high pressure vessels), and ability to utilise low cost heat sources (i.e., waste heat) as the principle energy source. Memstill pilots have been operating since 2006 fed with raw seawater, with the first in Singapore, two in the Netherlands at the E.ON Benelux Power Plant, then a more recent trial at BASF, Port of Antwerp running until March 2011. A less successful trial (third Memstill trial) was conducted on brackish water from the harbour of Rotterdam, failing due to lack of monitoring and incorrect pre-treatment [131]. Trialling has featured modules containing up to $300 \mathrm{~m}^{2}$ of membrane area. Current plans are to operate at $100 \mathrm{~m}^{3} /$ day scale on a petroleum refinery in Singapore located on Jurong Island [132]. The thermal energy required, claimed by Memstill in its years of trials, is as low as 56 to $100 \mathrm{kWh} / \mathrm{m}^{3}$ water produced (GOR up to 11.2). This is the lowest value reported from real testing (or highest GOR), but to achieve this, the water must be heated to $80-90{ }^{\circ} \mathrm{C}$. The electrical energy required was assumed to be $0.75 \mathrm{kWh} / \mathrm{m}^{3}$ [133].

The Memstill technology has been licenced to Aquastill and Keppel Seghers for industrial module production. In 2008 and 2009, there was a large investment to reduce the cost of the MD modules [131]. In June 2012, Aquastill's website indicates the availability of both air gap and direct contact MD modules as shown in Figure 9. These are in spiral wound configuration. 
Figure 8. Concept of the Memstill process based around AGMD [133].

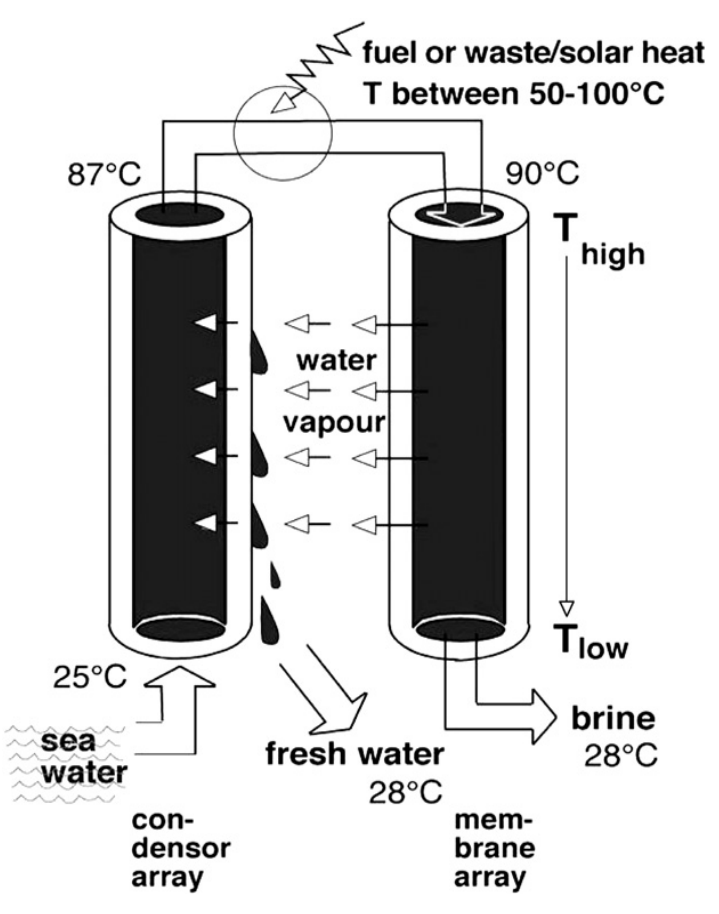

Figure 9. Aquastill process configurations as found on the Aquastill's website. Left configuration based on AGMD and right configuration based on DCMD with heat recovery.
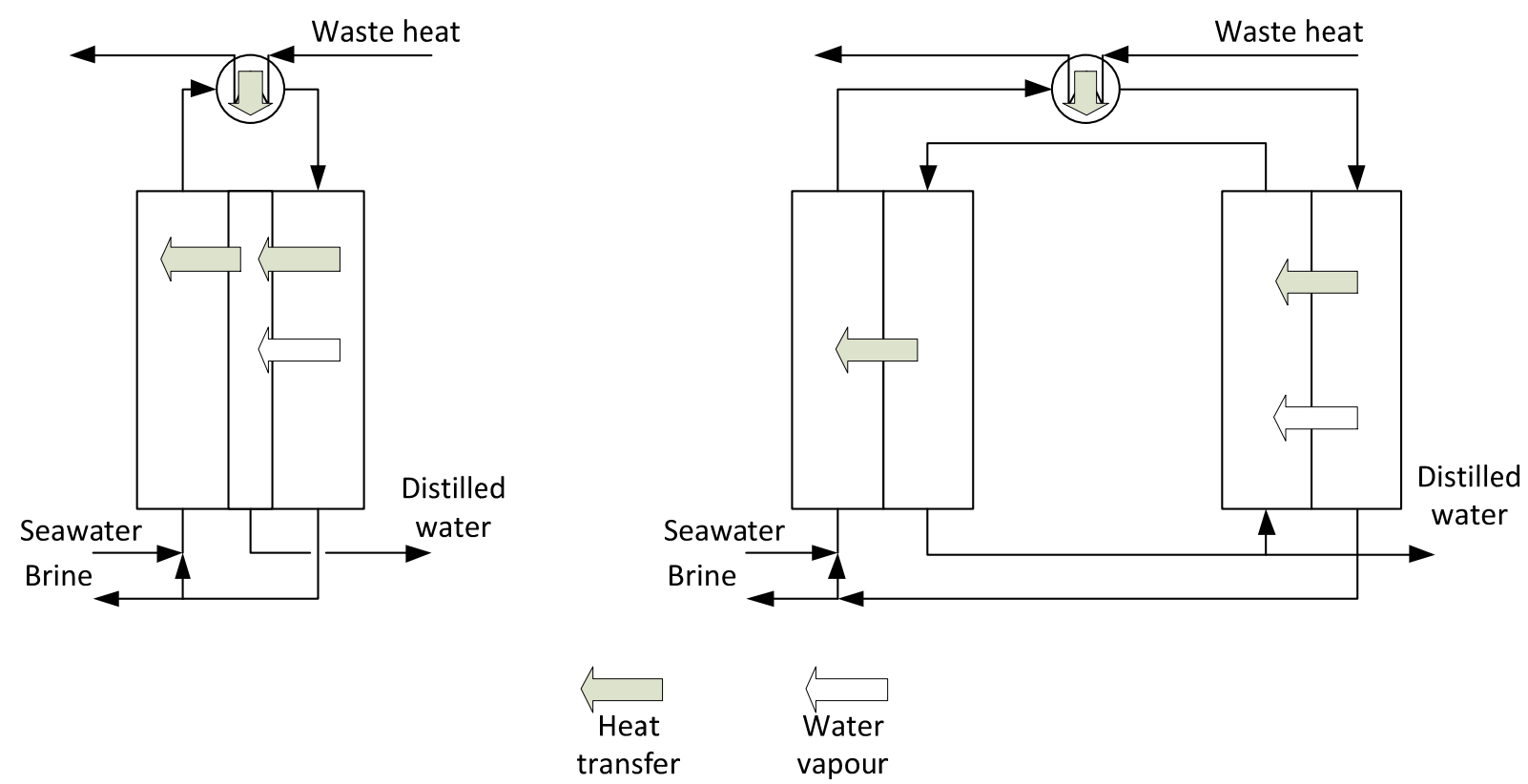

\subsubsection{Scarab AB}

The Scarab AB system features an AGMD module, and has been trialled on numerous projects worldwide. The Scarab AB system has been trialled on solar ponds in 2004 by University of Texas at El Paso sponsored by the US Bureau of Reclamation [134,135], and using solar thermal collectors in Spain and Mexico by the MEDESOL project starting in 2008 [136]. In 2011, a trial under the MEDESOL project lasting 4 months was reported, finding issues related to membrane wetting over the 
longer term, fluxes of up to $6.5 \mathrm{~kg} \mathrm{~m}^{-2} \mathrm{~h}^{-1}$, and thermal consumption of $810 \mathrm{kWh} / \mathrm{m}^{3}$ [137] (GOR of 0.78 ). In the same year, results were reported utilising five Scarab AB modules producing $1-2 \mathrm{~m}^{3} /$ day, trialled on a co-generation facility in Sweden (collecting the exhausted heat from power generation to send to district heating) [138]. The interesting feature of this work was the long term treatment of municipal water and flue gas condensate. The modules used in this trial, shown in Figure 10, involves a plate and frame design with each featuring a $1 \mathrm{~mm}$ air gap, $2.3 \mathrm{~m}^{2}$ membrane area, nine feed and nine cooling channels (total stack thickness $17.5 \mathrm{~cm}$ ). The most recent developments utilising the Scarab AB system include the installation of a 10 module facility at Hammarby Sjöstadsverket in Stockholm featuring the removal of pharmaceutical residues from treated wastewater. Also, small scale solar driven systems are currently being explored, which will also involve module improvements [139].

Figure 10. The five module Scarab AB system installed at Idbäcken Cogeneration Facility (Nyköping) in Sweden [138].

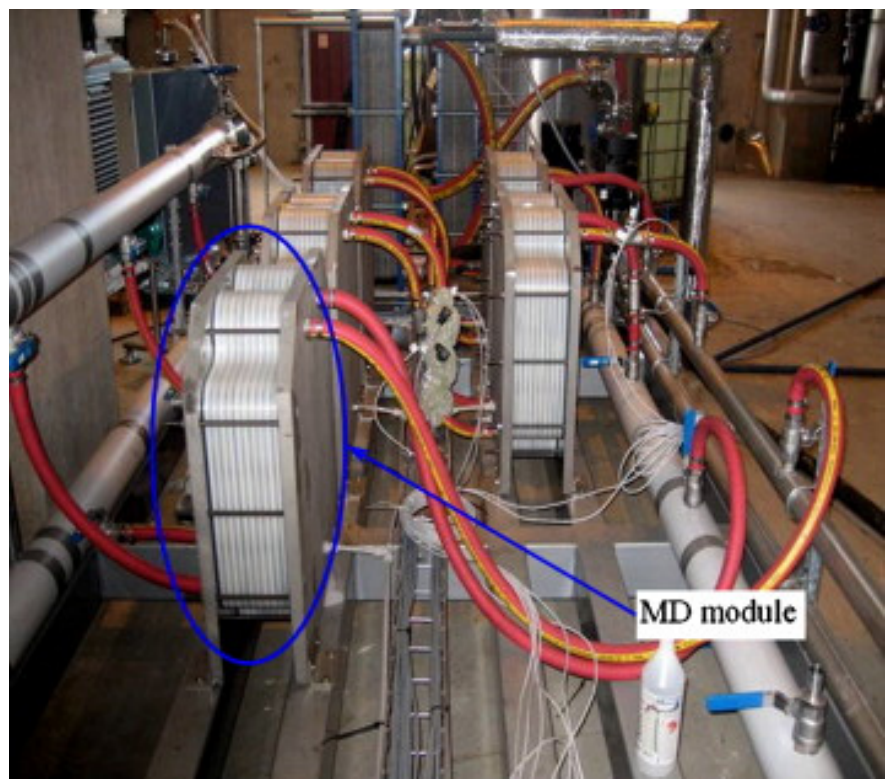

\subsubsection{Memsys}

The Memsys system is a relatively new MD technology that features a novel internal heat recycling concept that allows for reduced thermal consumption. The heat recycling shown in Figure 11, known as Vacuum-Multi-Effect-Membrane-Distillation (V-MEMD) utilises a multistage setup integrated into a compact plate and frame module. In doing this, Memsys has been regarded as state of the art in the MD technology field, as it has achieved a unique compromise in thermal energy consumption, membrane flux and module compactness. In its current state of development, since module production started in 2010, technical articles with trial results are currently unavailable. Pilot plants have been installed around the world, including in Singapore, Australia and India [140-142]. Memsys promises thermal energy requirements of $175-350 \mathrm{kWh} / \mathrm{m}^{3}$ (GOR up to 3.6) and electrical energy requirement of $0.75-1.75 \mathrm{kWh} / \mathrm{m}^{3}$. Memsys requires feed temperatures from 60 to $100{ }^{\circ} \mathrm{C}$ and cooling $<40{ }^{\circ} \mathrm{C}$. 
Figure 11. The new high thermal efficiency Vacuum-Multi-Effect-Membrane-Distillation (V-MEMD) process from Memsys [140].

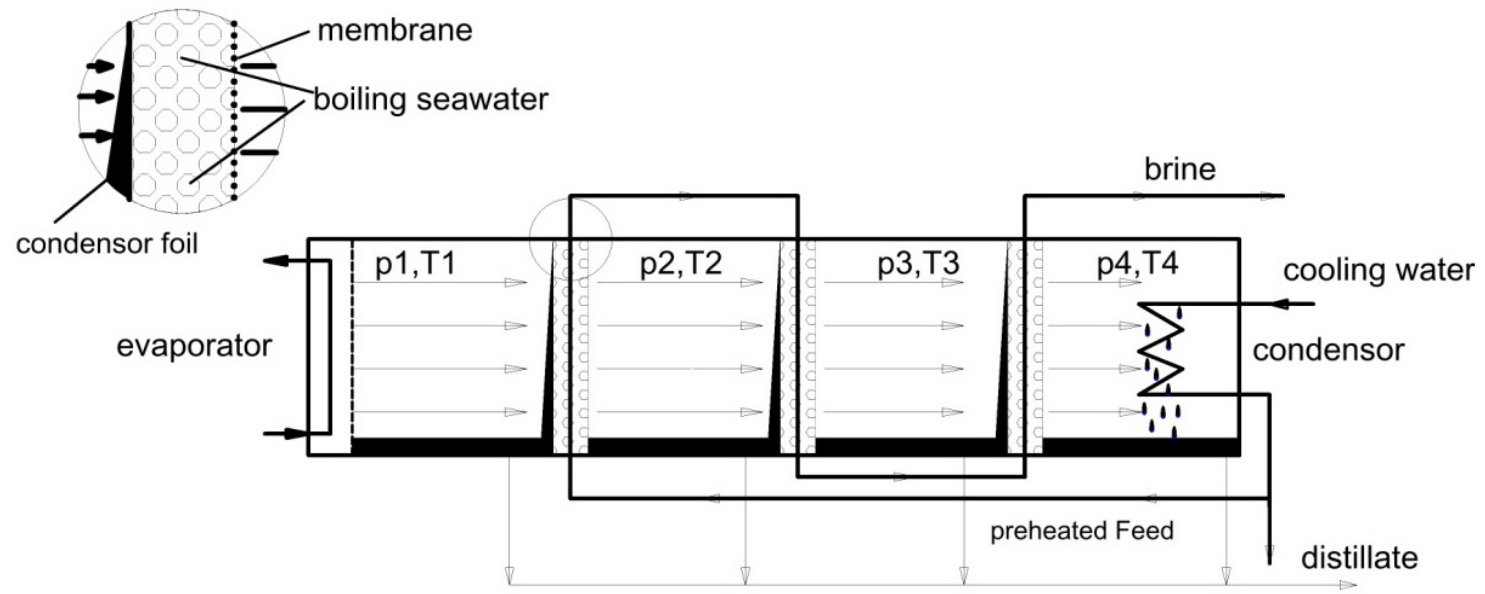

Memsys modules are $330 \mathrm{~mm} \times 700 \mathrm{~mm} \times 480 \mathrm{~mm}$ in dimension, with $3.5 \mathrm{~m}^{2}$ of both MD and condensation membranes. The MD membrane is made from PTFE and the condensation membrane is made from metal coated PP. Fluxes of Memsys systems have been demonstrated in the range of 6.8 to $9.5 \mathrm{~kg} \mathrm{~m}^{-2} \mathrm{~h}^{-1}$. Current module capacity is specified at $50 \mathrm{~m}^{3} /$ day [140].

\subsection{Hybrid MD Systems}

MD is a separation process that offers several unique features that conveniently allow it to be integrated within other membrane operations. Most commonly, MD is integrated into RO, nano-filtration (NF), and the more developmental forward osmosis (FO).

\subsubsection{Integration with RO or NF}

One of the most logical technology partners for MD is RO or NF. There are two ways in which they can be integrated. The first is by using the RO brine as feed to the MD, or the NF or RO permeate as feed to the MD. These are represented in the flow diagrams presented in Figure 12.

Figure 12. Simplified flow diagrams of hybrid RO/NF-MD systems. MD connected to RO concentrate (a) and to RO/NF permeate (b). Here NF is nano-filtration, FO is forward osmosis, $\mathrm{RO}$ is reverse osmosis.

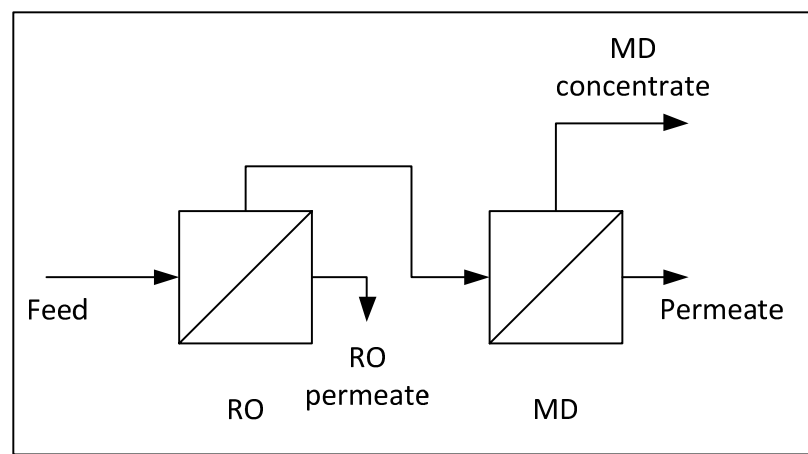

(a)

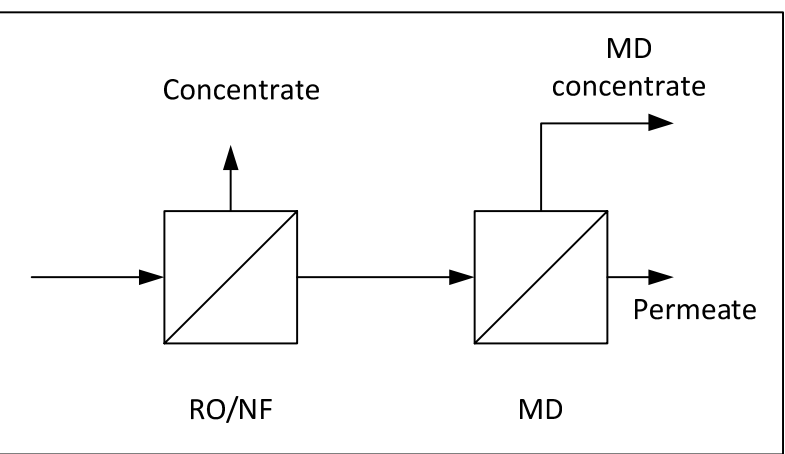

(b) 
Using RO brine as a feed to MD (Figure 12a) has a great potential for MD utilization. This directly addresses the upper concentration limit of $\mathrm{RO}$ at around $70,000 \mathrm{mg} / \mathrm{L}$, as $\mathrm{MD}$ is far less influenced by salt concentration. Typically, the need for an RO-MD process to increase water recovery is for inland applications where disposal of the brine is an issue. Testing of MD on RO groundwater concentrates revealed that the concept is indeed viable, but suffers from practical issues such as scaling on MD membranes [143]. A similar result was found for an RO-MD trial on a solar powered direct contact MD system in rural Victoria, Australia [104]. Membrane scaling led to flux declines, but flux was easily restored using an acid clean. Scaling was found to be effectively managed by cleaning or the addition of anti-scalant. For the RO-MD process, the individual RO recovery was $89 \%$, and MD recovery was $80 \%$, giving a total water recover of $98 \%$ for the combined system [143].

Integrating $\mathrm{MD}$ to treat RO or NF permeate (Figure 12b) is mostly concerned with MD pretreatment. Scaling has been identified as a major issue for MD membranes due to the capacity of scaling salts to "wet" the membrane (i.e., compromise the membrane hydrophobicity leading to saline water leaking into permeate) [72]. To remove scaling salts for water demineralisation applications (final water quality 1.5 to $2.5 \mu \mathrm{S} / \mathrm{cm}$ ), Gryta et al. [144] tested tap water treated by NF prior to MD. While $\mathrm{CaCO}_{3}$ scaling leading to flux decline was observed when treating the tap water directly by MD, $\mathrm{HCl}$ cleaning removed scaling and restored full flux performance. To avoid this fouling and cleaning issue, pretreatment using NF assisted the long term operation of $\mathrm{MD}$, but precipitation of a predominantly silica solids clogged the entrance of the module. However, this was remediated by a simple filter at the module entrance.

\subsubsection{Integration with FO}

Forward osmosis (FO) is an emerging low pressure water treatment process that relies on the natural osmotic force to transfer water through a semi-permeable membrane from one solution to another. These solutions have differing dissolved solid contents, which means that while the water has been taken from a non-potable saline solution (e.g., seawater), it must be removed from the second solution (draw solution) to become useable pure water. MD has been proposed for this second removal step in novel space or protein concentration applications [145-147], schematically represented in Figure 13. Although little explored, FO could recover water from a brine with scaling salts such as groundwater or seawater into a pure $\mathrm{NaCl}$ draw solution. The draw solution is then reconcentrated by $\mathrm{MD}$, and fresh water is recovered.

Figure 13. Simplified flow diagram of FO-MD process for water desalination.

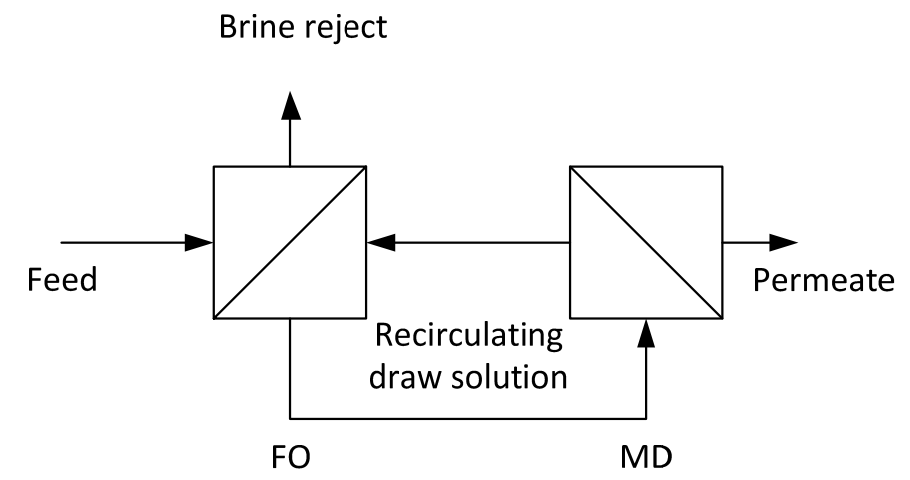




\subsection{Crystallization}

MD fluxes can remain relatively high at salt concentrations much higher than for RO [148]. MD, therefore, has a logical use in zero (or near zero) liquid discharge applications; however, precipitating salts must be managed to enable the high recoveries. MD crystallization has been proposed to remove the scaling/precipitating salts to maximise MD concentration factors [149-151]. The concept of an MD crystallization experiment is shown in Figure 14. MD crystallizers have been explored for model $\mathrm{NaCl}$ and $\mathrm{Na}_{2} \mathrm{SO}_{4}$ solutions, increasing salinity above saturation [149,151] and for sea water desalination [150]. Recently, the crystallisation of near saturated $\mathrm{NaCl}$ solution was explored, finding that at a certain concentration of the feed, sudden flux decline occurred. This was due to crystal formation at the membrane surface which in turn had detrimental effects to the membrane as salts can penetrate into the pores compromising salt rejection [152]. Further applications for MD crystallisers have also been explored in other industries, for example in drug development [153]. The merger of MD with crystallisation, therefore, is an emerging area for MD and can expand to various industries.

Figure 14. Experimental setup of the MD crystallization used by Tun et al. [149].

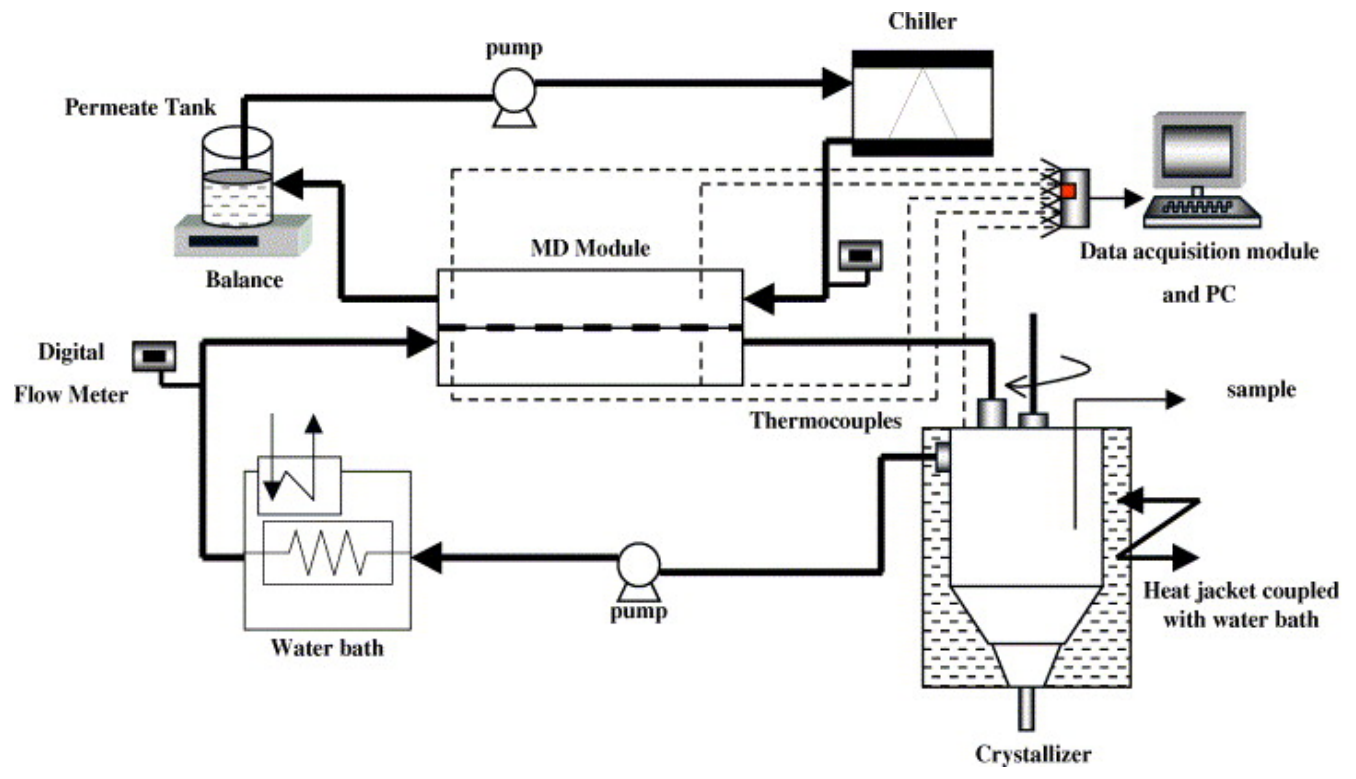

\subsection{Recent MD Processes and Modifications}

\subsubsection{Keppel Seghers}

A new module based around AGMD has been produced by the Singaporean enterprise Keppel Seghers. Two prototype units, "Module A" and a multistage "Module B" have been produced as shown in Figure 15, featuring $9 \mathrm{~m}^{2}$ of flat sheet membrane in each module [154].

Utilising the same solar field in Spain for the MEDESOL project [137], a 7 month trial was run in 2009 using the Keppel Seghers MD modules. Fluxes of up to $3.5 \mathrm{~kg} \mathrm{~m}^{-2} \mathrm{~h}^{-1}$ were achieved using "Module A" and up to $5.5 \mathrm{Lm}^{2} / \mathrm{h}$ using "Module B". To achieve these fluxes, temperatures around $80{ }^{\circ} \mathrm{C}$ were fed to the modules. Best thermal consumption of $294 \mathrm{kWh} / \mathrm{m}^{3}$ (GOR of 2.1) was reported using multistage "Module B". 
Figure 15. Keppel Seghers MD modules based around AGMD: (a) module A and (b) multistage module B [154].
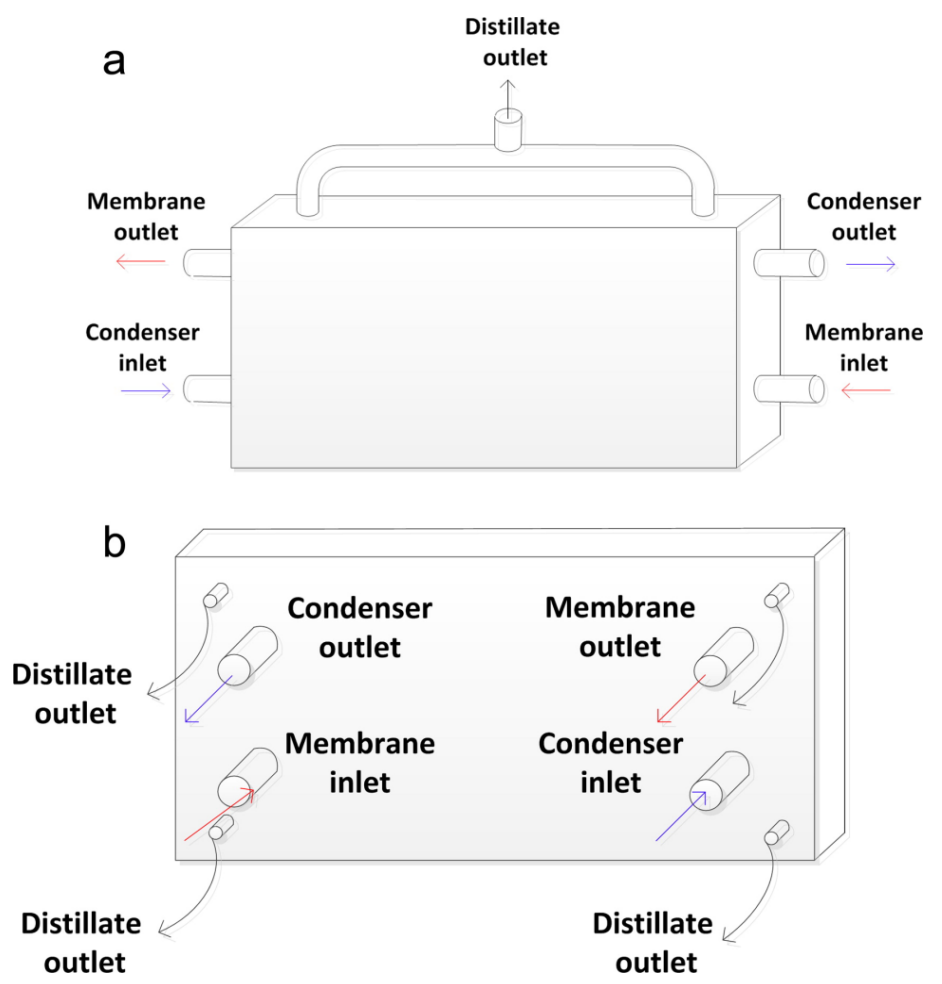

\subsubsection{Compact AGMD Modules}

A compact, small-scale and flexible AGMD unit was presented in 2012 by Cipollina et al. [142]. The unit has planar plate and frame geometry for easy assembly and disassembling, counter-current flows with internal heat recovery for thermal efficiency enhancement and cheap polymeric material (Figure 16). The system could be easily extended from single-stage to multi-stage units, and coupled with a polymeric heat exchanger for feed brine heating by means of solar energy or waste heat. The system can produce fresh water for small communities located in remote areas with potentially large availability of non-conventional energy sources.

Figure 16. MD configuration with planar geometry [142].

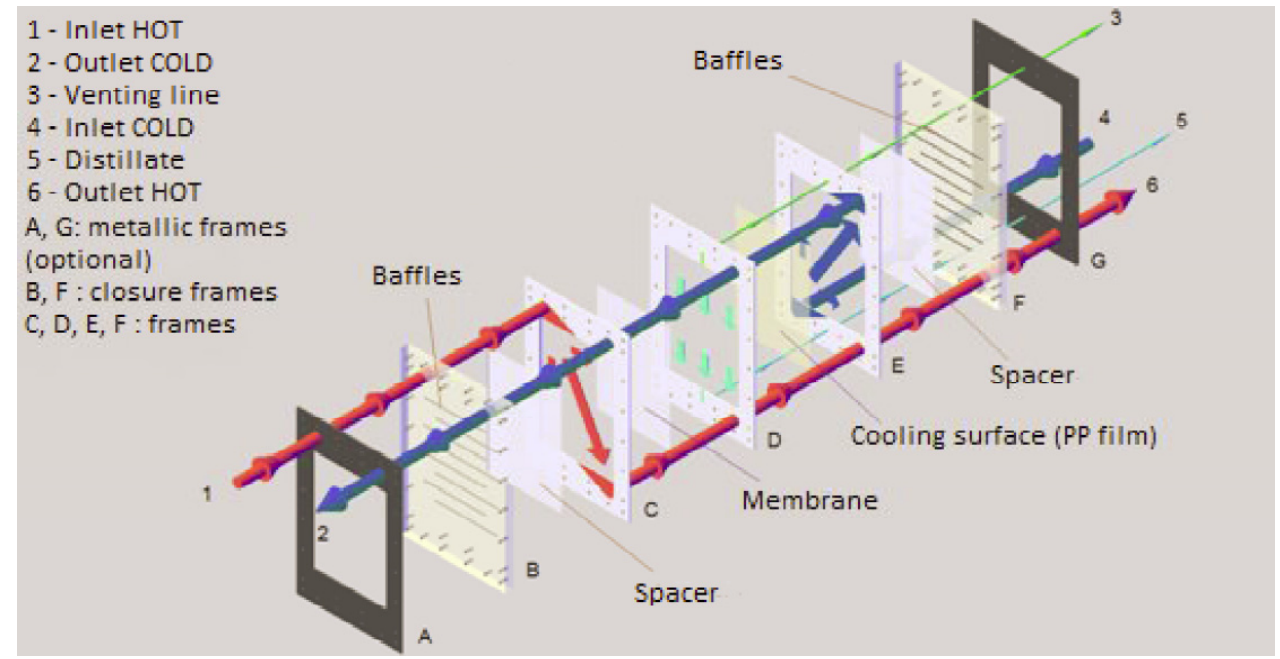




\subsubsection{Membrane Distillation Heat Exchanger (MDHX)}

As shown in Figure 17, the MD heat exchanger (MDHX) proposes a MD concept where the heat is coupled directly into the MD module by directing separate process streams into the MD module to both supply and remove heat from the MD channels $[155,156]$. The benefits include conveniently merging MD and process heat exchange into a single unit, but also it allows for direct heat conduction where it is lost. This overcomes the limitation presented in Equation (13), yielding no theoretical limit on single pass recovery.

Overcoming the single pass recovery limit was first explored theoretically by considering a module that condenses vapor on a heat transfer plate running in parallel to the membrane to supply the latent heat to the MD channel (Figure 18). The latent was then removed on the cold side of the MD channels by another parallel plate that boiled a fluid [126]. Despite promising improved single pass recovery that reduces the electrical energy requirement proposed in Equation (13), condensing/boiling vapor within a module is practically difficult and no experimental validation was presented. Instead, the MDHX concept is more practical, and the concept was validated with experimental data $[155,156]$.

Figure 17. Concept of MDHX system that couples heat directly to the MD process [156].

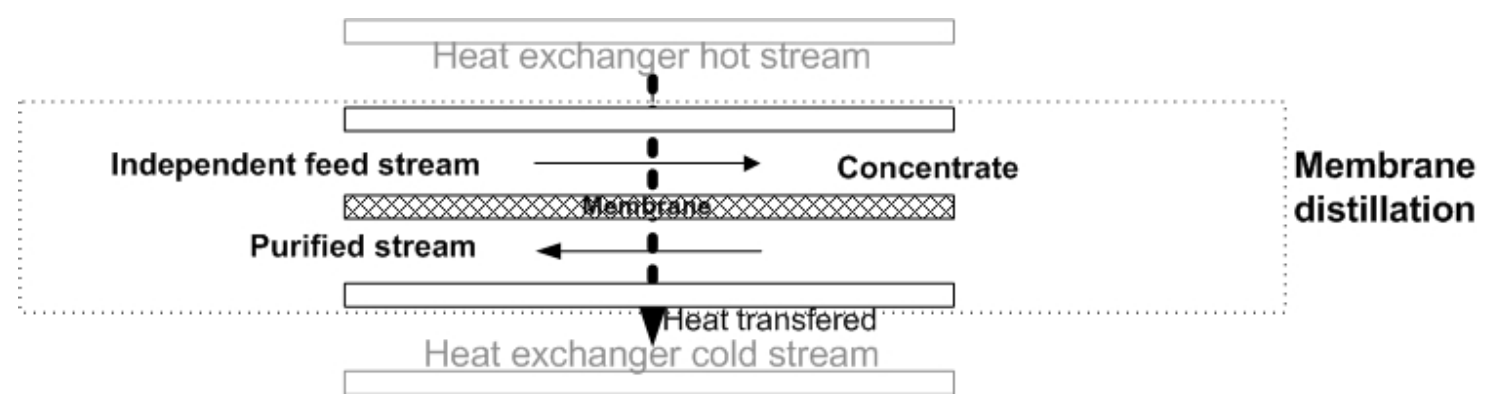

Figure 18. Concept of adding and removing heat directly from the MD module to overcome single pass recovery constraints [126].

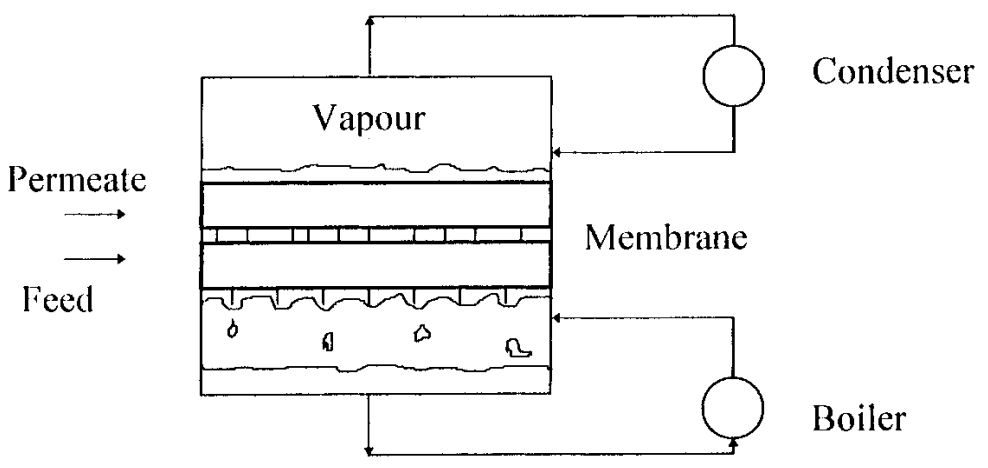

Early experimental work demonstrated that single pass recoveries can be increased from $2 \%$ to $14 \%$, which leads to an electrical energy consumption $<0.01 \mathrm{kWh} / \mathrm{m}^{3}$. Meanwhile, the thermal energy requirement is high, at around $1200 \mathrm{kWh} / \mathrm{m}^{3}$, so the simple form of the MDHX module has better applications in abundant, low temperature $\left(<40^{\circ} \mathrm{C}\right)$ waste heat applications. Higher thermal efficiency configurations are possible, but unexplored at this time. 


\subsubsection{DCMD Module Improvements}

In 2012, Yu et al. presented computational fluid dynamics results on the benefits of improving the flow conditions in DCMD modules [157]. They used DCMD hollow fiber modules with and without annular baffles attached to the shell wall to investigate the effect of the intrinsic mass-transfer coefficient of the membrane on the module performance. The baffled module provided a significant mass flux improvement compared to a non-baffled module at a higher temperature. They suggested that by adding the baffles the fluid dynamics of the systems may improve and reduce the degree of temperature polarization (TP), which is believed to be one of the main causes responsible for low water flux. However, the added turbulence has an electrical energy penalty following Equation (13), as the module backpressure would in turn increase. The improved flux would have to outweigh the increased pressure to ensure the electrical energy requirement is not substantially increased.

\section{Advances on MD Applications for Water Purification}

Membrane distillation has important advantages that enable coupling with waste heat or renewable energy-driven systems such as geothermal or solar energy. Some advantages include the ability to operate at lower temperatures $\left(50^{\circ} \mathrm{C}\right.$ to $\left.80^{\circ} \mathrm{C}\right)$, at higher brine concentrations and at lower pressures than other thermal-driven or pressure driven systems. Other advantages are the ability of the system to operate intermittently without causing damage to the membrane module or to the membrane if it dries out, and minimal chemicals are required for pre-treatment of the feed water [136,158].

\subsection{MD and Renewable Energies}

\subsubsection{MD-Solar Systems}

MD solar desalination is a sustainable option for regions with lack of freshwater that have large amounts of available solar radiation. Major components of a solar MD system are a solar collector, heat storage tank, heat exchanger, and MD module [43]. One of the reasons of interest for coupling MD with solar energy collectors is the ability for MD to tolerate fluctuating and intermittent operating conditions and to operate with low grade thermal energy [159]. The operating temperatures of MD are similar to the temperatures at which solar collectors exhibit highest efficiency [43]. The energy generated by the solar collectors and PV panels can provide the thermal energy supply for the low operating temperatures required by MD [160]. It was reported that even though the initial cost of a MD solar system is a limitation, once the system is installed and in operation, the operational and energy costs are minimal [159]. A recent study [161] showed that for the AGMD system, increasing the feed inlet temperature had a significant effect in lowering the cost while high feed flow rate resulted in increasing water production cost. In solar panel (SP)-MD systems, the MD configuration will impact the final cost of the water.

Bench- and pilot-scale studies have been undertaken on solar MD [43,130,137,159,161-166]; however, they are still few compared to studies with the more mature technology of solar PV-driven RO and solar distillation. A solar MD system was tested to recover water and reduce brine volumes from RO concentrates by Dow et al. [75]. The system consisted of evacuated solar tubes for collection 
of the required thermal input and a flat sheet MD module. The solar panels were capable of reaching $60{ }^{\circ} \mathrm{C}$, with efficiency as high as $70 \%$. The researchers found a reduction of the performance of the solar panel to nearly half of the design capacity due to solar energy variability caused by external factors such as cloudy and rainy weather. They also found reduction of the module performance due to gradual scale build up inside the module. The RO concentrate that fed the MD systems contained approximately $3300 \mathrm{mg} / \mathrm{L}$ TDS with $200 \mathrm{mg} / \mathrm{L}$ calcium, $100 \mathrm{mg} / \mathrm{L}$ magnesium, $200 \mathrm{mg} / \mathrm{L}$ sulfate, and $350 \mathrm{mg} / \mathrm{L}$ carbonate/bicarbonate. It also contained antiscalant which was added during the RO stage. The conductivity of permeate produced was $<50 \mu \mathrm{S} / \mathrm{cm}$ at a flux of $3.6 \mathrm{~kg} \mathrm{~m}^{-2} \mathrm{~h}^{-1}$.

Deng [167] found a decrease in thermal efficiency with time when using a flat solar collector to heat the feed water entering to a hollow fiber MD module, and attributed it to sunshine, wind, and cloud coverage. The purpose of the solar collectors was to provide the heat needed by brackish feed water entering the MD system. The maximum efficiency of the standard and flat panels evaluated was $32.75 \%$ and $70 \%$, respectively. The thermal efficiency of a homemade solar panel was also evaluated by the author, and found it to be only 5\% due to lack of proper insulation of the cover glass to retain the heat adsorbed by the collector.

An air gap membrane distillation (AGMD) module with a surface area of $9 \mathrm{~m}^{2}$ was tested for seawater desalination using a solar multistage MD system with a potential capacity of $0.5 \mathrm{~m}^{3} / \mathrm{d}$ to $50 \mathrm{~m}^{3} / \mathrm{d}[136,160]$. The heat source for the feed water used in the system was a compound parabolic solar concentrator. The system required a specific heat consumption of $1400 \mathrm{kWh} / \mathrm{m}^{3}$ with a total maximum distillate production of $20 \mathrm{~L} / \mathrm{h}$ per module and a maximum single pass recovery ratio of $2 \%$ per module. Another AGMD module with a total surface area of $2.8 \mathrm{~m}^{2}$ was coupled with a static solar collector field (Compound Parabolic Collector type) and tested during solar hours (Figure 19) [137]. The system was integrated into a multistage layout to minimize energy consumption. A non-fouling coating for heat exchangers was used to avoid scaling. The MD system proved to be suitable for coupling with transient solar thermal energy but scale-up from laboratory scale affected specific distillate production and thermal consumption. A maximum specific distillate flux of $71 \mathrm{~kg} \mathrm{~m}^{-2} \mathrm{~h}^{-1}$ was reported. Table 3 summarizes MD solar systems implemented and tested by different authors.

Figure 19. Schematic diagram of solar MD experimental prototype at PSA, Spain [137].

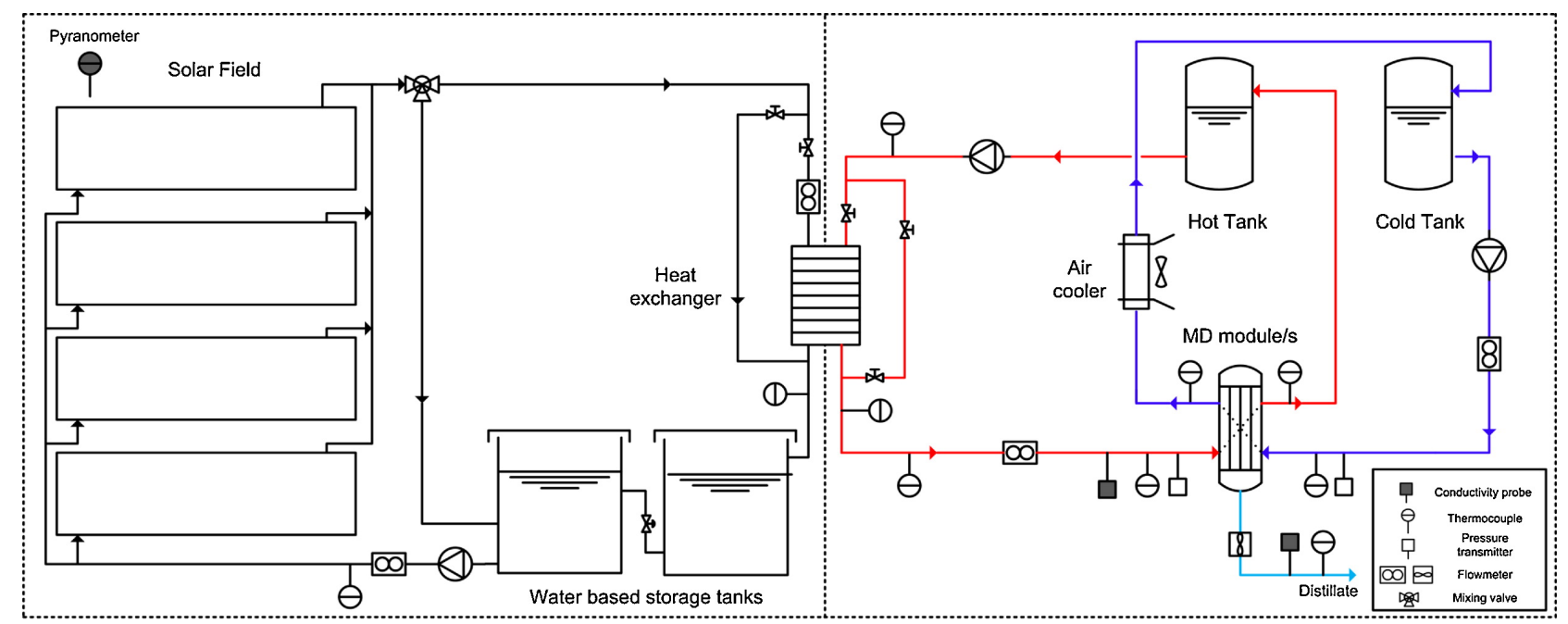


Table 3. Examples of reported solar-powered MD modules.

\begin{tabular}{cccccc}
\hline System & $\begin{array}{c}\text { Collector } \\
\text { area }\end{array}$ & Capacity & Flux & $\begin{array}{c}\text { Water } \\
\text { application }\end{array}$ & Reference \\
\hline Solar pond + AGMD & $2.94 \mathrm{~m}^{2}$ & - & $6 \mathrm{~kg} \mathrm{~m}^{-2} \mathrm{~h}^{-1}$ & - & {$[134]$} \\
Flat plate collector + hollow fiber MD & $3 \mathrm{~m}^{2}$ & $50 \mathrm{~L} /$ day & $17 \mathrm{~L} / \mathrm{m}^{2}$ day & - & {$[168]$} \\
Flat plate and vacuum tube collector MD & $12 \mathrm{~m}^{2}$ & $40 \mathrm{~L} / \mathrm{h}$ & - & - & {$[169]$} \\
Flat plate collector + spiral wound MD & $10 \mathrm{~m}^{2}$ & $100 \mathrm{~L} /$ day & - & brackish & {$[170]$} \\
Solar collector + hollow fiber VMD & $8 \mathrm{~m}^{2}$ & - & $32.2 \mathrm{~kg} \mathrm{~m}^{-2} \mathrm{~h}^{-1}$ & groundwater & {$[171]$} \\
Parabolic solar concentrator & - & - & $71 \mathrm{~kg} \mathrm{~m}^{-2} \mathrm{~h}^{-1}$ & seawater & {$[172]$} \\
\hline
\end{tabular}

Solar MD system performance is measured by the solar radiation profiles which in turn are established by the design, integration and control of the individual components of the system. One of the major difficulties of solar MD systems is reaching steady state operation due to the intermittent nature of the solar radiation $[75,167]$ and few attempts have been made to model the system behaviour. Chang et al. [43] developed a dynamic model for a solar driven spiral-wound AGMD system and investigated the performance of proportional-integral (PI) control systems with appropriate tuning of parameters and selection of set point settings. Proportional-integral-derivative (PID) control systems have proven to be robust and are the most used by industry [173]. The authors suggest the use of an interior coil heat exchanger configuration for higher thermal energy absorption and longer operation time. Small and large scale stand-alone solar MD desalination systems have been developed to provide potable water in remote areas that lack both electricity and drinking water but have abundant solar irradiation [40]. A summary of commercial solar-powered MD systems is presented in Table 4. Fraunhofer ISE developed solar thermally driven compact desalination systems based on spiral wound MD for capacities between 100 and $500 \mathrm{~L} /$ day and larger systems of up to $10 \mathrm{~m}^{3} /$ day. Eight pilot plants were installed in five different countries, i.e., Grand Canaria, Egypt, Jordan, Germany, and Italy $[130,162,165,174]$. The compact system in Italy was powered by a hybrid system using solar energy and waste heat from diesel engines [142].

Table 4. Multistage pilot and commercial solar-powered membrane distillation system $[40,130,137,142,165,174]$.

\begin{tabular}{|c|c|c|c|c|c|}
\hline Properties & Scarab & Medesol & Memstill & Memsys & Smades \\
\hline Configuration & AGMD & AGMD & AGMD & VMD & Spiral wound MD \\
\hline Surface area & $2.3 \mathrm{~m}^{2}$ & $2.8 \mathrm{~m}^{2}$ & $9 \mathrm{~m}^{2}$ & - & $72 \mathrm{~m}^{2}$ \\
\hline Membrane material & PTFE & PTFE & - & - & PTFE \\
\hline Capacity & $1-2 \mathrm{~m}^{3} /$ day & $0.5-50 \mathrm{~m}^{3} /$ day & $\begin{array}{l}80 \mathrm{~m}^{3} / \text { day } \\
50 \mathrm{~m}^{3} / \text { day }\end{array}$ & $1 \mathrm{~m}^{3} /$ day & 600-800 L/day \\
\hline Permeate flux & $12-27 \mathrm{~kg} \mathrm{~m}^{-2} \mathrm{~h}^{-1}$ & $5-10 \mathrm{~kg} \mathrm{~m}^{-2} \mathrm{~h}^{-1}$ & - & - & $2-11 \mathrm{~L} / \mathrm{m}^{2}$ day \\
\hline $\begin{array}{l}\text { Thermal energy } \\
\text { Consumption }\end{array}$ & $5-12 \mathrm{kWh} / \mathrm{m}^{3}$ & $810 \mathrm{kWh} / \mathrm{m}^{3}$ & $22-90 \mathrm{kWh} / \mathrm{m}^{3}$ & $175-350 \mathrm{kWh} / \mathrm{m}^{3}$ & $200-300 \mathrm{kWh} / \mathrm{m}^{3}$ \\
\hline $\begin{array}{l}\text { Electricity } \\
\text { comsumption }\end{array}$ & $0.6-1.5 \mathrm{kWh} / \mathrm{m}^{3}$ & - & - & $0.75-1.75 \mathrm{kWh} / \mathrm{m}^{3}$ & - \\
\hline Test sites & Sweden & Spain & $\begin{array}{l}\text { Singapore } \\
\text { Rotterdam }\end{array}$ & Singapore & Jordan \\
\hline Stage & Commercialised & Pilot plant & Pilot plant & Commercialised & Pilot plant \\
\hline
\end{tabular}


Even though solar MD can be applied to produce fresh water in regions with large amounts of available solar radiation, the water cost derived from its implementation is still high, particularly because the cost of the solar heater is over $70 \%-80 \%$ of the total cost for the MD system. Implementation of SP-MD systems may be possible if the cost of PV panels, solar heaters, the membranes or other fixed capital costs items can be reduce [161]. From these items, the solar heater cost impacts the overall cost of water the most. To reduce the cost of the solar heater, Saffarini et al. [161] proposed rapid development in the area of solar heaters to have higher efficiencies and lower collector prices, and restrictions on the use of solar energy. The proposed alternative is to use other sources of heat for water heating. Waste heat provided by high-temperature brine from thermal desalination plants and waste heat from produced water generated at oil and gas wells are two examples. DCMD coupled with a heat exchanger may still be the best choice from a cost-effective configuration perspective even though high conduction losses from the feed to permeate are present.

\subsubsection{MD-Geothermal Systems}

MD has been proposed as a desalination technology which can be driven by thermal energy from geothermal sources and only requires energy for pumping $[175,176]$. However, the use of geothermal energy for MD has not been widely developed. Bouguecha et al. [175] proposed coupling AGMD with a fluidized bed crystallizer (FBC) as an alternative for both desalination and removal of hardness from geothermal water. Some geothermal springs are characterized by high hardness and low grade temperature. In his experimental work Bouguecha et al. [175] found that the MD recovery fraction is not very high by using only the sensible heat from a geothermal well. To increase the recovery ratio, the researcher proposed coupling solar collectors with the geothermal energy. Hardness and coupling of FBC to MD are some of the difficulties encountered when attempting to obtain waste heat from geothermal water [175]. In geothermal areas with hot spring temperatures ranging from $145{ }^{\circ} \mathrm{C}$ to $170{ }^{\circ} \mathrm{C}$, brackish water is cooled to irrigate greenhouses and feed desalination plants. In the cooling process, a significant quantity of thermal energy is rejected to the atmosphere. Temperature requirements of traditional thermal desalination plants cannot be afforded by the supply of geothermal resources. Hot spring underground water contains minerals and dissolved organic material, including sodium, calcium, sulfate, and chloride. They can precipitate as the spring water discharges at the land surface [177]. Geothermal renewable energy can provide suitable and reliable heat supply for MD. However, the MD recovery fraction may not reach a high value using only the sensible heat from geothermal wells. Additional studies are required to explore the feasibility of coupling other energy systems with geothermal energy and MD with the purpose of increasing recovery ratio. Studies are also required to determine scaling and fouling caused by the hardness of the geothermal water. An economic analysis on geothermal MD was conducted by Bouguecha et al. [175] and is presented in Section 6.

\subsubsection{Industrial Wastewaters}

MD studies have been conducted using heat derived from waste sources as a viable treatment technology for industrial effluents. This will reduce discharge volumes to sewer and allow recovery of 
potable quality water without an increase of the greenhouse footprint. Availability to heat is unique for each location and process. Some MD experimental studies include those conducted by Dow et al. [75] to exploit the waste heat from heavy industry for treatment of saline effluents, producing high quality water for on-site reuse. Five different types of industries were selected for the study including a plastic foam producer, a frozen food producer, an electrical generator, a chemical manufacturer, and a plastics manufacturer. In their study, Dow et al. [75] obtained water recoveries greater than $90 \%$. However, the effluent quality presented challenges to MD efficiency by generating resistance to the permeate flux through scale formation. The authors suggested the use of antiscalant commonly used in the water industry to reduce scaling. Regardless of the feed water quality, the permeate produced was of consistently high quality, except for the cases where ammonia was present and passed through to the permeate because of its volatile nature. Dow et al. [75] demonstrated that waste waters that contained volatile species are likely to degrade the high quality of MD permeate.

MD has been used to desalt hot brines and other aqueous solutions at feed temperatures below $100{ }^{\circ} \mathrm{C}$. However, the potential to apply this technology to treat feed solutions above $100{ }^{\circ} \mathrm{C}$ was not explored until recently. This is an additional advantage for MD over other traditional membrane separation processes like RO, which cannot utilize the heat available in the feed solution and requires additional energy for cooling of the feed solution. Singh and Sirkar [178] used DCMD with PTFE membranes to treat produced water at $80-130{ }^{\circ} \mathrm{C}$ obtained from steam assisted gravity drainage (SAGD). The produced water had a TDS concentration of $10,000 \mathrm{mg} / \mathrm{L}$. Even though the pressure of the solution went up to 2-3 atm, the membrane did not show leakage of salt under the experimental conditions tested. The water generated from this process may be used for steam generation in the SAGD process.

Global water scarcity and high oil prices have accelerated research to develop novel hybrid MD systems using renewable energy or waste energy. A freeze desalination and MD hybrid process was developed using waste cold energy released from re-gasification of liquefied natural gas (LNG) [179]. Researchers demonstrated that utilizing LNG cold energy greatly reduced the total energy consumption of the hybrid process with a total water recovery of $71.5 \%$. It was reported that the water quality obtained met the standard for drinking water.

Another important source of waste heat is the nuclear industry which is dominated by nuclear power stations. When working with liquid radioactive waste, the chemical and radiochemical composition of the effluents and their activity and total salinity has to be taken into account. Radionuclides, which are present in liquid low-level radioactive waste in ionic form, have been separated using a spiral wound MD module with hydrophobic PTFE membrane [180]. Zakrzewaska et al. [180] reported that MD allows complete removal of radioactive species in one stage as compared to the multiple-stages process required with RO, and does not require additional processes to ensure sufficient purity of effluent discharged to the environment. The PTFE hydrophobic membranes used by Zakrzewska [180] showed good resistance to ionising radiation and strong chemical environments. The authors reported MD as a potential candidate for treating liquid low-level radioactive waste.

Zakrzewaska et al. [116] also proposed MD to concentrate the radioactive substances separated from the non-active portion into a small volume for subsequent conditioning and disposal. The author reported that one of the main advantages of MD over reverse osmosis, which has already been 
implemented by the nuclear industry, is that there is no adsorption of ions such as ${ }^{50} \mathrm{Co}^{2+},{ }^{137} \mathrm{Cs}^{+}$, and ${ }^{134} \mathrm{Cs}^{+}$inside the membrane pores; and the generation of secondary waste is minimized. Zakrzewaska et al. [181] also showed the existence of a diffusion isotope effect in membrane distillation that enhances the separation factors for $\mathrm{H}_{2} \mathrm{O} / \mathrm{HDO}$ and ${ }^{16} \mathrm{H}_{2} \mathrm{O} /{ }^{18} \mathrm{H}_{2} \mathrm{O}$ enrichment. Khayet et al. [182,183] conducted a comparative study of MD configurations for nuclear desalination. He proposed coupling DCMD with a nuclear reactor for water desalination and for low- and medium-level radioactive liquid waste concentration as an alternative integrated system for water and wastewater management in nuclear power plants.

Some limitations have been reported on the use of MD in radioactive waste treatment [184]. They are mostly related to the type of membrane. Even though MD is a suitable option for low and intermediate level liquid radioactive waste purification, its application to high level liquid waste is limited due to radiation instability of hydrophobic polymer based membranes such as PTFE, PVDF, and PP. High level radioactive wastes are strongly acidic and these membranes are chemically unstable in the waste [184]. Zakrzewska et al. [180] suggested that the proper selection of membranes depends on the chemical and radiochemical composition and total salinity of the effluent to be treated. MD has shown high retention capacity and large decontamination factors in the separation of radionuclides which are present in the radioactive waste mainly in ionic form [180].

A limitation for the implementation of MD in the nuclear industry is the high energy consumption and the difficulties with long term operation connected with the risk of membrane wettability. Spiral wound MD modules have a thermal energy consumption of about $600 \mathrm{kWh} / \mathrm{m}^{3}$ [180]. An alternative is to use MD for small and medium capacity plants utilizing waste heat or other cheap energy sources. An advantage of implementing MD in the nuclear industry is that a lot of waste heat can be recovered in many points around nuclear cycles and reused for technological purposes [180]. Hybrid RO-MD systems may also be applicable in the nuclear industry to improve both the efficiency of the RO process and the decontamination factor. The decontamination factor is calculated as the ratio of activity concentration of feed to activity concentration of permeates [184]. RO systems supplemented with MD units can help recover large quantities of high enthalpy streams and waste heat [180].

An increasing industrial application for MD is the treatment of wastewater resulting from the textile industry, including the purification of dye solutions. Typical treatment technologies for treating dye solutions are coagulation/flocculation, adsorption and oxidation by ozone or chlorination [185]. Recent studies coupled traditional treatment methods with DCMD [186,187]. Banat et al. [188] studied the potential applicability of VMD to separate methylene blue dye from aqueous solutions. In a more recent study VMD with PP membrane was used to concentrate solutions containing different amounts and types of dyes [185] while recovering pure water. The authors observed a decay in the permeate flux for all dyes studied, which was attributed to membrane fouling. Membrane swelling was also observed.

Inorganic concentrates from RO and other desalination technologies can be potentially separated into high quality chemicals and reusable water using MD. Membrane distillation crystallization (MDC) has been proposed to recover concentrated solutions of magnesium sulfate from brines [189]. Water activities for concentrated solutions of varying ratios of sodium chloride and epsomite have been calculated using geochemical software. It has been established that the addition of a crystallizer stage after MD treatment reduces both the cost and environmental impacts due to brine disposal [189]. The 
performance of MD can, however, be influenced if the crystallization of salts takes place inside of the membrane module. Therefore, an evaluation of the kinetics of the crystallization process has to be understood. Kinetic studies on the crystallization of $\mathrm{NaCl}, \mathrm{Na}_{2} \mathrm{SO} 4$, and $\mathrm{CaCO}_{3}$ have been conducted by Curcio et al. [190], Drioli et al. [191]; and Gryta [192,193]. Drioli et al. [191] used MDC to generate supersaturation in the salt crystallization process and recover $\mathrm{CaCO}_{3}, \mathrm{NaCl}$, and $\mathrm{MgSO}_{4} \cdot 7 \mathrm{H}_{2} \mathrm{O}$ from nanofiltration retentate. The influence of high concentrations of salts such as $\mathrm{NaCl}$, $\mathrm{MgCl}_{2}, \mathrm{Na}_{2} \mathrm{CO}_{3}$ and $\mathrm{Na}_{2} \mathrm{SO}_{4}$ on permeate flux as well as rejection factors in a solar power system coupled with AGMD has been investigated by Alkhudhiri et al. [194]. The authors also investigated the energy consumption for high salt concentrations. They suggested that the latent heat of evaporation is related to salt concentration and that the energy consumption is almost independent of membrane pore size.

Factors influencing flux at close to saturation and the formation of salt crystals using MDC have been discussed by Tun et al. [149]. The researchers used two aqueous solutions of $\mathrm{Na}_{2} \mathrm{SO}_{4}$ and $\mathrm{NaCl}$ which have different solubility-temperature coefficient. They found that when operating in batch concentration mode without the crystallizer the flux gradually declined due to vapor pressure suppression and concentration polarization up to a critical degree of saturation. They also observed a rapid flux decline beyond the critical degree of saturation. They attributed this behavior to crystal deposition and scale formation on the membrane which reduced the membrane permeability. The $\mathrm{Na}_{2} \mathrm{SO}_{4}$ operated at a slightly higher degree of saturation due to its negative solubility-temperature coefficient which favours solubility in the polarization layer [149]. A narrow crystal size distribution with an average particle size of 60-70 $\mu \mathrm{m}$ were produced by a batch-type MD-assisted crystallizer. Tun et al. [149] concluded that temperature and saturation concentration both in the MD and the crystallizer are critical operating parameters for developing a steady state MDC process. The properties of $\mathrm{CaSO}_{4}$ crystal formation on the membrane surface in the MD process have been investigated by Gryta (2009) [192]. Gryta [192] confirmed that the formation of a deposit layer on the membrane surface is responsible for both flux decline and membrane wetting. The formation of $\mathrm{CaSO}_{4}$ crystal on the membrane surface may also penetrate into the pore interior resulting in a damage of the membrane. Gryta [192] proposed to use crystallization to continuously remove salt from solutions that were contaminated with sparingly soluble compounds to prevent damage to the membrane. Gryta [192] also found that the negative effect of $\mathrm{CaSO}_{4}$ scale was weakened when co-precipitated with $\mathrm{CaCO}_{3}$.

Membrane distillation has also found applications in metallurgical processes for which no other membrane-based systems apply. Some applications include concentrating waste acid, caustic and salt solutions with concentrations as high as $1 \mathrm{M}$ [195]. In the metallurgical industry a large amount of waste heat is usually available. Additionally, the process generates stripping and extract solutions that require concentration [158]. A combination of Diffusion Dialysis (DD) and VMD has been proposed to concentrate sulfuric acid from the $\mathrm{TiO}_{2}$ hydrolysis process; concentrations of $65 \%$ purity have been obtained [196]. Diffusion dialysis prevented the crystallization and precipitation of $\mathrm{FeSO}_{4}$ that occurred when the concentration of $\mathrm{H}_{2} \mathrm{SO}_{4}$ increased inside of the VMD module. VMD was investigated to recover hydrochloric acid $(\mathrm{HCl})$ from rare earth chloride solutions [197-199]. Highly concentrated $\mathrm{HCl}$ solutions are used in the solvent extraction process for rare earth solutions as the stripping reagent. Concentrations of $\mathrm{HCl}$ in the stripped liquor are as high as $2-5 \mathrm{~mol} / \mathrm{L}$. A traditional 
method for removing the $\mathrm{HCl}$ from stripped liquors is neutralization with large amounts of ammonium bicarbonate or by diffusion dialysis. One of the main disadvantages of neutralization is the generation of large quantities of waste reagent. The disadvantage of dialysis is a slow reaction process. Hybrid DD and VMD has been used to recover sulfuric acid from rare earth sulfate solutions as well [199].

A novel application for MD has been proposed by Cath et al. [147]. He incorporated MD into a combined direct osmosis/osmotic distillation (DO/OD) process to treat combined hygiene and metabolic wastewater in the NASA DOC test unit. In this study, Cath et al. [147] evaluated two configurations: A direct osmosis/MD (DO/MD) and a DO/membrane osmotic distillation (DO/MOD). The DO/OD process is isothermal and the only driving force stems from the concentration gradient across the two membranes. In the DO/MD configuration the driving force was temperature gradient only. In the DO/MOD configuration both the concentration and temperature gradients were the driving forces of the system. Over a period of 15 days the DO/MD and DO/MOD fluxes were 4-20 and 8-25 times higher, respectively, compared to the DO/OD process. MD and/or OD can be combined with DO in a dual membrane configuration to treat complex liquid streams that cannot be treated with either individual process. In the DOC test unit (Figure 20a) the hygiene wastewater is pretreated by DO (DOC \#1). The stream of concentrated wastewater from DOC\#1 is treated by DO/OD (DOC\#2). The driving forces in the DO/OD membrane contactor are the osmotic pressure and partial vapor pressure gradients across the two membranes, which are induced by the concentration difference between the feed wastewater and the osmotic agent (OA) (Figure 20b). The DO/OD process takes place in a plate-and-frame module having four plates with eight pairs of membranes (Figure 20c). Figure 21 shows the concentration and temperature profiles for the three dual membrane processes evaluated by Cath et al. [147].

Figure 20. (a) Flow diagram for the NASA DOC wastewater treatment process, DO (DOC\#1) and dual DO/OD (DOC\#2); (b) Mass transport in the DO/OD membrane process in DOC\#2; (c) Cross section of the DOC\#2 plate-an-frame design [147].

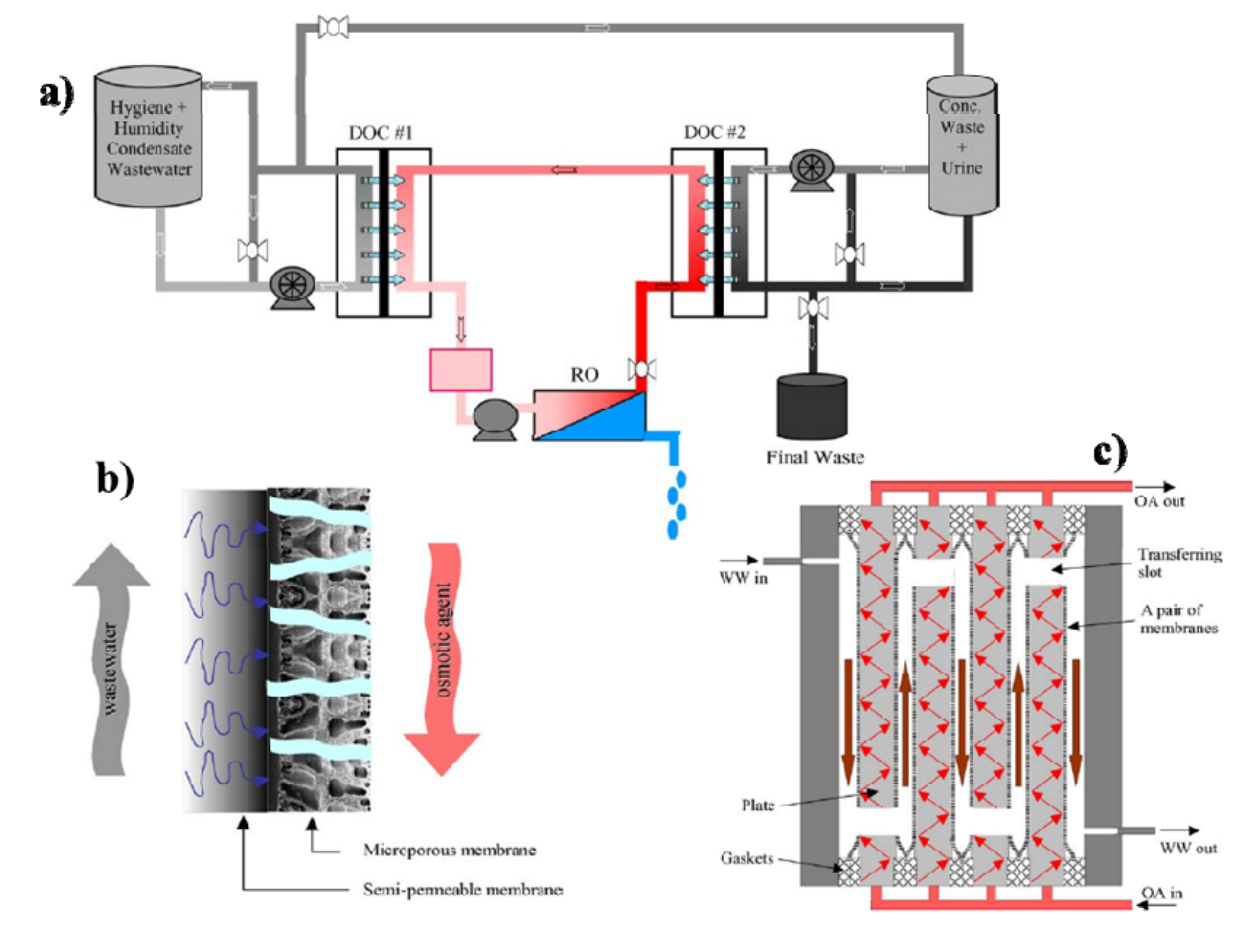


Figure 21. Concentration and temperature profile in (a) DO/OD; (b) DO/MD; and (c) DO/MOD dual processes [147].
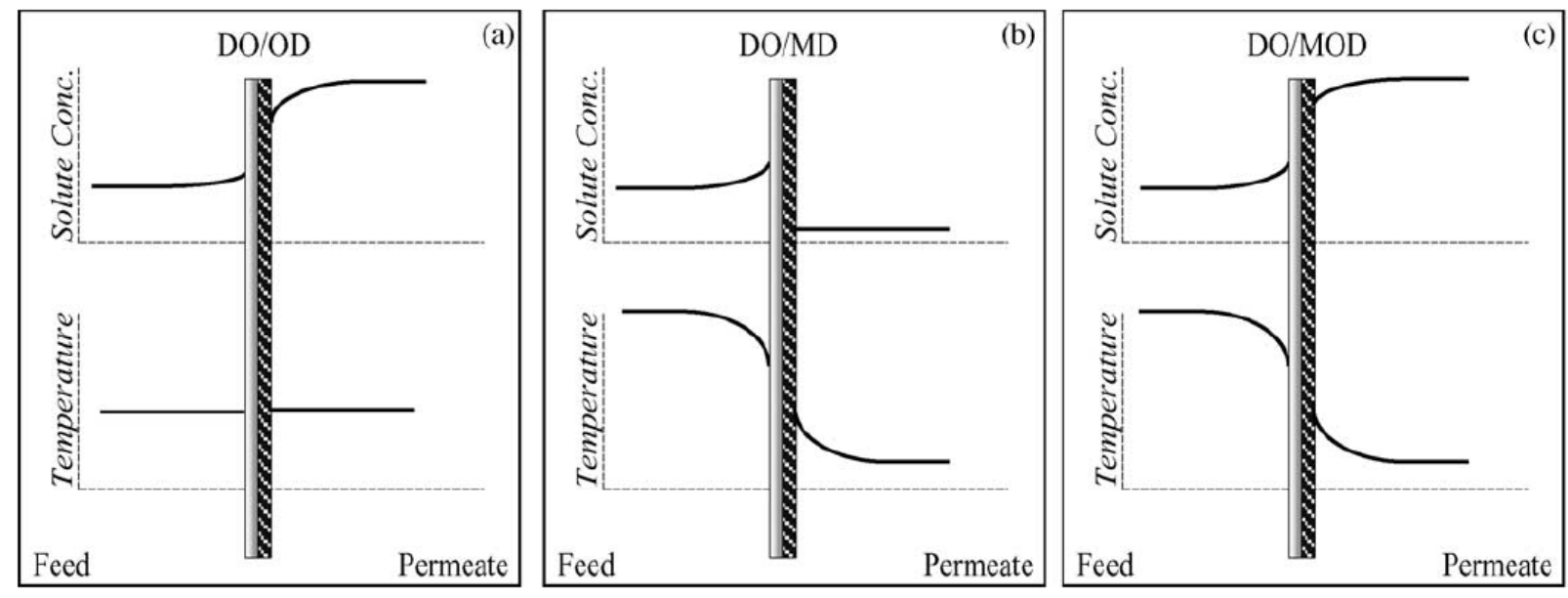

Recently Susanto [158] summarizes novel applications for MD. They included separation of methanol-water mixtures by combining micro-fluidic channels with SGMD, and separation of benzene-toluene mixtures. The performance of the MD based micro-separator was studied with different liquid-vapor/gas membrane contactors with respect to the separation factor and the distillate flux. Operating parameters of the system that were varied include methanol concentration in the feed, the feed temperature, the feed flow rate, and the flow rate of the inert carrier gas nitrogen. The nitrogen flow rate was the most important parameter influencing the separation performance of the micro-separator. The temperature polarization effect was reduced by selecting an appropriate membrane liquid-vapor/gas contactor. Hydrophobic PVDF, oleophobic PTFE on PE support, and oleophobic PES on PE support micro-porous membranes were used [158,200].

To separate benzene and toluene, a ceramic hollow fiber membrane contactor was used. The ceramic hollow fibers were operated at $93-97{ }^{\circ} \mathrm{C}$ for $100 \mathrm{~h}$ and demonstrated high chemical and thermal stability, conditions that most polymeric membranes would not stand. The membrane contactors operated over the flooding limit of conventional packed columns because the vapor and the liquid phases were separated from each other. The use of ceramic hollow fiber membrane contactors looks promising for solvent distillation at a large scale [158,201].

\subsection{Food Industry}

\subsubsection{Juice Industry}

The food industry has great interest in MD systems for a wide variety of reasons and MD has principally been explored for juice applications. MD can be used in its conventional arrangement driven by temperature difference across the membrane, but vapor pressure difference can also be imposed by differences in concentration [53]. This MD type is known as osmotic distillation. Avoiding high temperatures of evaporators, or by using different operating conditions to RO, a unique function in the separation can be obtained, for example avoidance of flavor losses in fruit juice processing [202,203]. A potential application for MD is the concentration of fruit juices at temperatures lower than other thermal methods. The main advantage of concentrating juice at low 
temperatures is that the organoleptic traits, as well as flavours, of the fresh juices are better preserved [204,205]. Reduction of flux may occur due to increase of the juice viscosity and deterioration of the hydrodynamic conditions of the process. In the concentration of apple juice using DCMD, Gunko et al. [206] obtained 50\% solids content when the permeate flux reached $9 \mathrm{~kg} \mathrm{~m}^{-2} \mathrm{~h}^{-1}$. The author observed that by further concentrating the juice to $60 \%-65 \%$ solids the flux reduced to about $3.0-3.8 \mathrm{~kg} \mathrm{~m}^{-2} \mathrm{~h}^{-1}$, which may result in a decrease in the biological value of the concentrate [206]. Using DCMD and a hollow fiber module Lagana et al. [119] produced a highly concentrated apple juice. They found that the trans-membrane driving force decreased with increasing membrane temperature but increased with higher feed and distillate flow rates. The author also found that the viscosity of the juice at high concentration induced a high polarization phenomena.

Orange juice was concentrated by using DCMD and PTFE membranes treated with alcohol-water solutions [207]. The purpose of the mixture was to modify the hydrophobicity of the membrane. Parameters such as feed flow rate, temperature difference, and concentration of sugar solution were studied as a function of the trans-membrane flux. Researchers observed that the trans-membrane flux increased with increasing flow rate for both treated and untreated membranes, which was attributed to a reduction of the temperature polarization. An increase of $36 \%-43 \%$ of trans-membrane flux as compared to non-treated membrane was also observed. It was attributed to improvements in the membrane surface, which may have been caused by converting it from hydrophilic to hydrophobic during the treatment with alcohol. Results obtained with AGMD using sucrose aqueous solutions have also been reported [208].

Additional applications in the juice industry have been found using VMD. Results on must concentration using vacuum membrane distillation (VMD) to increase the alcoholic potential of the must have been reported by Bandini and Sarti [204]. Must is an acid complex juice obtained from grape pressing that contains a variety of aroma compounds. More recently, a hollow fiber VMD module was used to recover the main pear aroma compound, ethyl 2,4-decadienoate from a model solution dissolved in an ethanol-water mixture [209]. Operating variables such as aroma feed concentration, feed flow rate, temperature, and downstream pressure were tested. The authors found that the temperature and pressure are variables with a strong influence on process performance. Reversible sorption of the aroma compound onto the membrane material was also observed.

\subsubsection{Dairy Industry}

MD has been explored to evaluate its potential application for dairy processing. In dairy applications, evaporating whey and skim milk can be done with MD at milder temperatures [129,210]. Recently a study was conducted in Australia to concentrate whole milk, skim milk, whey and a pure lactose solution using DCMD with PTFE flat sheet membranes [129]. The purpose of the study was to evaluate the performance of the process for improving the sustainability of dairy processing from milk down to pure lactose. Dissolved solids retention of about $100 \%$ and no effect of the dry-matter concentration in the feed was reported. However, the flux from DCMD using whey solutions $\left(10 \mathrm{~kg} / \mathrm{m}^{2} \mathrm{~h}\right)$ were two times greater than the flux treating skim milk $\left(5 \mathrm{Kg} / \mathrm{m}^{2} \mathrm{~h}\right)$, indicating that caseins reduce performance of DCMD with the PTFE membrane materials used. Despite the drivers in 
product quality, the need for membrane technology in dairy processing should focus on water and energy sustainability [211].

Despite the potential for MD in foods systems (juice and dairy), wide commercial implementation has not taken place yet. The reasons are similar to water treatment in that while RO and evaporators are readily available and commercial, MD struggles to find a niche [212]. The economic drivers in foods industries are similar to water treatment in that MD proposes to be a cheaper alternative to evaporators used to concentrate products including juices and dairy mentioned above, or even sugarcane juice [120]. Evaporators enjoy their state-of-the-art status, long industry experience, and wide variety of suppliers world-wide. Likewise, when competing with RO, MD faces the lack of maturity in comparison to RO already working in food processing lines. But uniquely for foods industries, the value of the product processed is greater than for water treatment, so technology drivers can also focus on the high value of various concentrated compounds. Efforts to justify MD in foods industries should focus on the unique separation functions compared to alternatives, as well as the cost incentives already understood from the costing applied to water treatment. Based on the virtues of MD for water and energy sustainability, it is likely to be commercial opportunities in foods industries will be measured by both energy savings and improved food product quality.

\section{Advances on Membrane Fabrication for MD}

The structure and chemistry of membranes for Membrane Distillation (MD) are critical to achieve high performance, i.e., the generation of a large amount of distilled solvent at very low salt concentration. The membranes need to be specifically designed to maximize the solvent vapor permeability while avoiding liquid solvent transport. Although MD has also been used to separate mixed organic solvents and organic-aqueous mixtures, most of the examples and studies described and discussed in this section will concern, unless otherwise specified, membranes designed for the treatment of solutions where water is the major solvent.

A number of membrane fabrication strategies have been investigated since the early days of MD research, but as initially defined by Smolders et al. in 1989 [13], a suitable membrane needs to exhibit certain characteristics in order to be viable in MD. Although, the membrane should be porous, it should not be wetted by the process liquids under the pressure applied within the membrane module. Furthermore, no capillary condensation should occur within the pores, while the membrane itself should not affect the vapor/liquid equilibrium of the system being desalinated. Finally, at least one side of the membrane should be in direct contact with the process liquids while only vapor should be transported across the pores of the membrane.

The properties and structure of the surface of the membrane are highly important, and the requirements may vary depending on application and the type of MD configuration in which the membrane is being used: VMD, AGMD, SGMD or DCMD. While SGMD and VMD are the most energy intensive MD techniques, they are generally preferred to separate two mixed liquids having different boiling points to avoid further treatments linked to the contamination of another carrier liquid on the permeate side $[1,19,22,30,213]$. On the other hand for water purification, desalination and dewatering AGMD and DCMD are generally used since only water is evaporated from the bulk feed [115,214-220]. 


\subsection{Membrane Properties}

\subsubsection{Morphology}

Both flat-sheet (FS) and hollow fiber (HF) membranes have been operated in MD [218-221]. HFs exhibits a higher area-per-volume ratio and can be more easily assembled into membrane modules. However, HFs were also shown to be more susceptible to mechanical failures than FS membranes. In this section, focused on membrane materials, few considerations will be given to the geometry of the fibers, and discussion will focus on different membrane morphologies.

Appropriate MD membranes can be either symmetric or asymmetric with, respectively, one single thick active layer or a thin active layer reinforced on a support layer. Although the criteria developed in this section [13] apply to the four MD configurations, DCMD is preferred when high flux is required as it has a small air-gap through which vapor is driven. The air-gap in DCMD is confined to the membrane thickness/porosity whereas because of the additional feature required to condense the water vapor, it is larger in the other setups. Furthermore, as DCMD relies on a liquid/air gap/liquid interface, membranes designed and used in DCMD typically exhibit the highest resistance to vapor permeability [222]. Performance across the membranes will therefore be more sensitive to surface chemistry or morphology variations in DCMD compared to the other MD configurations. DCMD therefore, stands as a better benchmark to test the impact of different membrane materials and structures on the process performance. It should be noted however, that DCMD is also more susceptible to reduced energy efficiency and flux resulting from thermal conduction through the membrane because of the higher heat transfer coefficient from the membrane to the liquid permeate phase compared to the heat transfer coefficients from the membrane to the gas phase for the other MD configurations. Therefore, membrane performance in DCMD will over emphasis the significance of membrane thermal conductivity if the membranes are to be considered for use in AGMD, VMD or SGMD.

As shown in Section 1, vapor transport across a membrane in MD can be defined globally by the following Equation:

$$
f=K(T) \times\left(\frac{r \times \mathcal{E}}{\tau \times b}\right)^{\alpha}
$$

where $f$ is the permeance of the membrane, $K(T)$ is a function of temperature and molecular weight of the gas; $r$ is the average radius of the pores, $\varepsilon$ the porosity, $b$ the thickness and $\tau$ the tortuosity of the membrane. The value of $\alpha$ varies with the type of permeation regime under which vapor permeates across the porous membrane. The value $\beta$ varies with the ratio of the mean free path, $l$, to the average pore size of the membrane $[1,78]$.

The active layer needs to be as thin as possible to enhance permeance while presenting a low tortuosity path to the water vapor (Equation (14)). Membranes for MD generally have pore size distributions lying between 0.2 and $1 \mu \mathrm{m}$ [1,222,223] while the porosity of commercially available membranes is often $>60 \%-70 \%$ and the thickness of their active layer comprised between a few dozen up to a hundred microns. However, membranes that are too thin are thought to allow liquid transport 
through the membrane [52] and a practical minimum thickness for $1 \mu \mathrm{m}$ pore size membranes is $>30 \mu \mathrm{m}$.

\subsubsection{Surface Energy}

The typical upper limit pore size finds it source in the second main criteria ruling MD: avoiding direct liquid bridges across the membrane. As shown in Equation (15), the LEP of a membrane relies on a number of parameters. The LEP defines the minimum pressure to be applied across a membrane to generate direct liquid permeation. The likelihood for wetting across the membrane decreases with smaller pores as it does with more hydrophobic materials, repelling the water and forming a positive meniscus above the membrane surface.

$$
L E P=\frac{-2 B \gamma_{L} \cos \theta}{r_{\max }}
$$

where $B$ is a geometric factor determined by the pore structure, $\gamma_{\mathrm{L}}$ the liquid surface tension and $\theta$ is the liquid/solid contact angle and $r_{\max }$ the largest pores in the structure.

The pore size is, therefore, critical in order to limit the risk of liquid bridging across the membrane. Although no thorough study has been published concerning the change of LEP with water or synthetic seawater for different materials exhibiting similar morphologies and tested in very similar conditions, two publications on the change of LEP as a function of the alcohol content in aqueous mixtures can enlighten the reader and further demonstrate how surface energy and pore size are critical to achieving high selectivity [224,225]. As shown in Equation (14), the permeance is directly proportional to the average pore size and to the porosity of the membrane. Therefore, a trade-off is necessary and the pore size needs to be small enough to address the wetting criterion while large enough to facilitate efficient vapor transport.

\subsubsection{Heat Transfer in MD}

The third critical membrane parameter in MD is the thermal conductivity of the membrane which directly impacts on the heat transfer, and therefore on the vapor pressure equilibrium as presented in Section 4.1.1. Most of the heat transferred across the membrane should be carried with the vapor, and heat losses due to conduction through the membrane material and convection of liquid in the boundary layers should be minimised for optimum energy efficiency. A Global heat transfer coefficient, $\mathrm{G}^{\mathrm{MD}}$ in DCMD has been previously defined as in Equation (16) according to [78]:

$$
G^{M D}=\left(\frac{1}{h_{f}}+\frac{1}{h_{p}}+\frac{1}{h_{m}+\frac{J_{w} \Delta H_{v}}{T_{m f}-T_{m p}}}\right)^{-1}
$$

where $h_{\mathrm{f}}$ is the feed boundary layer heat transfer coefficient, $h_{\mathrm{p}}$ the permeate boundary layer heat transfer coefficient, $h_{\mathrm{m}}$ the membrane heat transfer coefficient, $J_{\mathrm{w}}$ the pure water flux across the membrane, $\Delta H_{\mathrm{v}}$ the variation of enthalpy, and $T_{\mathrm{mf}}$ and $T_{\mathrm{mp}}$ the temperature of the membrane surface for the feed and permeate, respectively.

As the driving force in MD is directly related to the vapor pressure difference between the boundary layers on each side of the membrane, it is critical to maintain a large temperature difference and reduce 
heat loss by conduction. As shown in Equation (17), reducing the heat transfer coefficient $h_{\mathrm{m}}$ of the membrane material will directly impact the global heat transfer coefficient and reduce process heat losses [226,227]. As $h_{\mathrm{m}}$ is directly proportional to the thermal conductivity, an accurate measurement of the thermal conductivity or of the thermal diffusivity can therefore lead to a better understanding of the heat transfers in DCMD. Tuning the material's heat conduction properties and especially the membrane surface heat diffusivity can, therefore, have a significant impact on the shape and depth of the boundary layers, and have the potential to enhance performance.

$$
h_{m}=\frac{\lambda_{T h}}{\delta}
$$

\subsubsection{Surface Roughness}

Surface roughness is also critical, because it will affect a number of properties including surface fouling [228] and the contact angle of water on the membrane surface [229]. A change of wetting behaviour will likely affect heat conduction across the top membrane layer, therefore, clearly affecting performance of MD membranes. Although wetting was shown to be facilitated by rough hydrophilic surfaces [230] as more points for spreading are offered to the liquid, this is not always true for homogeneous hydrophobic materials and was shown to highly depend on the composition of the surface and the shape of the roughness extrusions [231,232]. As the average roughness increases, the advancing angle of liquids on hydrophobic surfaces tends to be increased due to the larger number of interactions between the nodules and obstacles composing the surface of the membrane and the liquid. This tendency, known in surface science as the lotus effect, is particularly enhanced for materials exhibiting contact angles $>150^{\circ}$ with the wetting liquid [232,233]. A convenient way to measure roughness is typically given by the roughness factor $\kappa$, defined as:

$$
\kappa=\frac{A_{m}}{A_{n}}
$$

where $A_{\mathrm{n}}$ and $A_{\mathrm{m}}$ are respectively the area calculated as the projection of the object on a plan normal to the main direction of the surface, and the surface area measured by any experimental adsorption technique [229].

The measured surface roughness and area can be obtained by a number of techniques, such as atomic force microscopy (AFM) [234], gas adsorption (BET) [235], diffuse X-ray spectroscopy [236] or laser light scattering [237] depending on the size of the pores and the accuracy sought. In the case of membrane surfaces, the difficulty resides in the definition of what the true roughness is or, in other words, how deep one wants to consider fluctuations from the surface as the surface or the inside of the pores [238-240]. The characterization of surface roughness is often ignored in MD as the process is considered to be mostly unaffected by fouling. However, surface roughness as shown does have other implications on the performance of membranes for MD and should, therefore, be more thoroughly studied. 


\subsection{Inorganic Based Membranes}

\subsubsection{Ceramic Membranes}

Metal oxides of alumina, iron, silica, titania or zirconia are commonly used for the fabrication of ceramic membranes [241]. These membranes can either be intrinsically selective due to the bulk material's pore size, or composed of a thin active layer supported on a highly porous alumina support. Such membranes are typically applied to filtration applications, but some work for MD applications is emerging. The morphology of these membranes is typically more homogeneous than that of polymeric membranes as the crystallites forming the network of the membranes are even in size (SEMs in Figure 22a,b). Although most work utilises commercial supporting materials, other works investigated the use of natural clay [242], in the form of aluminium phyllosilicates, to process thin membranes. The advantages of ceramic membranes over organic membranes are associated with their mechanical stability over large $\mathrm{pH}$ ranges and when exposed to aggressive chemical environments. The membranes can, furthermore, be applied with a range of organic solvents without enduring strong degradation [202,243], whereas most polymeric materials are not suitable for use with chemically aggressive feeds [241].

As shown in Table 5, most of the ceramic membranes fabricated were tubular membranes. The contact angle on raw metal oxide materials were typically around $60^{\circ}$ to $80^{\circ}$. The materials exhibit high surface energy and are therefore naturally hydrophilic, requiring functionalisation with hydrophobic groups in order to satisfy MD requirements [244,245]. Short aliphatic oligomers, alkoxy-silanes or fluoro-polymers can be easily grafted onto the surface of the membrane following a sol-gel approach, where the hydroxyl groups naturally present on the metal oxide are used to react with functional groups of the oligomers [242,246-248].

When pore sizes of the membrane approach that of the water molecule, the membrane participates in size selective diffusion and thus the process becomes known as pervaporation. Pervaporation based desalination on ceramic membranes with small pore top layers was conducted on silica and zeolite materials [249-252]. The advantage of pervaporation based desalination is that the material no longer needs to be hydrophobic to retain the liquid water. Since water must diffuse at (or close to) the molecular level in the small pores of the material $(<1 \mathrm{~nm})$, liquid water cannot freely penetrate the material at low pressures so the material can be hydrophilic and is therefore not susceptible to wetting issues.

Due to the brittleness of the materials, the thickness of the membrane wall was typically between $\sim 500$ and $2000 \mu \mathrm{m}$, decreasing the permeability of the membrane when compared to thin polymeric membranes. Although most of the membranes studied were symmetric, the best performing membranes were asymmetric, being surface grafted fluoro-silanised alumina membranes [246]. These membranes gave fluxes up to $8.1 \mathrm{~kg} \mathrm{~m}^{-2} \mathrm{~h}^{-1}$. The lower performance, when compared with polymeric materials, added to the higher cost of the materials and of processing has limited their development. 
Table 5. Performance of inorganic membranes.

\begin{tabular}{|c|c|c|c|c|c|}
\hline $\begin{array}{c}\text { MD } \\
\text { configuration }\end{array}$ & Material & Geometry & $\begin{array}{c}\text { Maximum flux } \\
\left(\mathrm{kg} \mathrm{m}^{-2} \mathrm{~h}^{-1}\right)\end{array}$ & $\begin{array}{c}\text { Driving } \\
\text { force * }(\mathrm{kPa})\end{array}$ & Reference \\
\hline AGMD & Alumina-fluorosilane functionalized & Tubular & $6.02-6.76$ & 70 & [247] \\
\hline DCMD & Alumina-silanized & Flat disc & $7.8-8.1$ & 12.23 & [246] \\
\hline VMD & Titania (5) & Tubular & 6.08 & 0.3 & [244] \\
\hline VMD & Zirconia (50) & Tubular & 7.5 & 0.3 & [244] \\
\hline AGMD & Zirconia (50) & Tubular & $2.7-4.7$ & $38.5-83.9$ & [244] \\
\hline DCMD & Zirconia (50) & Tubular & $1.7-3.95$ & $38.5-83.9$ & [244] \\
\hline AGMD & Alumina & Tubular & 5.39 & 70 & [248] \\
\hline AGMD & Zirconia & Tubular & $2.8-6.9$ & 70 & [248] \\
\hline AGMD & Alumino-silicate & Tubular & 5.08 & 83.9 & [245] \\
\hline AGMD & Alumina & Tubular & $4.91-5.04$ & 83.9 & [245] \\
\hline AGMD & Zirconia & Tubular & 5.08 & 83.9 & [245] \\
\hline AGMD & $\begin{array}{l}\text { clay with perfluorodecytriethoxysilane } \\
\text { (pore size } 15 \mathrm{~nm} \text { ) }\end{array}$ & Flat disc & $3.95-5.83$ & 47.36 & [242] \\
\hline AGMD & $\begin{array}{l}\text { clay with perfluorodecytriethoxysilane } \\
\text { (pore size } 180 \mathrm{~nm} \text { ) }\end{array}$ & Flat disc & $5-7.2$ & 47.36 & [242] \\
\hline $\mathrm{VMD}^{+}$ & Alumina & Flat sheet & 0.72 & 47.36 & [249] \\
\hline $\mathrm{VMD}^{+}$ & Silica & Flat sheet & 1.7 & & [249] \\
\hline
\end{tabular}

Notes: * The driving force was calculated from the provided values of temperature and Antoine's equation was used to calculate the pressure difference across the membrane air gap; ${ }^{+}$Even though the configuration is VMD, The system performs as pervaporation.

\subsubsection{Carbon Nanotube Based Membranes}

Carbon nanotubes (CNTs) have attracted growing attention in separation due to their unique mechanical, thermal and chemical properties [253,254]. As grown multi-wall CNT are intrinsically inorganic structures as they do not contain any $\mathrm{C}-\mathrm{H}$ bonds, except at their tips. Recent work investigated assemblies of CNTs into paper-like structures called Bucky-papers (BP) as self-supporting membranes, where the CNTs were held together solely by Van der Waals forces [54]. Very thin membranes, with narrow pore size distribution averaging ( 20 nm, SEM in Figure 22c) were processed this way and permeance up to $0.8 \times 10^{-8} \mathrm{~kg} \mathrm{~m}^{-2} \mathrm{~h}^{-1} \mathrm{~Pa}^{-1}$ were achieved in DCMD for a temperature difference of $60{ }^{\circ} \mathrm{C}\left(T_{\mathrm{hot}}=65^{\circ} \mathrm{C}, T_{\text {cold }}=5{ }^{\circ} \mathrm{C}\right)$. The major limitation of these membranes was their short lifespan, as cracks were found to form across their thickness during testing. These cracks, although localised, lead to direct bridging between the feed and permeate, which over time reduced salt rejection (Table 6).

Table 6. Properties and performance of the CNTs membranes for water Desalination.

\begin{tabular}{|c|c|c|c|c|c|c|c|c|}
\hline Sample & $\begin{array}{c}\text { Porosity } \\
\text { (\%) }\end{array}$ & $\begin{array}{l}\text { Thickness } \\
\qquad(\mu \mathrm{m})\end{array}$ & $\begin{array}{c}\text { Pore } \\
\text { size } \\
(\mathrm{nm}) \\
\end{array}$ & $\begin{array}{l}\text { Contact } \\
\text { angle }\left(^{\circ}\right)\end{array}$ & $\begin{array}{c}\text { Flux } \\
\left(\operatorname{kg~h}^{-1} \mathrm{~m}^{-2}\right)\end{array}$ & $\begin{array}{c}\text { Salt } \\
\text { rejection } \\
(\%) \\
\end{array}$ & $\begin{array}{c}\mathrm{dP} \\
(\mathrm{kPa})\end{array}$ & $\begin{array}{c}\text { Permeability } \\
\left(\times 10^{-8} \mathrm{~kg} \mathrm{~m}^{-1} \mathrm{~h}^{-1} \mathrm{~Pa}^{-1}\right)\end{array}$ \\
\hline Self-supporting BP & 90 & 55 & 25 & 118 & 12 & 94 & 40.43 & 1.63 \\
\hline Sandwiched BP & 90 & 140 & 25 & 105 & 15 & 95.5 & 55 & 3.81 \\
\hline PTFE coated BP & 88 & 105 & 25 & 155 & 7.75 & 99 & 78 & 1.04 \\
\hline $\begin{array}{c}\text { Alkoxy-silane } \\
\text { functionalized BP }\end{array}$ & 90 & 62 & 23 & 140 & 9.5 & 98.3 & 35 & 1.68 \\
\hline
\end{tabular}


Multi-layer BP composites were processed by hot-pressing the BP with a thicker poly(ethylene) (PE) porous support. In addition, a series of composite membranes infiltrated with poly(styrene) (PS) and poly(vinyl-fluoride) (PVDF) were fabricated in order to mechanically stabilize the structure and improve the lifespan and performance of the membranes [214,254]. These structures were tested continuously over periods of time up to $40 \mathrm{~h}$, and exhibited similar permeation and improved salt rejection. CNTs were also side functionalized with alkoxy-silanes in order to enhance the hydrophobicity of the surface layer [255]. In a similar approach, BPs were surface coated with poly(tetra-fluoro-ethylene) (PTFE) in order to lower the membrane surface energy [256] (Table 6). The improved performance and lifespan of the surface modified membranes demonstrated the importance of surface hydrophobicity in MD and how better more efficient membranes could be fabricated by finely tuning the chemistry of the CNTs. The permeance for water desalination across all these membranes, however, remained lower than that of commercial $0.2 \mu \mathrm{m}$ pore size PTFE membranes, used here as a benchmark. This was attributed to the combined smaller pore size distribution of the BP membranes and to the larger thermal conductivity of the CNTs. Although, given the chemical and mechanical stability of the nanotubes, the later more robust membranes could find applications in the treatment of organic solvents where organic membranes remain more sensitive to degradation.

The thermal conductivity of the self-supporting BP membranes was found to be $\sim 10$ times greater than PTFE membranes tested in similar conditions [54]. This was attributed to the much larger heat conduction of graphene as opposed to PTFE and was proposed as an explanation for the lower permeation across the BP membranes.

\subsection{Organic Based Membranes}

\subsubsection{Polymeric Membranes}

Polymeric membranes made of PTFE or PVDF have been commercialized since the early 1980s by a number of companies (Table 7). These membranes were not initially directed to membrane distillation but as hydrophobic membranes for MF or UF.

Membranes made of a single polymer or copolymers have been processed since the early 1990s at laboratory scale [257]. As described in Section 4.1, commercial micro and ultra-filtration membranes made of PVDF, PTFE and PP have been used for decades as MD membranes. The main materials typically used for laboratory scale membrane fabrication are PVDF (SEMs of hollow fiber membrane in Figure 22f-h). Poly(ether sulfone) (PES), cellulose acetate (CA), and PE as these can be dissolved in a variety of solvents, easily cast to fabricate a membrane and functionalized to alter their properties. PVDF has particularly attracted attention as its hydrophobicity is naturally larger than the other polymers. PVDF copolymers exhibiting a larger fluoride ratio have also been fabricated to further enhance the hydrophobicity [258]. However early works also considered using hydrophilic membranes, such as cellulose acetate. These membranes were used either as supports for the deposition of more hydrophobic materials [259] or surface modified to render them hydrophobic [257]. 
Table 7. Examples of commercial membranes used in MD.

\begin{tabular}{ccccccc}
\hline Product & Manufacturer & Material & Support & $\begin{array}{c}\text { Pore size } \\
(\boldsymbol{\mu m})\end{array}$ & $\begin{array}{c}\text { LEP } \\
(\mathbf{k P a})\end{array}$ & Reference \\
\hline TF200 & Gelman/Pall & PTFE & PP & 0.2 & 282 & {$[260]$} \\
\hline TF450 & Gelman/Pall & PTFE & PP & 0.45 & 138 & {$[260]$} \\
\hline TF1000 & Gelman/Pall & PTFE & PP & 1 & 48 & {$[260]$} \\
\hline \multirow{4}{*}{ Emflon } & Pall & PTFE & PET & 0.02 & 1585 & \\
& Pall & PTFE & PET & 0.2 & 551 & {$[261]$} \\
& Pall & PTFE & PET & 0.45 & 206 & \\
\hline FGLP & Pall & PTFE & PET & 1 & 137 & \\
\hline FHLP & Millipore & PTFE & PE & 0.2 & 280 & {$[260]$} \\
\hline \multirow{3}{*}{ Gore Filtration media } & Millipore & PTFE & PE & 0.5 & 124 & {$[260]$} \\
& Gore & PTFE & PP & 0.2 & 368 & \\
& Gore & PTFE & PP & 0.45 & 288 & {$[260]$} \\
\hline GVHP & Gore & PTFE & PP & 0.2 & 463 & \\
\hline & Millipore & PVDF & None & 0.22 & 204 & {$[260]$} \\
\hline \multirow{2}{*}{ HVHP } & Millipore & PVDF & None & 0.45 & 105 & \\
& Memrane solutions & PTFE & PP & 1.0 & 24 & \\
& GE & PTFE & PP & 0.22 & 154 & {$[260]$} \\
& GE & PTFE & PP & 0.45 & 91 & \\
\hline
\end{tabular}

Notes: PP, PE, PET respectively correspond to poly(propylene), poly(ethylene) and poly(ester). The contact angle on PVDF and PTFE was reported to be $90^{\circ}$ and $140^{\circ}$, for surface energies of $30.3 \mathrm{mN} \mathrm{m}^{-1}$ and 9-20 $\mathrm{mM} \mathrm{m}^{-1}$ at $20^{\circ} \mathrm{C}[262]$.

\subsubsection{Hydrophilic/Hydrophobic Membranes in DCMD}

The concept of dual hydrophilic/hydrophobic membranes was initially introduced in the early 1990s as a novel approach to limit heat polarization across the membranes in DCMD. The heat polarization effect is stronger in DCMD than in other MD process as heat is directly diffusing from the hot feed to the cold permeate and there is no air insulating layer on the permeate side. The dual layer approach consists of forming a membrane which will exhibit simultaneously both hydrophilicity and hydrophobicity. Typically the two sides of the membranes present opposite water wetting behaviours. Previous publications have shown that multi-layer approaches with gradients of hydrophobicity/hydrophilicity can lead to high performance MD membranes [47,61,259]. This suggests that hybrid structures where a highly hydrophobic surface is put in contact with the feed, while a hydrophilic surface is in contact with the permeate may provide improvements in MD performance (Figure 22d). The wetting is more favourable on the permeate side which was shown to reduce temperature polarization and help condensation of the water vapor and diffusion of the heat into the bulk permeate water $[263,264]$. This might lower the temperature difference between the two sides of the membrane and also improve thermal efficiency by reducing the thickness of the air gap across the membrane. As previously described, partial wetting could enhance the chances of low rejection, and work to understand the process behind multi-layer MD membranes and their potential has been conducted [77,259,265]. Although dual layer membranes were mostly processed as HF [127,265-269], a number of studies also performed similar approaches on flat sheet membranes [263]. 
Research continues to improve MD membrane permeability, as this is one of the main reasons for wetting and low permeate flux. Hydrophilic ultrafiltration PES membranes have been converted into hydrophobic membrane for $\mathrm{MD}$ using $\mathrm{CF}_{4}$ plasma surface modification [270]. The plasma modification converted hydrophilic membranes of a contact angle of $0^{\circ}$ into hydrophobic membranes with water contact angle above $120^{\circ}$. It was assumed that fluorination was responsible for the wettability change of the membrane from hydrophilic to hydrophobic due to insertion and possibly deposition. Stable membrane performance with no leakage, high water flux, and high salt rejection was reported.

With the purpose of reduce wettability in the DCMD process, PVDF membranes have been successfully engineered to make them super-hydrophobic, with water contact angle of $130^{\circ}$, and super-oleophobic to glycerol. The modification was made by generating multilevel roughness and reducing the surface free energy of the membranes via $\mathrm{TiO}_{2}$ coating by low temperature hydrothermal process followed by fluoro-silanization of the surface [271]. A significant 50\% increase of the liquid entry pressure (LEP) of water, without compromising the mean pore size, was reported. The interaction between the feed water solution and membrane surface was reduced by shifting the wettability of the membrane surface toward super-hydrophobicity, thereby preventing feed liquid penetration or flooding of the membrane pores, and generation of contaminated water and low fluxes.

\subsection{Hybrid and Exotic Membranes}

\subsubsection{Mixed Matrix Nano-Composite Membranes}

Graphene particles and multi-wall CNTs have also been incorporated into PVDF HF to alter the thermal properties of the membranes [267]. As opposed to what is typically assumed in MD diffusion [52], the larger water vapor permeation across the CNT-PVDF hollow fibers was attributed to the composite membranes increased thermal conductivity. The presence of $40 \mathrm{wt} \%$ graphene and $10 \mathrm{wt} \%$ CNTs increased the thermal conductivity by nearly 6 times when compared to the $40 \mathrm{wt} \%$ graphene only composite membrane and up to 11 times when compared to that of pure PVDF. The morphology of the HFs processed this way, did not highly differ from that of the pure PVDF membranes, although graphene and CNTs were found to be nodules and bridging points in the composite structure (Figure 22e). An alternative explanation to the permeation increase may be related to the fact that the presence of the nano and macro particles had in fact reduced the true heat diffusivity of the membrane, as opposed to that of the bulk material. The measurement of thermal properties for a porous material is difficult due to issue of the control of the interface of contact between the membrane surface and the measurement device. Although in a bulk dense material, the trends reported by the authors would make sense, it is not obvious for a porous material. Additionally the presence of the particles may have increased the surface roughness of the membranes, therefore, affecting the contact angle and the surface heat conduction or reduced the compressibility of the membrane.

A number of studies have also incorporated hydrophobic macro-particles in the polymer blends used to alter the surface energy of the polymer membranes [56,64,263,264]. Upon phase separation, the migration of the particles led to a drastic change of the surface energy and surface roughness of at least one side of the membrane, which enhanced the performance of the membranes when compared 
with the un-modified membranes. This again likely increased the surface hydrophobicity while simultaneously decreasing the thermal conductivity of the membrane surface by reducing the contact area between the membrane and the liquid streams.

Figure 22. Morphology of membranes used in MD: Flat sheet (left column) and hollow fibers (right column): (a) Hendren et al. [246] Anodisc PFS surface treatment; (b) Krajewski et al. [247] zirconia supported alumina membrane; (c) Dumée et al. [256] PTFE coated carbon nanotube bucky-paper-scale bar corresponds to $400 \mathrm{~nm}$; (d) Qtaishat et al. [263] used poly(sulfone) as a base material and modified the surface with different amounts of fluorinated macromolecules (M4 membrane-scale bar corresponds to $100 \mu \mathrm{m}$ ); (e) $\mathrm{Su}$ et al. [267] added graphite particles and carbon nanotube to a PVDF/PAN blend (M3 membrane-overall shape and inner layer); (f) Teoh et al. [45]—PVDF/PTFE composites $50 \mathrm{wt} \%$ PTFE particles-overall HF view and inner layer-scale bar is $100 \mu \mathrm{m}$ (left) and $1 \mu \mathrm{m}$ right; (g) Teoh et al. [272] grooved membranes-PVDF multichannel membranes - scale bars: top $300 \mu \mathrm{m}$ and bottom $500 \mu \mathrm{m}$, right $5 \mu \mathrm{m}$; (h) Wang et al. [269]—super high flux membranes D3 — scale bar left $200 \mu \mathrm{m}$ right $5 \mu \mathrm{m}$.
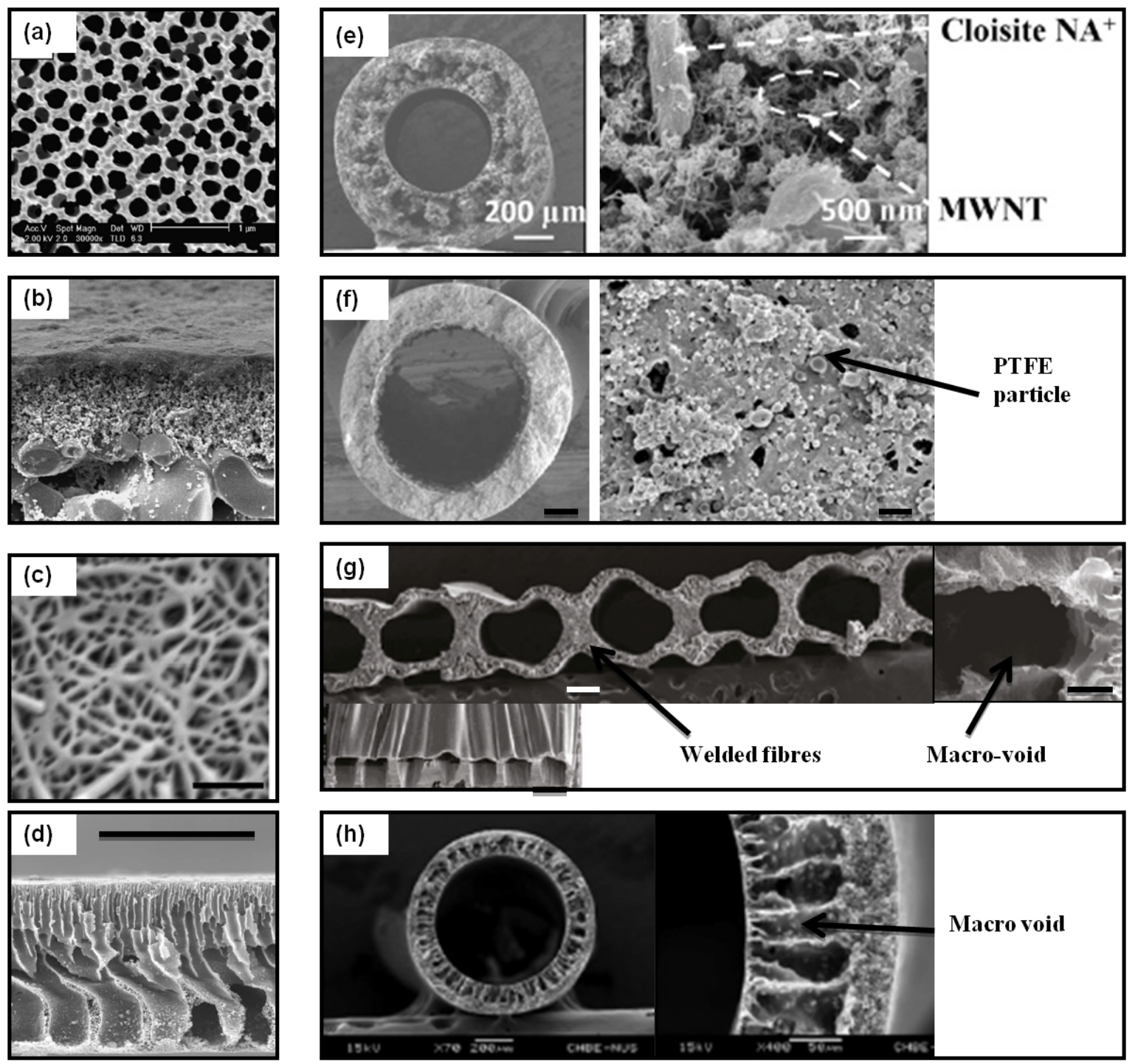
The development of novel architectured membranes is of great importance to enhance membrane performance in MD [273]. For this purpose novel carbon nanotube immobilized membranes have been developed and tested, where the carbon nanotubes served as a sorbent and provided an additional pathway for mass transport of water vapor across the membrane. It has been reported that CNTs can increase the permeability of a substance through a membrane as well as increase its selectivity. In the particular case of MD, the high thermal conductivity of the CNTs may reduce the temperature gradient in membrane pores, allowing for reduced liquid condensation and therefore increasing the performance of $\mathrm{MD}$ in terms of concentration enhancement, generation of purified water, and mass transfer coefficients [273]. CNIM has been used for simultaneous generation of pure water and concentrating pharmaceutical wastes which are classified as emerging contaminant.

\subsubsection{Electro-Spun Membranes}

Electro-spun fibers can be assembled into a non-woven like structure, with pore size, thickness and porosity that can be tuned by changing the spinning conditions [274]. Feng et al. [275] investigated the processing of PVDF nano-fibers and desalination of $3.5 \mathrm{wt} \% \mathrm{NaCl}$ solution with salt rejection rates between $98.7 \%$ and $99.9 \%$. The morphology of electro-spun membranes (Figure 23) is highly suitable for membranes in MD. The pores formed by the interstitial gaps between nano-fibers can be tuned by changing the fibers morphology by varying the spinning conditions. Furthermore, the thickness of the membrane can be controlled by varying the spinning time, while a variety of substrates can be used as reception-supports for the fibers. While the contact angle is dependent on the materials of the nano-fibers, it was also demonstrated to be dependent on the size of these fibers and on the topography of the surface of the membrane. The very high contact angle $\left(130^{\circ}\right)$ when compared to classical PVDF membranes $\left(80^{\circ}-85^{\circ}\right)$ could be an advantage to further control the surface properties. This might be due to the presence of nodules and to the diameter distribution of the fibers, which greatly enhanced surface roughness. Previous studies on electro-spun web composites also demonstrated that nano-particles can be embedded within the fibers if properly spun and mixed with the initial solution [276,277]. A large variety of polymers can be spun by electro-spinning opening further routes for membrane development [278]. This could further lead to enhanced property materials for MD. Although electro-spun webs are today commonly manufactured as affinity membranes for the study and growth of biological cells, they have been identified as potential membranes for micro [279,280], ultra or nano filtration [281]. Their development as membranes for MD remains limited, but further work deserves to be pursued.

The addition of clay nano-particles in the electro-spun fibers has been reported in [282]. PVDF base solution was loaded with dispersed hydrophobic nano-particles in order to increase the contact angle of the flat sheets. The contact angle of the membranes was largely enhanced from $\sim 80^{\circ}$ up to $154^{\circ}$ and the flux across the $8 \mathrm{wt} \%$ modified PVDF electro-spun membranes was higher by up to $10 \%$ when compared with unmodified PVDF electro-spun membranes. The flux remained lower $\left(<6 \mathrm{~kg} \mathrm{~m}^{-1} \mathrm{~h}^{-1}\right)$ compared to dual layer hollow fiber membranes. 


\subsection{Modified Commercial Membranes}

Although a large number of studies have used readily available commercial membranes, typically made of PVDF or PTFE (Table 7) to demonstrate the feasibility and advantages of MD for the treatment of solutions, a very limited number of studies have focused on modifying commercial membranes in order to enhance their performance or change their properties. Recently Lai et al. reported on plasma treatment of commercially available PTFE membranes [283]. The membranes were exposed to various $\mathrm{N}_{2} / \mathrm{H}_{2}$ plasmas in a dose matrix, and it was shown that although the surface of the membrane was rendered hydrophilic, the performance was changed and the energy cost reduced. It is likely that the enhancement of permeation was due to, as partially suggested by the authors, a change in the heat polarization boundary layer at the surface of the treated membrane. The degradation induced by the plasma reduced the contact angle but also permanently grafted amine and amide groups, resulting from radicalisation of the stream gas on the membrane surface.

Figure 23. Electro-spun membranes used in MD: (a) Prince et al. [282] and (b) Feng et al. [275]; the scale bar corresponds to $10 \mu \mathrm{m}$.

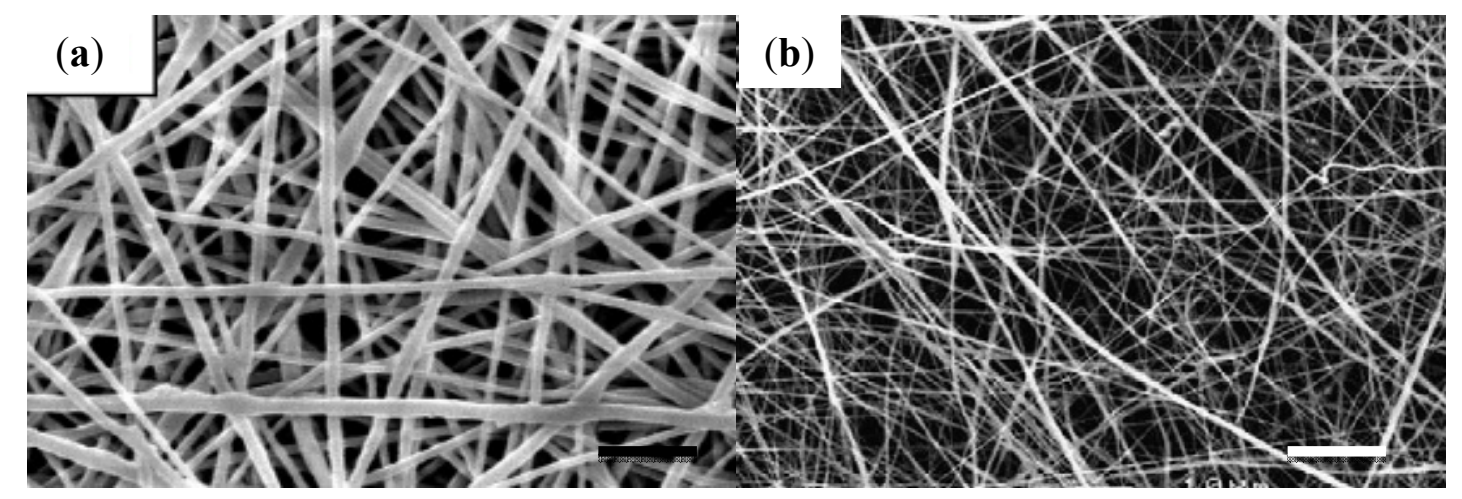

4.6. Impact of the Membrane Morphology and Surface Energy on the Permeation of Water Vapor and the Rejection of Salts

\subsubsection{Performance of Inorganic Membranes}

When considering the nominal ceramic membrane pores size given by many references, it is apparent that generally larger pore size membranes did not lead to enhanced flux and that factors other than pore size alone, such as porosity, surface wetting or surface roughness, affect permeability (Figure 24). According to Equation (14), membrane thickness, porosity and tortuosity also effect membrane permeability. In essence, it is important to be critical about the accuracy of the different structural parameters reported in the preparation of membranes.

As shown in Figure 24, there is no obvious correlation between the flux across the membrane and the average reported pore size. To date, the highest flux obtained for the ceramic membranes were obtained for alumina silanised membranes at feed and permeate temperatures of $53{ }^{\circ} \mathrm{C}$ and $18{ }^{\circ} \mathrm{C}$, respectively [246]. Despite their lower pore size, these inorganic membranes did not exhibit a very high contact angle $\left(141^{\circ}\right)$ when compared with other membranes (up to $175^{\circ}$ as shown in [244]). It clearly underlines the importance of surface energy in both reducing temperature polarization and 
creating a clear and constant air gap in the membrane structure. In addition to hydrophobicity, these membranes were demonstrated to be chlorine tolerant, which is critical for water applications. No other work reported here evaluated the resistance of the hydrophobic modifications to strong oxidizing agents such as chlorine.

Figure 24. Flux across the membranes in different MD configuration as a function of the nominal reported pore size.

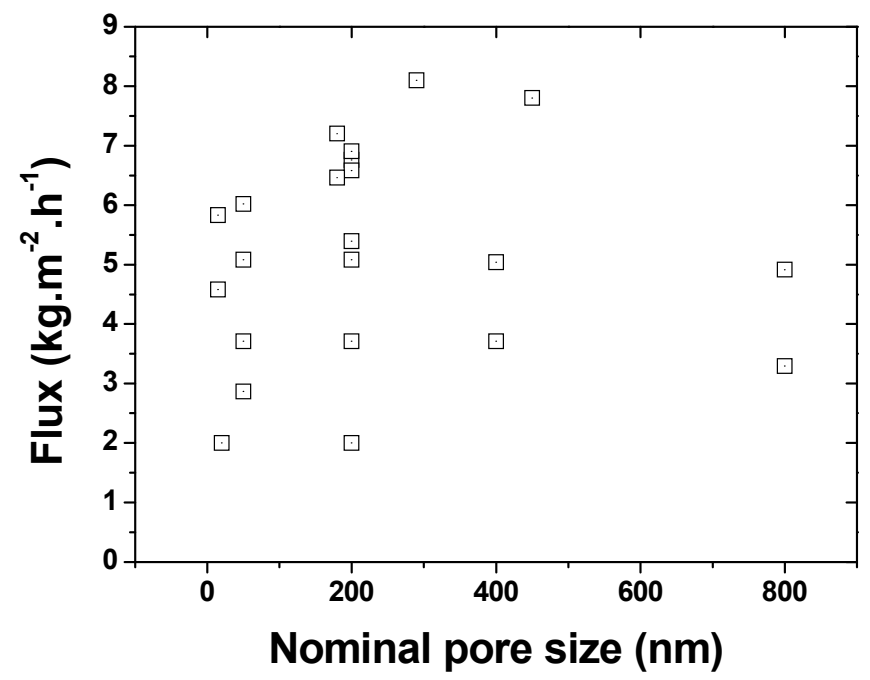

Interestingly, as shown in Figure 25, the flux across the inorganic membranes was generally proportional to the water vapor pressure difference across the membrane for both AGMD and DCMD experiments. The only controversial exception to this rule was found for VMD tested samples which exhibited very high flux at lower pressure difference.

Figure 25. Flux as a function of the vapor pressure difference across inorganic membranes calculated from the reported temperature difference.

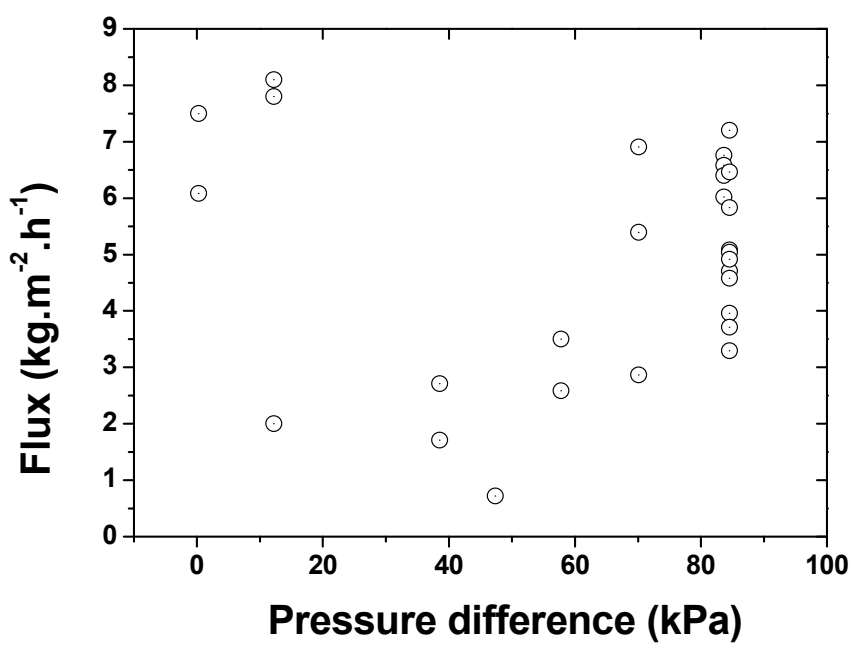

The permeance of the different samples was also found to increase with dP except for the VMD samples (Figure 26). These results are in accordance with neither theory nor the other trends and should therefore be cautiously considered. It is, however, recognized that VMD is more energy 
intensive for water evaporation as it involves vacuum and typically a condensation step. Although the permeance of the membranes would be a better way to compare the different materials and structures, the lack of information from the literature on the true membrane wall thickness did not allow such a study. The asymmetric structure of most of the ceramic membranes made the measurement of their active layer difficult.

Figure 26. Permeance across ceramic MD membranes.

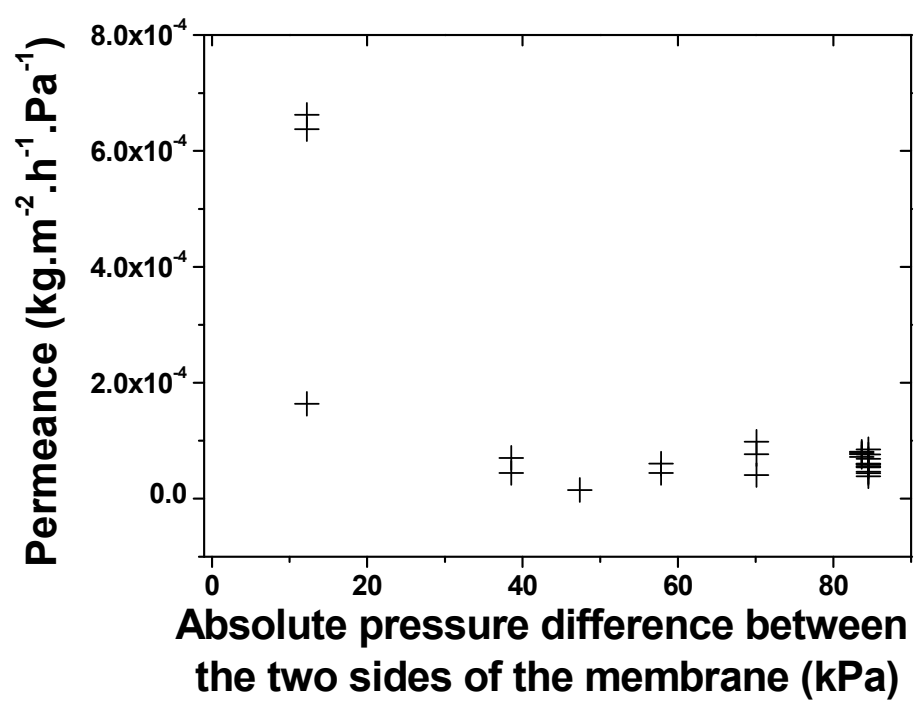

\subsubsection{Performance of Organic and Hybrid Membranes}

The performance of the polymeric and hybrid membranes was correlated to their properties. To be comprehensive a number of parameters should be normalized and studied. As presented at the beginning of this section, since membranes for MD must be porous, the control of geometrical parameters is critical to achieve both high permeance and salt rejection. In this case, the main parameters typically evaluated by the research groups working on membrane fabrication are the membrane pore size, porosity and thickness. However, other parameters such as the thermal conductivity or the surface energy are as, if not more, important in order to achieve high performance. Although the surface energy of the membrane surface is often evaluated by contact angle measurement, it is not necessarily representative of the inner pore and air gap wetting behavior. For example, a surface treatment designed to enhance the membrane hydrophobicity will therefore not necessarily be efficiently applied within tight pores. Water vapor adsorption and water wetting within the pores may then differ from the modified surface and explain discrepancies in performance. In addition, very few papers deal with the impact of the thermal properties of the membrane on water permeation, although it was demonstrated that the surface thermal conductivity of the membrane will significantly influence the formation of heat polarization layers. Although it is difficult to comprehensively review and critically compare the different structures due to inherent differences in the testing conditions and in geometrical properties (especially the membrane thickness and tested area), general conclusions on the impact of the different parameters can be drawn from the change in permeation as a function of these parameters. This section will review the impact of the different parameters studied and presented by the different groups. 
As shown in Figure 27, overall the permeance across the membranes was found to be dependent with the surface contact angle. Membranes with lower surface energy exhibit larger contact angle with water and therefore have less tendency for pore wetting. In addition to the contact angle, hydrophobic structures have also been shown to exhibit lower thermal conductivity [284]. This is preferable, especially in DCMD, since it reduces the heat losses due to conduction across the membrane and prevents the formation of strong heat polarization layers on the membrane surface and in the membrane pores.

Figure 27. Permeance as a function of the surface contact angle for the papers presented in this review.

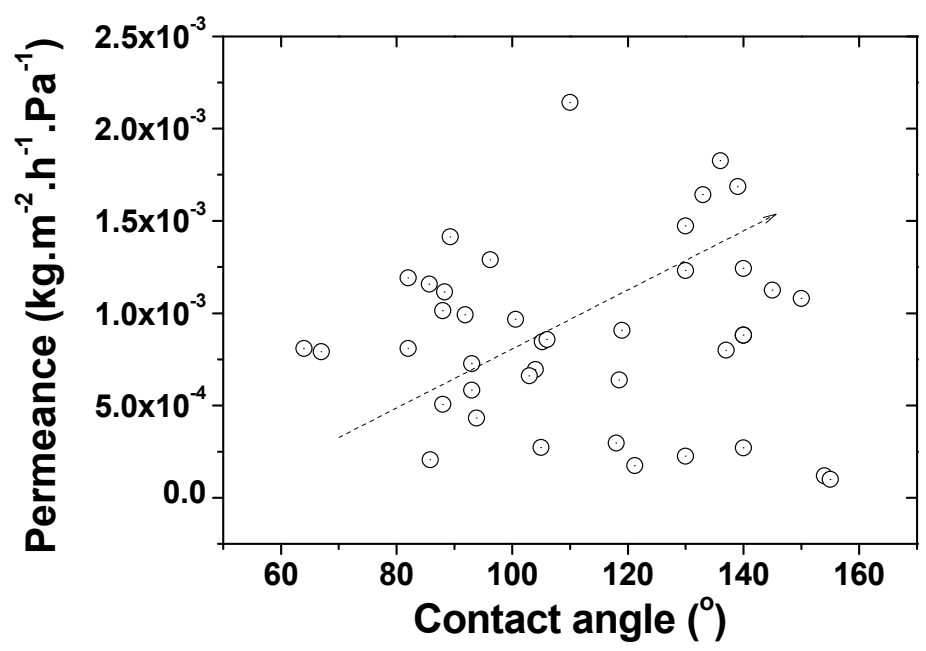

The permeance was also found to be largely increasing with the average pore size of the membrane (Figure 28). The fact that some of the larger pore size membranes exhibit lower permeance can be attributed to other geometrical parameters of the membranes, such as their larger thickness. Interestingly, most of the laboratory-made membranes have pore sizes between 20 and $100 \mathrm{~nm}$, although the pore size distribution of commercial PTFE and PVDF membranes most often falls within a 200 to $400 \mathrm{~nm}$ range.

As for pore size, porosity appears to be critical with more porous membranes (porosity $>80 \%$, Figure 29) exhibiting the best performance. Again some of the very highest porosity materials tested showed much lower permeance than other less porous materials. This can be again traced back to other structural parameters such as pore size, or thermal conductivity, as in the case of the carbon nanotube based membranes. Although the porosity of these membranes is superior with porosities up to $90 \%$, they exhibit thermal conductivity $\sim 5$ to 10 times higher than most commercial polymeric membranes with the average pore size falling around $20 \mathrm{~nm}$. This confirms again, that a combination of properties is necessary to achieve high performance membranes.

The thickness of the membrane wall is one of the most difficult parameters to evaluate experimentally (Figure 30). Most thickness measurements are performed either with micrometers or through scanning electron microscopy image analysis. Both these techniques evaluate the membrane thickness over small surface areas and are, therefore, not always representative of the whole membrane area. Large variations of average membrane wall thicknesses can arise especially when casting or spinning polymeric membranes. In the case of phase separated membranes, it is also very often 
difficult to clearly define the membrane wall_-or active thickness, as the gradient of pores and macro voids is progressively changing across the membrane thickness. For this reason the values of membrane wall thickness reported in literature are difficult to objectively compare and analyse. As shown in Figure 30, no clear trend of the membrane wall thickness can be obtained from the data from the papers here studied.

It is clear from the performance of the membranes presented in the previous two sections, that organic base membranes have shown better promise for water desalination than inorganic based membranes. This has to be attributed to a number of parameters, including the ability to cast thinner polymeric membranes making them better performing in MD. The lower surface energy of naturally hydrophobic polymers is also more suitable for MD. Finally, the higher cost of ceramic materials is certainly a limitation to their development, although they exhibit better chemical and thermal stability than polymeric materials. It is likely that ceramic membranes could find application in the separation of mixed solvents.

Figure 28. Permeance as a function of the mean pore size for the papers presented in this review.

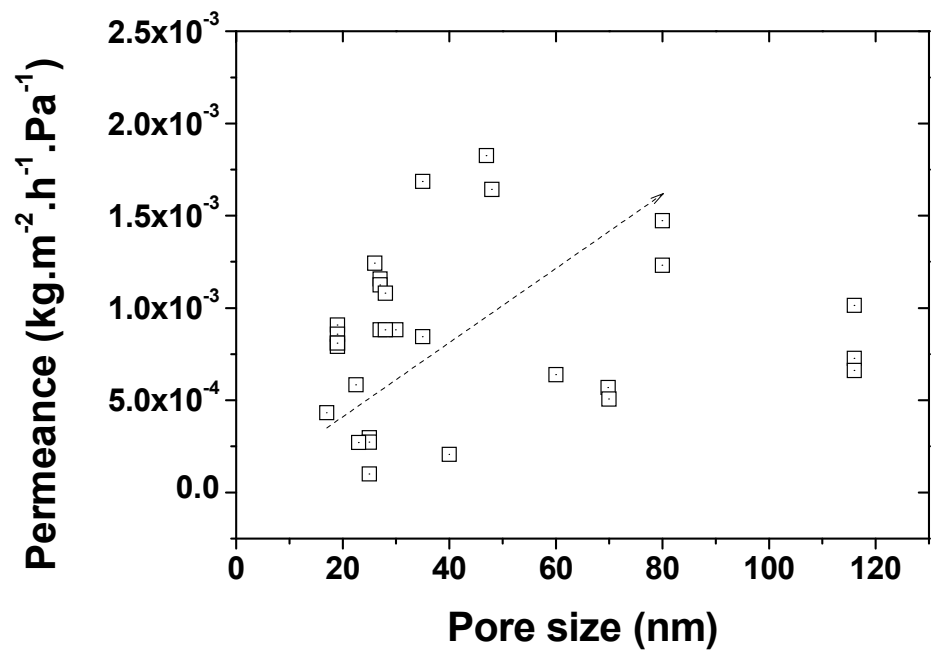

Figure 29. Permeance as a function of the porosity for the papers presented in this review.

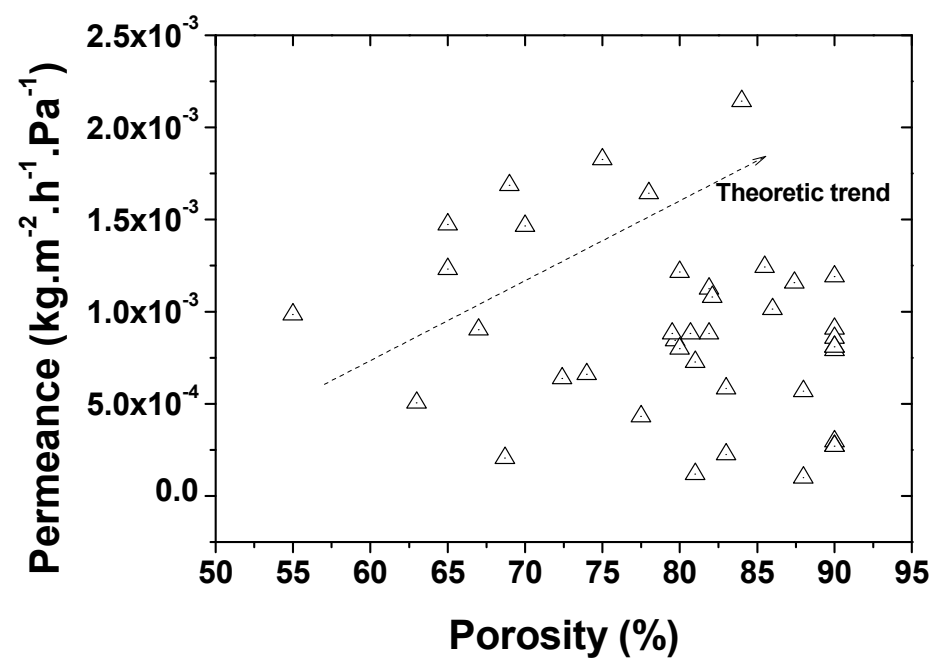


Figure 30. Permeance as a function of the thickness for the papers presented in this review.

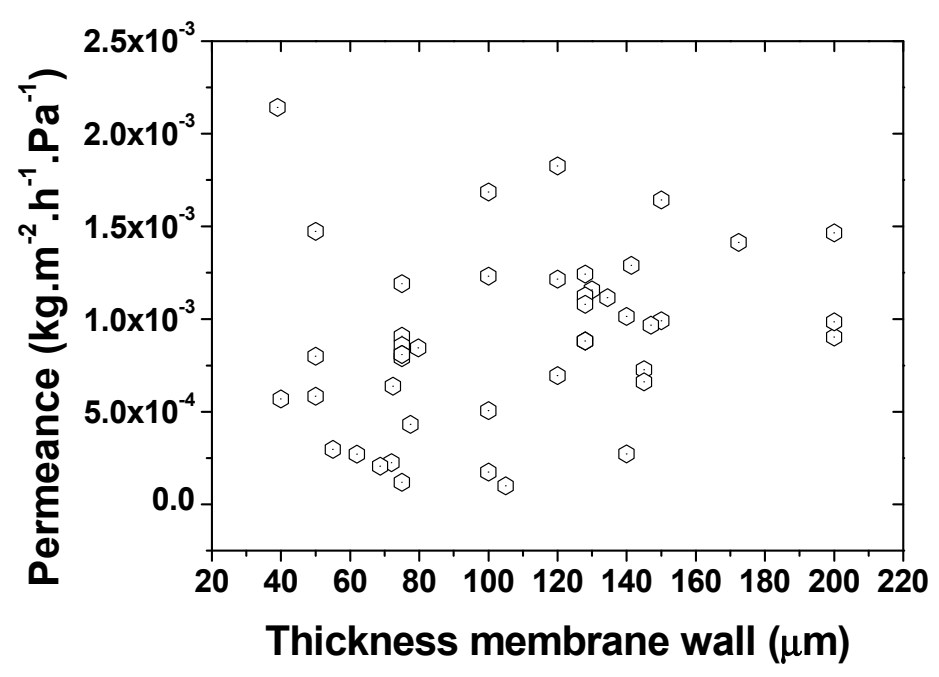

\subsubsection{Comparison between Hollow Fiber and Flat Sheet Membranes}

Despite limitations reported in scientific literature, it is interesting to directly compare the performance of the flat sheet and hollow fiber membranes. As shown in Figures 31 and 32, very large differences in term of flux were found when comparing laboratory processed flat sheet and hollow fiber. While the maximum flux obtained for flat sheet membranes hardly reaches $30 \mathrm{~kg} \mathrm{~m}^{-2} \mathrm{~h}^{-1}$, several hollow fiber structures have exhibited flux higher than $65 \mathrm{~kg} \mathrm{~m}^{-2} \mathrm{~h}^{-1}$, including one close to $100 \mathrm{~kg} \mathrm{~m}^{-2} \mathrm{~h}^{-1}$ for similar vapor pressure differences $(\sim 45-46 \mathrm{kPa})$. On the other hand, the calculation of the permeances as shown in Figures 33 and 34 diverges from the flux trends. The divergence could be related to inaccuracy in the true pressure difference due to possible temperature polarization [285] across the membrane. In addition, heat loss due to water evaporation leads, as it is commonly known in MD [222], to a drop of the temperature of the feed between the inlet and outlet. Therefore, flux reduces as membrane length increases. Most of the studies do not comment on this drop and consider only the temperature of the fluid for the pressure difference calculation. Differences of permeances may also arise from the different MD techniques used here [14]. Although most of the tests were done with DCMD, most of the MD tests performed on ceramic membranes used VMD, which is known to lead to higher flux but is more energy intensive, because either cooling of the air or vacuum needs to be provided to generate the driving force and condense the water vapor [226,260]. For these reasons no general trends can be extrapolated from the permeance graphs.

In addition, the large variations of flux cannot be attributed only to the material, as most of these membranes were made of PVDF or its co-polymers. It is the geometric structure of the membranes, and especially the geometry of the supporting layer of the hollow fiber membranes that make of them more suitable membranes for MD. The process conditions, such as flow rate, temperature and the membranes packing density, will be affected by the different geometries. It is recognized that higher packing densities can be achieved with hollow fiber membranes. 
Figure 31. Flux for flat sheet membranes.

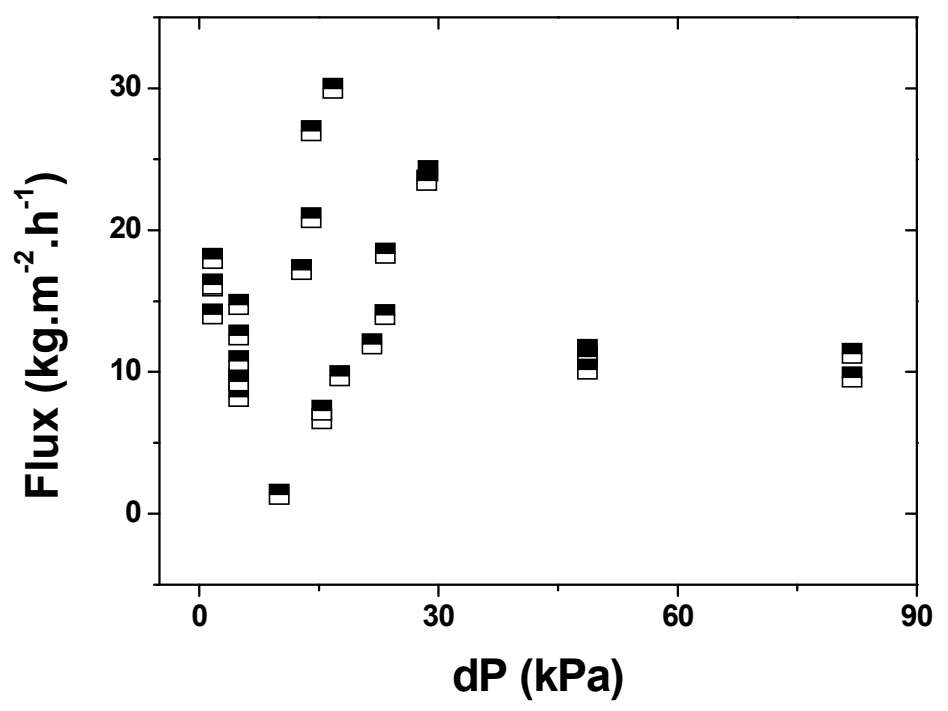

Figure 32. Flux for HF membranes.

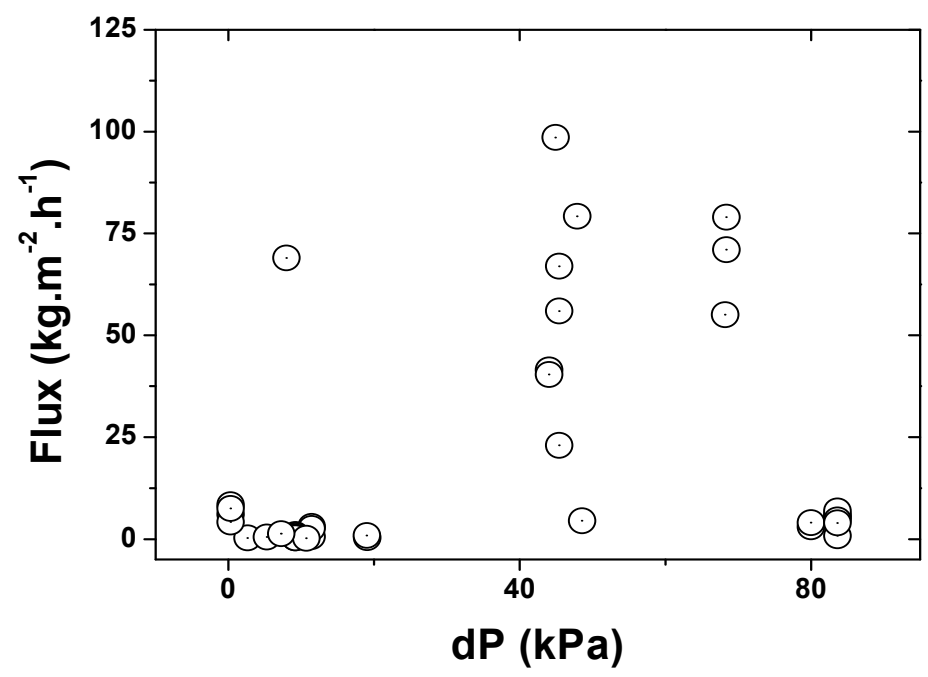

Figure 33. Permeance for selected flat sheet membranes.

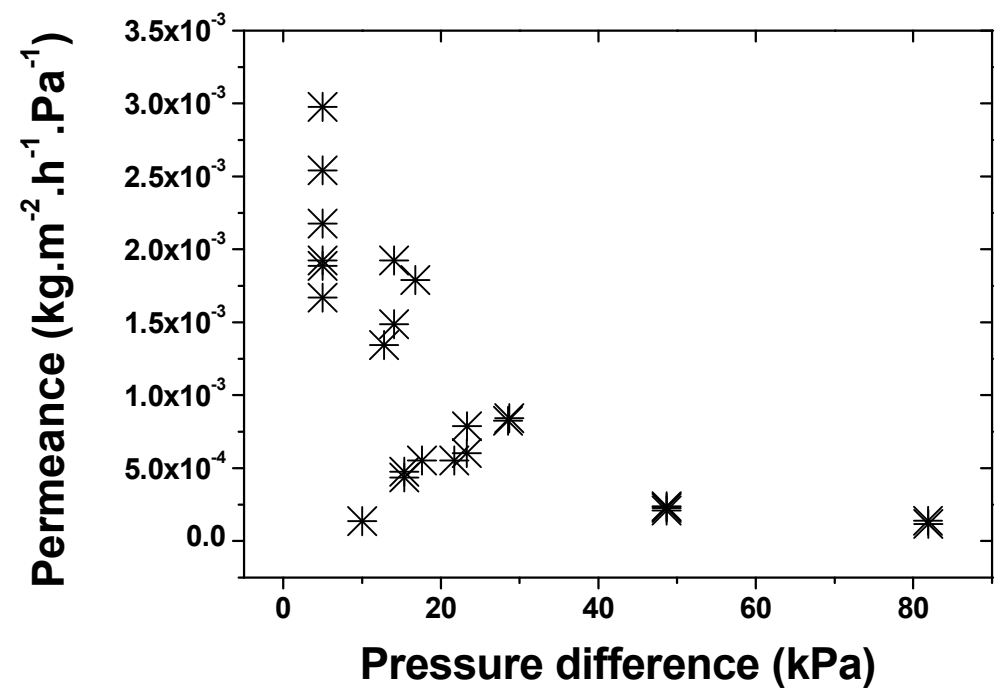


Figure 34. Permeance for selected hollow fiber membranes.

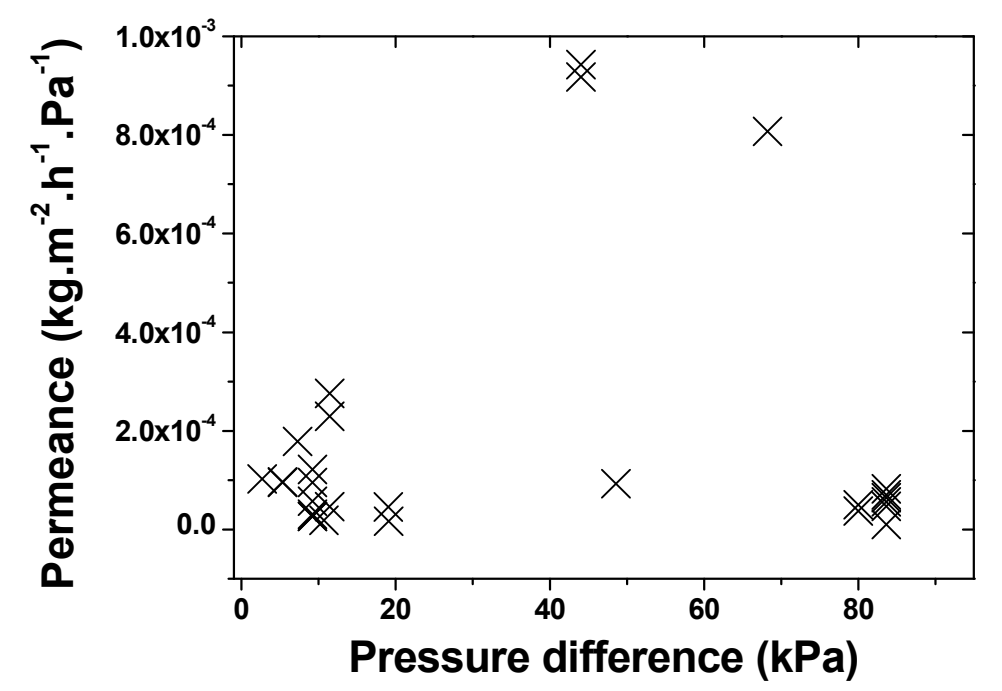

Several properties and parameters are affected by the geometry of the membranes. The fluid dynamics between hollow fiber and flat sheet membranes is not similar and does lead to different heat and mass transfer behaviours [286]. In addition, the total active surface area of membrane available is higher in the case of hollow fiber membranes due to both the higher packing density and the individual membrane surface area. Furthermore, as explained by Bonyadi et al. [49,50] and Wang et al. [269] in their respective papers, the size, shape and connectivity of the macro-voids highly affects water vapor permeation across the membrane. By engineering larger macro-voids connecting the lumen to the membrane wall, Wang et al. [269] managed to increase the water vapor permeability up to $98 \mathrm{~kg} \mathrm{~m}^{-2} \mathrm{~h}^{-1}$ at feed and permeate temperatures of $80.2{ }^{\circ} \mathrm{C}$ and $15{ }^{\circ} \mathrm{C}$ respectively, and for a total membrane surface area of approximately $100 \mathrm{~cm}^{2}$, making these membranes potential competitors with the commercial best performing FS membranes.

\section{Global Water Candidates for Membrane Distillation Treatment}

Rapid population growth has resulted in increasing demands for energy, water, transportation, housing and food supply. Population growth has traditionally occurred in and around large population centers, which are often faced with limited water supplies. Water utilities have been forced to transition from traditional water sources such as surface water and fresh groundwater to alternative supplies such as brackish groundwater, seawater desalination, and water reclamation, including aquifer storage and recovery. Current desalination technologies are used to produce high-quality water for municipal, industrial and agricultural needs from brackish groundwater, saline wastewater and seawater.

In 2002, the total worldwide installed seawater desalination and brackish desalination plant capacity was 37.75 million $\mathrm{m}^{3} /$ day of fresh water [287]. The International Desalination Association (IDA) [288] reported a global contracted capacity of desalination plants of 71.7 million $\mathrm{m}^{3} /$ day in 2010 , including those under construction. This reflected a three-fold increase in cumulative desalinated water capacity over the last decade. The total capacity of completed plants, including plants that have already come online and those under construction that are expected to come online by the end of 2011 is 
6.7 million $\mathrm{m}^{3} /$ day (Figure 35) [289]. This number is even higher than the total capacity of plants contracted in $2010\left(5.9 \mathrm{~m}^{3} /\right.$ day $)$ and is the result of ambitious desalination programs in Algeria, Spain and Australia [289]. Municipal use accounted for almost two-thirds of worldwide installed capacity. An additional $26 \%$ is used for industrial purposes, and $6 \%$ for power generation stations [289]. In 2011, based on their desalination capacity, the five leading countries in the world were Saudi Arabia, United States, the United Arab Emirates, Spain, and Kuwait. In the same year, seawater and brackish water account for $59 \%$ and $21 \%$, respectively, of all desalinated water sources in the world; wastewater and brine account only for $5 \%$ and $0.2 \%$, respectively [289].

Figure 35. Worldwide annual contracted and commissioned desalination capacity. Source: GWI Desaldata/IDA [289].

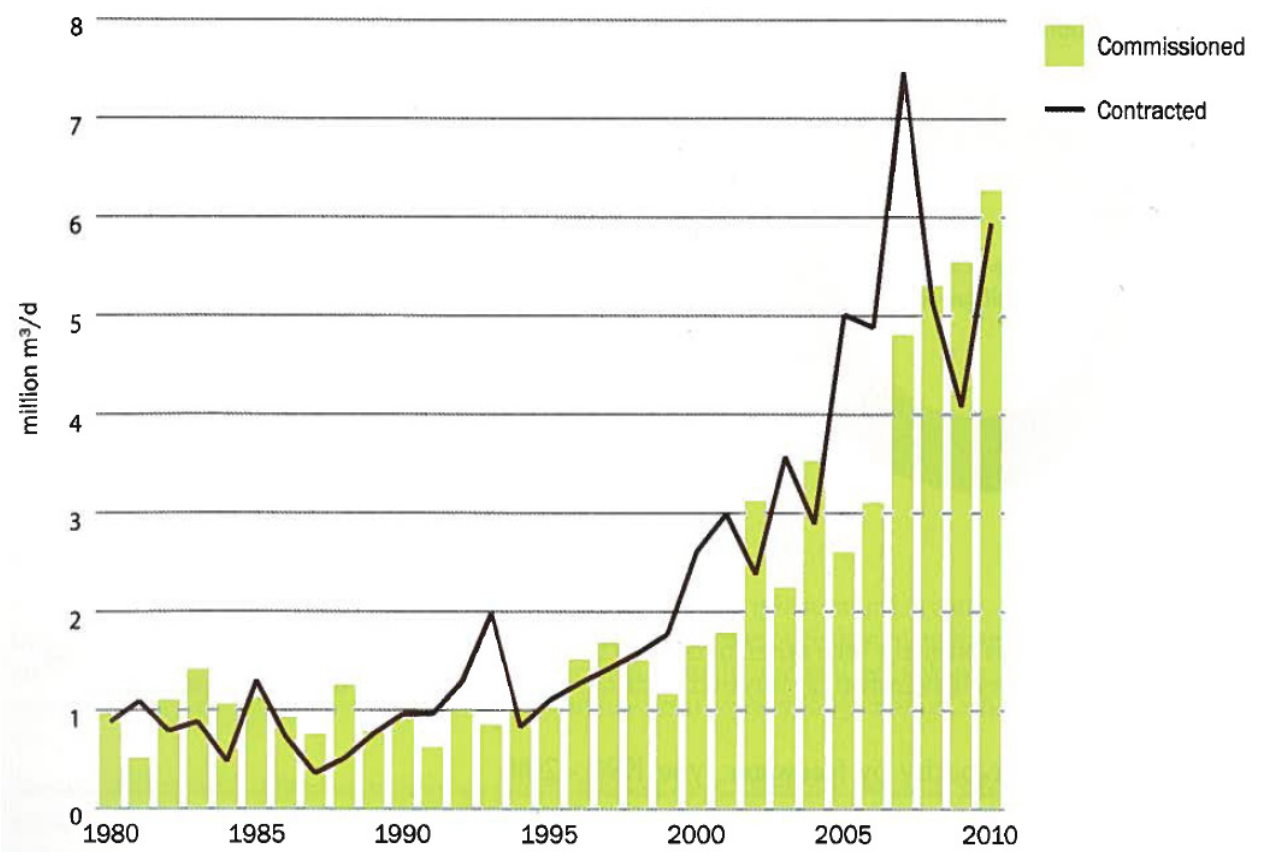

Non-traditional water sources may be potential candidates for treatment with desalination technologies. Non-traditional sources include brackish surface and groundwater with elevated levels of minerals and/or other constituents, desalination concentrate, produced water, industrial effluents and municipal wastewater effluents. Reverse osmosis (RO), multi-stage flash (MSF) distillation, |multiple-effect distillation (MED), and electrodialysis (ED) are the main treatment technologies used for potable water production with a total worldwide installed capacity of $60 \%, 26 \%, 8 \%$, and $3.5 \%$ respectively [289]. A study conducted by Mickley [290] established that in the United States, 72\% of desalination is conducted using brackish water RO, 2\% using seawater RO, 15\% using electrodialysis and electrodialysis reversal (ED/EDR), and $11 \%$ using nanofiltration (NF). The main disadvantage of these technologies is fouling and scaling of membranes and the subsequent disposal of significant volumes of brine [291,292].

Recent concern emerging from greenhouse-gas emissions has prompted the desalination industry to consider the use of renewable energy as a key factor for new desalination technologies that are being developed [293]. As a thermally based membrane process, renewable energy (solar or geothermal), waste heat from industrial processes, and warm produced water can provide the thermal energy needed 
to drive the MD separation process. Waste heat from impaired waters or industrial processes can be used as energy input to produce high-quality water to augment existing water supplies or reduce brine disposal volumes by treating waste brine streams. Therefore, MD technology may be a suitable treatment alternative from an energy-water-nexus perspective, or MD can be a complimentary treatment process to reduce waste disposal costs. In this section information related to the availability of impaired water sources, as well as their composition, to assess their potential for application of MD technologies will be presented.

\subsection{Brackish Groundwater}

Two major reasons for needing to increase water availability in the United States, and all around the world, are increasing water demands in urban centers with limited water resources, and the over-pumping of fresh groundwater aquifers [294]. As more communities diversify their water sources, brackish groundwater and the use of membrane based processes has gained significant traction. RO technology is mature and well understood; however, its implementation for brackish water desalination is limited by two main drawbacks: cost (capital and operating) and disposal of desalination concentrate. Brackish groundwater is defined as "a source of water that exceeds the secondary drinking water standard of $500 \mathrm{mg} / \mathrm{L}$ total dissolved solids (TDS) or the World Health Organization (WHO) guidelines for drinking water quality of $1000 \mathrm{mg} / \mathrm{L}$." In the United States, secondary standards are established for aesthetic purposes and as such are not enforceable. Typical composition of brackish water as compared to sea water and other impaired waters is presented in Table 8.

In the United States, the State of Texas has significant brackish groundwater resources that have been extensively documented [295]. The Texas Water Development Board identified more than 780 million acre-feet ( 1 acre-foot is equivalent to $1.23 \mathrm{ML}$ ) of brackish aquifers amenable to desalination [296]. About two-thirds of the 2.7 billion acre-feet (3.3 billion ML) of brackish water available in the state can be classified as slightly brackish (1000-3000 mg/L TDS). The quantity and quality of this resource represents a significant opportunity for implementation of desalination technologies to augment water resources statewide [297]. The Kay Bailey Hutchison Desalination Plant (KBHD) operating in El Paso, Texas, treats inland brackish groundwater wells from the Hueco-Mesilla Bolson, which has an average TDS concentration of $2000 \mathrm{mg} / \mathrm{L}$. It has a design capacity of 27.5 MGD (104 million liters per day (MLD)) of drinking water. Operation of the KBHD plant at full capacity results in the generation of up to 3 MGD (11.4 MLD) of RO concentrate with potential opportunities for further recovery. The state of Florida in the United States has the largest number of facilities using desalination technologies to treat mostly brackish ground and surface water (more than 140). It also produces the highest volume of potable water each day (about 2000 MLD) [298]. Other brackish water desalination plants are operating in Virginia, North Carolina, California and other states [299]. 
Table 8. Comparison of typical composition of produced water and other impaired waters for potential MD applications.

\begin{tabular}{ccccc}
\hline \multirow{2}{*}{ Element } & \multicolumn{4}{c}{ Concentration (mg/L) } \\
\cline { 2 - 5 } & Sea Water & Brackish Water & Grey water & Natural gas produced water \\
& {$[299]$} & {$[300]$} & {$[301]$} & {$[126]$} \\
\hline Chloride $(\mathrm{Cl})$ & 19,400 & 1,093 & 65.4 & 81,500 \\
Sulfate $\left(\mathrm{SO}_{4}\right)$ & 904 & 187 & 7.23 & 47 \\
Calcium $(\mathrm{Ca})$ & 411 & 135 & 30 & 9,400 \\
Sodium $(\mathrm{Na})$ & 10,800 & 609 & 144 & 37,500 \\
Magnesium $(\mathrm{Mg})$ & 1,290 & 35 & 10 & 1,300 \\
Potassium $(\mathrm{K})$ & 392 & 19 & 12 & 149 \\
\hline
\end{tabular}

In the State of Kuwait and in Saudi Arabia, Bahrain, and Qatar the Dammam aquifer is a potential source of groundwater [302]. The aquifer is the main natural groundwater reservoir that supplies water to Kuwait. Salinity in this aquifer ranges from 2500 to $10,000 \mathrm{mg} / \mathrm{L}$ in the central part of the State, and from 10,000 to $150,000 \mathrm{mg} / \mathrm{L}$ in the northeastern part. The salinity of the groundwater results from a dissolution process where chloride $(\mathrm{Cl})$, sulfate $\left(\mathrm{SO}_{4}\right)$, sodium $(\mathrm{Na})$, and calcium $(\mathrm{Ca})$ are the dominant ions. The brackish groundwater is blended with water from distillation plants to make the water suitable for drinking. Treated water is also used to cover agricultural and domestic needs in Kuwait [302]. In Jordan, the technical and economic feasibility of brackish groundwater treatment by RO for potable water production has been investigated [291]. This country is characterized for having arid to semi-arid climate, and its population is increasing at an annual rate of $3.6 \%$. The study was intended to contribute to the development of efficient technologies to produce affordable potable water in Mediterranean countries where the threat of water shortage is a severe problem. The number of inland desalination plants is growing considerably in Europe and other parts of the world. As compared to most desalination plants that return the salt concentrate to the ocean, inland plants must find other alternatives for disposal and reduction of concentrate [299]. Membrane distillation can be a complementary technology to treat the brine waste generated by RO. As an example, Macedonio and Drioli [303] demonstrated that combining MD with RO operation using a process intensification approach can increase the RO recovery factor and extend the life of the RO membrane. In this approach, one portion of the RO permeate is treated in the MD system instead of passing all the first stage RO permeate through a second RO stage.

\subsection{Seawater}

Desalination of seawater has been utilized to supply water for municipal, industrial and agricultural purposes in the Middle East and other coastal areas of the world where fresh water resources are scarce. Seawater composition, while more consistent than brackish groundwater, varies depending on the geographic location of the facility. Salinity ranges from 20,000 to $45,000 \mathrm{mg} / \mathrm{L}$ or higher depending on how much freshwater influence is present [304]. The practice has largely relied on distillation technologies including multiple effect distillation (MED), multi-stage flash distillation (MSF), and vapor compression (VC). However, in the past three decades membrane-based technologies have gained traction to the point that the most recent seawater desalination plants utilize 
RO membranes as opposed to distillation technologies [289]. However, seawater desalination using RO membranes has significantly lower water recovery (about 40\%), when compared to brackish groundwater RO desalination (generally $70 \%-90 \%$ recovery) [305].

In the Arab countries, mainly in the Gulf countries, a total of approximately $30,000 \mathrm{~m}^{3}$ of desalted seawater are being produced every year due to water scarcity [304]. Production of desalted water in Saudi Arabia reached 7400 MLD in 2006 [306]. In the Middle East and North Africa (MENA) countries, desalination accounts for $1.8 \%$ of the region's water supply. A massive expansion of seawater desalination on the order of 24,200 MLD is expected by 2025 . The increase in desalination capacity will concentrate almost exclusively in the high-income, energy-exporting wealthier countries, primarily in the Gulf countries. In the Gulf there is increasing concern about the amount of desalination taking place in the small, enclosed sea that is used as source of water for all these nations [307].

In Australia, the main feed source to be used for desalination is seawater ( $86 \%)$ and is followed by brackish water (1.2\%) and industrial water (12\%) [305]. In this country, the amount of desalted water in 2008 was $0.57 \%$ of the total water consumption for $2004-2005$ of $51.5 \mathrm{GL} /$ day. The amount of desalted water is expected to rise to $4.3 \%$ in 2013. Spain is one of the largest users of seawater RO in the world, with more than 700 desalination facilities producing more 2 billion $\mathrm{m}^{3} / \mathrm{d}$ [308]. Desalination of seawater is one of several alternative water supplies identified for Florida to meet the projected increase in the state's water demand, which is expected to grow by more than $25 \%$ to about 33,000 MLD by 2025. Coastal surface water is treated in Florida at the Tampa Bay Seawater Desalination Facility [309].

A concern exists about brine discharge and potential environmental impacts associated with the practice of seawater desalination. In seawater plants, brine is discharged to the sea. Therefore, all chemicals added to the desalination process for scaling control, fouling, and corrosion prevention flow back into the sea [307]. Proper mitigation measures should be taken as well as extensive studies conducted during the planning and design phases of the project to minimize potential impacts. In addition to scaling, deposition of colloidal matter, adsorption of organic compounds and biofouling can drastically reduce membrane productivity in seawater RO [305]. As reported by Hoang et al. [305], the type, concentration and growth potential of the biological species are determined by the temperature, sunlight, $\mathrm{pH}$, dissolved oxygen content and the presence of organic and inorganic nutrients. MD could play an important role in reducing the environmental impact by reducing the amount of brine waste for disposal, particularly if it is integrated with RO. If integrated with RO, MD could also reduce fouling issues because the pores of membranes used for MD are relative large compared to the pores or diffusion pathways in RO and are not as easily clogged. Pores in RO membranes are approximately three orders of magnitude smaller than those of MD membranes [310].

Recently a consortium of industry, academic institutions, technology providers, and water utilities was formed in Qatar to evaluate the suitability of MD for seawater desalination in the region [311]. The research study was carried out in multi-phases including bench scale studies, model development, low grade waste heat evaluation and pilot scale demonstration. The purpose of the study was to sustainably augment water production, reduce environmental impact, and build capacity in the State of Qatar. In doing this, MD could help to increase the RO recoveries in Middle East countries. In this 
region, where about two thirds of the desalinated water of the world is produced, the RO recovery rate was reported as $35 \%$ in 2008 [292].

\subsection{RO/ED/EDR Concentrate}

Reverse osmosis of brackish groundwater (BWRO) has found increasing application in semi-arid and arid countries to treat brackish groundwater for drinking, industrial, or irrigation purposes [312,313]. In the Middle East and the United States, RO treatment plants have been implemented and are in operation [290,291]. RO plants are also in operation in Europe and Australia [289]. The last one has six seawater RO plants for its major cities and one to support mining operations. Additionally, Australia has a vapor compression system to support mining operations. The Tampa Bay Seawater Desalination Facility in Tampa, United States, which is the only large-scale facility in the country using a coastal surface water source, operates using reverse osmosis [309]. The largest seawater RO plant in the world, located in Ashkelon, Israel, has a design capacity of 326 MLD [292]. The Sorek desalination plant in Israel to be completed in 2013 will have a design capacity of 410 MLD.

One of the major concerns for BWRO is the disposal of the RO concentrate, arising from the presence of anti-scalants, pre-treatment chemicals, and remoteness from the sea or another economically viable concentrate disposal options [292,311]. The volume of concentrate produced depends on factors such as source water quality (e.g., salinity level) and technology utilized. Table 9 presents examples of concentration of feed water and corresponding RO concentrate for various brackish waters in the State of Texas, United States and The United Arab Emirates [313].

Table 9. Examples of main composition in feed water and concentrate in desalination facilities $(\mathrm{mg} / \mathrm{L})$ [313].

\begin{tabular}{ccccccccc}
\hline Facility & pH & TDS & SO $_{4}$ & Cl & Na & K & Ca & Mg \\
\hline El Paso, TX, USA & & & & & & & \\
Feed & 7.70 & 1,540 & 592 & 374 & - & - & - & - \\
Concentrate & 8.11 & 5,101 & - & 1,410 & - & - & - & - \\
\hline Dell City, TX, USA & & & & & & & \\
$\quad$ Feed & - & 753 & 588 & 19 & 16.5 & - & 205 & 61 \\
Concentrate & - & 1,170 & 968 & 24 & - & - & - & - \\
\hline Adam, United Arab Emirates & & & & & & \\
$\quad$ Feed & 8 & 2,000 & 773 & 506 & 410 & 12 & 103 & 70 \\
Concentrate & 6 & 8,747 & 4.336 & 1,974 & 1,670 & 43 & 417 & 280 \\
\hline & Esherja, United Arab Emirates \\
$\quad$ Feed & 7 & 30,638 & 4,104 & 15,868 & 8,630 & 355 & 496 & 1,100 \\
Concentrate & 7 & 48,510 & 6,139 & 24,062 & 14,800 & 631 & 481 & 1,900 \\
\hline
\end{tabular}

In the United States the main concentrate disposal method is deep-well injection [305]. In Australia, most of the facilities dispose their concentrate via ocean outfall, although smaller inland plants discharge to the sewer or evaporating basins, or use ground infiltration [305]. The presence of salt, metals, and silica at or above super-saturation due to the addition of antiscalant and dispersants during the RO process may be a major concern for disposal of desalination concentrate in deep well 
injection [305], since eventually unwanted precipitates may form. A study conducted by Macedonio and Drioli [303] reported that combining RO with MD allowed total boron and arsenic rejection from salty water without the need for addition of oxidizing agents, resulting in less environmental impact.

\subsection{Produced Water}

Produced water from oil and gas wells is a potential candidate for MD treatment. Approximately $3300 \mathrm{ML}$ of produced waters are generated annually in the United States [314]. Produced water is characterized as groundwater with elevated concentrations of total dissolved solids as well as other water quality parameters [315]. Reuse of produced water can be possible if certain quality conditions are met; however, most produced water generated is disposed of via injection wells.

Low-grade heat from the produced water can be utilized as the energy source to drive MD desalination, because it contains energy that would otherwise be released to the environment without being used. Produced water with temperatures lower than $70^{\circ} \mathrm{C}$, which otherwise are difficult to use by traditional thermal process, is suitable to be used by MD [316]. Other potential sources for waste heat include industrial stack emissions or cooling circuit heat that is rejected to rivers, lakes, or atmosphere via heat exchangers or cooling towers [316]. Costs associated with the use of waste heat include the cost of installing and operating heat recovery systems [316].

Beneficial reuse of produced water includes primary agricultural and industrial uses. Agricultural applications include crop irrigation, livestock watering, aquaculture, and hydroponic vegetable cultivation. One of the challenges on using produced water for agricultural applications is the high levels of salinity and the excess of sodium, when present in the water, which can reduce the hydraulic conductivity of soils and prevent plant growth. Industrial applications include process water for hydraulic fracturing operations at oil and gas well sites, water for power generation, dust control, and fire protection and control [317,318]. Pretreatment is required but it is not as extensive as it is for agricultural purposes.

Regulations regarding beneficial reuse of produced water are changing worldwide, as is the case of the Australian Coal Seam Gas (CSG) industry, due to the fact that oil and gas exploration activities in shale formations have rapidly increased in the past five years. CSG will be treated in the Kenya Water Treatment Plant in Australia by using a combination of ultrafiltration, ion exchange, RO and brine concentration evaporation technology to achieve zero liquid discharge [289]. Examples of other places with increasing oil and gas activities include the Marcellus Shale in Pennsylvania and the Eagle Ford Shale in South Central Texas. The numbers of wells being drilled in PA, TX, WI, SD, KS and other places represents hundreds of wells monthly and annually.

Recently a study based on peer-reviewed literature and available information was conducted to characterize produced waters in the United States with the purpose of determining potential beneficial uses. Produced water sources included shale gas (SG), conventional natural gas (NG), conventional oil, coal bed methane (CBM), and tight gas sands (TGS) [314]. A comparison of some of the produced waters' constituents is presented in Table 10. The study reported that one-fourth of the produced water samples are fresh and need minimal treatment for removal of metal and metalloid constituents prior to use. Other portions of produced water samples are brackish with chloride concentrations of 5000-30,000 mg/L and saline with relative high metals and metalloids that may require considerable 
treatment. Other produce waters are hyper-saline $(>30,000 \mathrm{mg} / \mathrm{L}$ TDS) and produce a considerable waste stream from reverse osmosis, thus significantly affecting the viability of utilizing RO to recover water from the waste stream. Once saline produced waters are treated, they may be suitable for irrigation and replenishing of surface waters. Hyper-saline produced water may not be feasible for remediation.

Table 10. Range of some produced water constituents [314].

\begin{tabular}{|c|c|c|c|c|c|c|c|c|c|c|}
\hline \multirow[t]{2}{*}{ Parameter } & \multicolumn{2}{|c|}{$\begin{array}{l}\text { Natural gas } \\
(\mathrm{mg} / \mathrm{L})\end{array}$} & \multicolumn{2}{|c|}{$\begin{array}{c}\text { Oil } \\
(\mathrm{mg} / \mathrm{L})\end{array}$} & \multicolumn{2}{|c|}{$\begin{array}{c}\text { Coal-bed } \\
\text { methane }(\mathrm{mg} / \mathrm{L})\end{array}$} & \multicolumn{2}{|c|}{$\begin{array}{c}\text { Shale gas } \\
(\mathrm{mg} / \mathrm{L})\end{array}$} & \multicolumn{2}{|c|}{$\begin{array}{c}\text { Tight gas sand } \\
(\mathrm{mg} / \mathrm{L})\end{array}$} \\
\hline & Min & Max & Min & Max & Min & Max & Min & Max & Min & Max \\
\hline $\mathrm{PH}$ & 3.1 & 7 & 5.18 & 8.9 & 6.56 & 9.87 & 1.21 & 8.36 & 5 & 8.6 \\
\hline $\begin{array}{l}\text { Conductivity } \\
(\mu \mathrm{S} / \mathrm{cm})\end{array}$ & 4,200 & 586,000 & 838 & 1,469 & 94.8 & 145,000 & - & - & - & 24,400 \\
\hline Alkalinity & 0 & 285 & 300 & 380 & 54.9 & 9,450 & 160 & 188 & - & 1,424 \\
\hline Nitrate & - & - & 1 & 2 & 0.002 & 18.7 & nd & 2,670 & - & - \\
\hline Phosphate & - & - & - & - & 0.05 & 1.5 & nd & 5.3 & - & - \\
\hline Sulfate & 1.0 & 47 & 8 & 13,686 & 0.01 & 5,590 & nd & 3663 & 12 & 48 \\
\hline Chloride & 1,400 & 190,000 & 36 & 238,534 & 0.7 & 70,100 & 48.9 & 212,700 & 52 & 216,000 \\
\hline Oil and grease & 2.3 & 60 & - & 92 & & - & - & - & - & 42 \\
\hline Uranium & - & - & - & & 0.002 & 0.012 & - & - & - & - \\
\hline $\mathrm{Ra}^{226} \mathrm{bq} / \mathrm{L}$ & - & - & 0.1 & 9.7 & - & - & - & - & - & - \\
\hline $\mathrm{Ra}^{226}(\mathrm{pCi} / \mathrm{g})$ & - & - & - & - & - & - & 0.65 & 1.031 & - & - \\
\hline $\mathrm{HCO}_{3}$ & - & - & 15 & 3,501 & - & - & nd & 4,000 & 10 & 4,040 \\
\hline $\mathrm{Al}$ & 0.4 & 83 & - & 0.06 & 0.5 & 5,290 & nd & 5,290 & - & - \\
\hline As & 0.002 & 11 & 0.17 & 0.857 & 0.0001 & 0.06 & - & - & - & 0.17 \\
\hline $\mathrm{Cd}$ & 0.02 & 1.21 & 0.03 & 0.2 & 0.0001 & 0.01 & - & - & - & 0.37 \\
\hline $\mathrm{Fe}$ & nd & 1100 & 0.1 & 0.5 & 0.002 & 220 & nd & 2,838 & - & 0.015 \\
\hline B & nd & 58 & - & - & 0.002 & 2.4 & 0.12 & 24 & - & - \\
\hline $\mathrm{Hg}$ & - & - & - & - & 0.0001 & 0.0004 & - & - & - & - \\
\hline K & 0.458 & 669.9 & 1.6 & 42.6 & 0.3 & 186 & 0.21 & 5,490 & 5 & 2,500 \\
\hline $\mathrm{Ca}$ & nd & 51,300 & 4 & 52,920 & 0.8 & 5,870 & 0.65 & 83,950 & 3 & 74,185 \\
\hline $\mathrm{Na}$ & 520 & 120,000 & 405 & 126,755 & 8.8 & 34,100 & 10.04 & 204,302 & 648 & 80,000 \\
\hline $\mathrm{Mg}$ & 0.9 & 4,300 & 2 & 5,096 & 0.2 & 1,830 & 1.08 & 25,340 & 2 & 8,750 \\
\hline
\end{tabular}

The recently increased generation of produced water presents an opportunity for MD in that it can be used to remove low and high levels of salt as well as heavy metals which are commonly present in produced water. A study conducted by Macedonio and Drioli [303] reported that integration of MD and a first stage RO system increased water recovery, and the produced fresh water had boron and arsenic concentrations below the WHO and EPA maximum recommended levels for boron and arsenic in fresh water. Boron removal by $\mathrm{RO} / \mathrm{NF}$ is possible only if the removal process takes place at $\mathrm{pH}$ higher than 10, but working at this high $\mathrm{pH}$ may increase the tendency for RO membrane scaling by carbonate minerals. Boron removal by $\mathrm{RO} / \mathrm{NF}$ is typically ineffective when operated at near-neutral $\mathrm{pH}$, as boron primarily exists as uncharged boric acid [316].

Energy-driven processes such as reverse osmosis and other desalination technologies may be suitable approaches to recover high quality water from these streams. Location of the water to be treated, environmental conditions, and economic and social needs are factors to take into account when 
selecting the most appropriate treatment method [314]. Section 3 presented an example of an MD-energy driven systems that, if combined with RO, could potentially increase the recovery of produced water.

\subsubsection{Oil and Gas Industry}

In the United States, one of the main sources of produced water is from the oil and gas (O\&G) industry. Produced water is the largest wastewater stream in the oil exploration and production process [318]. Annually the O\&G industry introduces hundreds of millions of cubic meters of brackish wastewater that have to be taken to reinjection sites, evaporation ponds, recycling facilities or any other means for disposal. In Norway $120 \mathrm{GL}$ of produced water were expected to be discharged in 2000 [318]. Typical composition of produced water varies with respect to location and depends on the characteristics of the host geological formation as well as the O\&G composition (Table 9). Major components of produced water are total dissolved solids (TDS), oil and grease, inorganic and organic compounds incorporated during the production process, and naturally occurring radioactive materials. Oil and grease content ranges from $40 \mathrm{mg} / \mathrm{L}$ to $2000 \mathrm{mg} / \mathrm{L}$, and TDS range from 1000 to 400,000 mg/L [315,317]. Table 11 shows approximate salinity levels of produced water in US oil fields. Sodium chloride is the dominant species in produced water (over $76 \%$ ), followed by sodium bicarbonate and sodium sulphate [317,319]. Other major cations include calcium and magnesium. Minor cations are potassium, strontium, and barium. The $\mathrm{pH}$ of produced waters is typically controlled by the carbonate system [313].

Table 11. Approximate salinity of produced water from United States oil fields [294].

\begin{tabular}{cc}
\hline Name of Oil Field & Total Dissolved Solids (mg/L) \\
\hline Willinston & $40,000-140,000$ \\
Powder River & $5,000-20,000$ \\
Big Horn & $5,000-9,000$ \\
Wind River & $4,000-10,000$ \\
Green River & $6,000-30,000$ \\
Denver & $9,000-40,000$ \\
Paradox Total & $11,000-120,000$ \\
San Joaquin & $20,000-40,000$ \\
Central Kansas & $45,000-120,000$ \\
San Juan & $8,000-60,000$ \\
Andarko & $60,000-130,000$ \\
Los Angeles & $40,000-45,000$ \\
Permian & $60,000-120,000$ \\
\hline
\end{tabular}

The volume of produced water generated by production wells is proportional to the age of the well; therefore, overtime oil production decreases as the water production increases [317]. In contrast, the volume of produced water from natural gas activities follows the opposite trend-More water is produced early in the process and gas productivity increases over time. Volume of produced water generated during oil production represents about $70 \%$ of the total wastewater and oil volumes produced during oil production, and in many cases is seven to eight times greater by volume than oil 
produced at any given oil field [320]. Disposal costs of produced water represent as much as $10 \%$ of the total cost of hydrocarbon production [126].

A recent study conducted by Clark and Veil [317] reported a total generation of about 3300 GL/year of produced water from State and Federal onshore production in the United States, with the greatest amount of produced water (75\%) generated in the states of Texas, California, Wyoming, and Kansas. More than $60 \%$ by volume of produced water coming out of the natural gas industry is reinjected into designated reinjection zones, which are deemed to be geologically isolated from potential underground sources of drinking water [321]. According to Hayes and Arthur [322], the percentage of produced water reinjected rises to greater than $90 \%$ when produced water from oil and gas operations is considered together. Currently, 2000-3000 GL/year of produced water are generated with the production of oil and gas in the United States [322]. It is anticipated that in future years, the oil and gas industry will have to dispose of more than 159 million cubic meters/year of produced water using methods other than deep well injection [321]. It is estimated that the market for water and wastewater technologies for the O\&G industry is worth over $\$ 550$ million annually.

Treatment and disposal of stored produced water is costly, and as the demand for natural gas increases the volume of produced water generated increases. It is estimated that in the United States approximately 6 trillion liters of natural gas was consumed in 2005. A total of 2.2 trillion liters of natural gas is stored in underground storage facilities. A total of 27 to $214 \mathrm{~L}$ of water is produced for each $27 \mathrm{~L}$ of natural gas that is extracted from the storage facility [319]. Produced water is transported to specialized treatment facilities or disposed of by injection into deep wells. However, these approaches are expensive and innovative approaches for treating these waters are needed. Injection of produced water may not be the most sensible option due to the potential for groundwater contamination by heavy metals and other chemical constituents of disposed water. A case has been reported in the northwest of Turkey where about 40 oil and gas production wells generate small amounts of produced water each day. A portion of the produced water discharged via deep injection well for final disposal came back to the surface just after injection into the well; therefore, deep well injection could no longer be a solution for final disposal of produced water at this site [320]. Prior to injection, appropriate pre-treatment of produced water is required due to the presence of high levels of TDS and other constituents in the water [317]. This implies removal or control of excess of solids, dissolved oil, corrosive chemicals, chemical reactions and microorganisms. However, most produced water discharged via deep well injection is not treated, since this requires additional cost. Reducing and oxidative environmental conditions may play an important role to promote undesired chemical precipitation reactions that have the potential for blockage of the aquifer, and hence need to be removed before reinjection. MD may be implemented as a secondary step after the RO process to remove heavy metals and reduce potential groundwater contamination. After this is done, a beneficial use may be found for the purified water instead of reinjection. The potential of removal of excess salt in the presence of total organic carbon (TOC) from simulated produced water was reported by Camacho et al. [323]. Heavy metals and radionuclides such as uranium have proved to be efficiently removed from impaired water as reported by Yarlagadda et al. [324]. 


\subsubsection{Shale Oil and Gas Exploration and Development}

Production of coal-bed methane (CBM) or coal-bed natural gas $(\mathrm{CBNG})$ is limited by challenges in the management of large volumes of produced water. $\mathrm{CBM} / \mathrm{CBNG}$ is an unconventional natural gas resource with large reserves in the United States and Worldwide [325]. Greater amounts of produced water from CBM wells are obtained compared to conventional natural gas wells. These large volumes of water are contained in the many fractures and pores of coal beads. The water in the coal bed helps to maintain the pressure in the reservoir that keeps methane gas adsorbed to the surface of the coal. Water is removed via pumping to reduce reservoir pressure and cause desorption of methane from the coal [326]. The amount of water produced and the ratio of water to gas are determined by the properties of the basins containing CBM. Major components of produced water from CBM are sodium, bicarbonate, and chloride ions, with relatively low sulfate content due to the conversion of sulfate to sulfide in the coal bed. It may also be low in hardness and contain suspended solids, iron, silica, and barium. Other chemical compounds are present due to activities related to industrial well development and maintenance. Organic compounds such as phenols, biphenyls, polycyclic aromatic hydrocarbons (PAHs), aromatic amines, and phthalates have been identified in CBNG waters. PAHs represent the group of organic compounds most commonly observed [327]. Other chemical compounds are present due to activities related to industrial well development and maintenance. The organic composition of produced water from CBNG wells might be a cause of environmental concern and pose significant challenges for ultimate disposal [327]. Table 12 presents a comparison of typical composition for conventional gas well water, CBM water and traditional waters.

Most CBM water has better quality than produced water from conventional O\&G wells, particularly because concentrations of trace elements and volatile organic compounds are relatively low [326]. Due to its high salinity, water generated in CBM production must be disposed of via regulated injection wells or surface discharge. It can also be used for beneficial applications; however, its application is hindered by limited knowledge of water quality [313,325]. A composite geochemical database was recently generated by Dahm et al. [325] to assess the geochemical signature of CBM produced water in four of the major CBM basins in the Rocky Mountain region of the United States. The database was used to compare CBM produced water quality to suggested constituent concentrations for beneficial use application. Results reported that TDS, sodium adsorption ratio (SAR), temperature, iron, and fluoride are the parameters that most commonly exceed standards for drinking, livestock and irrigation water applications. Database water composition was dominated by sodium bicarbonate and sodium chloride type waters with TDS concentrations of 150 to $39,260 \mathrm{mg} / \mathrm{L}$ [325]. The U.S. Bureau of reclamation reports that within basins, the TDS of CBM water varies from 200 to $170,000 \mathrm{mg} / \mathrm{L}$ [326]. Based on the database it was suggested that prediction of water quality compositions for beneficial use applications in CBM-producing basins worldwide is going to be based on basin geology, hydrogeology, and methane generation pathways [325]. The unique quality of produced water from $\mathrm{CBM} / \mathrm{CBNG}$ as well from the oil and gas industry provides opportunities for novel treatment technologies. Such applications might be an opportunity for implementation of MD as a stand-alone technology or as a hybrid system with energy-powered systems or RO, particularly if considering that such high TDS concentrations are unfeasible for treatment with a single technology. MD is capable of treating feed waters with TDS concentration in excess of 35,000 mg/L [328]. Likewise, theoretical 
rejection for all non-volatile solutes, including sodium, silica, boron, and heavy metals, is $100 \%$. As a stand-alone technology, MD may be capable of achieving similar water recoveries as brackish water RO, but recovery may be even improved up to $80 \%$ or more if coupled with other technologies to reduce scaling [328]. Produced water treatment may require a complex system of pre-treatment, treatment, and post-treatment. MD could be the fine-tuning technology that will open the opportunity for a wider range of produced water reuse applications.

Table 12. Typical composition of gas well, CBM, and traditional waters [322].

\begin{tabular}{|c|c|c|c|c|c|}
\hline \multirow{2}{*}{ Parameter } & \multicolumn{3}{|c|}{ End Use Criteria } & \multirow{2}{*}{ CBM water } & \multirow{2}{*}{$\begin{array}{c}\text { Non-CBM water } \\
\text { (conventional gas well) }\end{array}$} \\
\hline & Drinking & Irrigation & Livestock & & \\
\hline $\mathrm{pH}$ & 6.5 & - & $6.5-8$ & $7-8$ & $6.5-8$ \\
\hline TDS (mg/L) & 500 & 2,000 & 5,000 & $4,000-20,000$ & $20,000-100,000$ \\
\hline Benzene $(\mu \mathrm{g} / \mathrm{L})$ & 5 & 5 & 5 & $<100$ & $1,000-4,000$ \\
\hline SAR * & $1.5-5$ & 6 & $5-8$ & Highly varied & Highly varied \\
\hline $\mathrm{Na}^{+}(\mathrm{mg} / \mathrm{L})$ & 200 & - & 2,000 & $500-2000$ & $6,000-35,000$ \\
\hline Barium (mg/L) & - & - & - & $0.01-0.1$ & $0.1-0.4$ \\
\hline $\mathrm{Cl}^{-}(\mathrm{mg} / \mathrm{L})$ & 250 & - & 1,500 & $1,000-2,000$ & $13,000-65,000$ \\
\hline $\mathrm{HCO}_{3}^{-}(\mathrm{mg} / \mathrm{L})$ & - & - & - & $150-2,000$ & $2,000-10,000$ \\
\hline
\end{tabular}

Note: * Sodium Absorption Ratio.

\subsection{Industrial Reuse}

Worldwide dairy effluents generate large volumes of water that need to be treated. It is estimated that the average daily volume of wastewater produced on dairy farms is 12 to $15 \mathrm{~L}$ per cow. Annually, $24 \mathrm{~m}^{3}$ of manure per cow are generated and a total of about 10 to $25 \mathrm{~m}^{3}$ of wastewater per cow must also be properly disposed of or treated [329]. The main components of dairy farm effluents include nutrients such as total nitrogen $(55 \mathrm{mg} / \mathrm{L})$ and total phosphorus $(140 \mathrm{mg} / \mathrm{L})$. There are also small percentages of solids $(0.21 \%)$. Nutrient composition can vary considerable and requires management or treatment. Current practice for treatment of dairy effluents is surface application for land irrigation; however, the quantity of effluent applied to farmland must not exceed crop nutrient requirements.

In Finland, wastewaters from rural areas are a concern due to decreasing ground water quality and lack of dissolved oxygen in the receiving rivers. New regulations are in place that requires effluents from old housing, including dairy farms, to remove and reduce BOD, phosphorus and nitrogen by 2013 [330]. Rural residents in Finland represent 20\% of the population. Dairy wastewater is produced during milking and milk container washing on dairy farms. The wastewater has high chemical oxygen demand (COD) and nutrient content. Composition and volume generated depend on cattle size, washing method, detergents utilized, and total water used. Waste heat is usually contained in dairy wastewater $\left(40-80{ }^{\circ} \mathrm{C}\right)$ due to the use of hot water during the washing process [330].

Reverse osmosis has been considered as an alternative for on-site load reduction of dairy effluents. It has been found, however, that even with this technology the effluent is still too highly contaminated with nitrogen and phosphorus, and therefore it requires further treatment prior to discharge into the watercourse [329,331]. Advances in membrane technology will play an important role in 
implementing MD for nitrogen and phosphorus removal. Another industrial waste suitable for treatment includes wash water from potatoes and carrots, and pig and cattle slurry [332].

\subsection{Other Impaired Waters}

Grey water is generated in households by showers, bathtubs, kitchen and bathroom sinks, washing machines and other household basins. Grey water accounts for up to $75 \%$ of the wastewater volume produced by households. Hotels, in comparison, usually produce very dilute grey water. It is estimated that hotel guests in Europe generate as much as 170 to $360 \mathrm{~L}$ of water per guest-night. Typical COD concentration in grey water from Spanish hotels is about $171 \mathrm{mg} / \mathrm{L}$. The composition of grey water varies depending on factors such as the quality of the source water and the activities of the household. Reported values for COD range from 171 to $4770 \mathrm{mg} / \mathrm{L}$ [300]. Trace elements in grey water such as boron occasionally exceed the allowable concentration for reuse in long term irrigation and therefore treatment is required. One of the main concerns regarding reusing grey water for irrigation is the relative high concentration of sodium, which could reach values of approximately $144 \mathrm{mg} / \mathrm{L}$. High sodium concentrations limit the reuse potential of these waters to irrigation of sodium tolerant crops [300]. Total boron and heavy metals rejection have been achieved from high salinity water using MD, values not easily achieved with other treatment technologies [303]. Table 8 shows a comparison of typical composition of produced water and other impaired waters for potential MD applications.

Industrial activities use $22 \%$ of global water reserves and generate considerable amounts of effluents. In India, 392 MLD of industrial effluents are generated from five out of 28 states. Industrial effluents have varying chemical composition, with toxic and non-toxic effects [333]. Usually they carry significant loads of organic and inorganic pollutants [334]. Reuse of effluents depends on the particular application. Beneficial reuse of industrial water may include primary agricultural uses. In farming applications, factors such as site-specific soil type, climate, and crop type are to be taken into account. Some of these effluents may benefit from the removal of excess salt and may have some form of waste heat to run the MD process. Some studies have been conducted to evaluate effluent discharges by different industries [333-336]. A recent study conducted by Dow et al. [337] demonstrated that a plastic manufacturer possessed an accessible source of waste heat and a cooling tower blowdown stream that would benefit from a MD desalination treatment.

A study was conducted by Humboldt State University (Arcata, CA, USA) in 2009 to identify the industries and products that are the most water-intensive within the United States. The study determined that in 2000, the total US industrial water withdrawals were estimated to be about 74,500 MLD; from this, $89 \%$ was freshwater and $11 \%$ saline water [336]. The states that used the most industrial freshwater were Lousiana (14\%), Indiana (13\%) and Texas (8\%). The industries identified as being the most water-intensive were apparel, automotive, beverage, biotech/pharmaceutical, chemical, forest products, food manufacturing, high-technology/electronics, metal mining, refining, utility, paper products, and coal products. Apparel, food, and beverage manufacturing were the most water-intensive segments of the industries' value chains [336]. As an example, the total water involved in producing a pint of beer is roughly $76 \mathrm{~L}$, and $500 \mathrm{~L}$ of water are required to make a 2 L bottle of soda [336]. Effluents generating $250 \mathrm{~L} / \mathrm{kL}$ of beer from breweries and $12,000 \mathrm{~L} / \mathrm{kL}$ of alcohol from distilleries 
could be mined for crops if applied to low-saline soils [335]. Water used by the industry can be classified as cooling, boiler, and process waters [338].

A review of 139 companies from 11 global water-intensive industry sectors conducted in 2007 concluded that even though water recycling and reuse is an important component of sustainable water management and use in the industrial sector, companies rarely report on water recycling and reuse [339]. This study indicates that there is a significant opportunity to identify the full potential for water reclamation and reutilization within the industrial sector if sustainable incentives are in place. The level of treatment will largely depend on the composition of the effluent streams.

\section{Economic Aspects of MD and Other Desalination Systems}

The cost of membrane desalination has decreased significantly over the past three decades while traditional water resources have become less available. Similarly, the cost of desalinated water continues to be higher than the cost of obtaining water from conventionally treated sources, such as surface water. Advances in technology may help both reducing the cost and enabling a more sustainable water supply. Reduction in seawater membrane desalination costs is due to technological improvements by suppliers, automation in the manufacturing process and competition. Improvements in new membranes and modules have helped decreased the cost of brackish water desalination as well [340]. Factors such as plant capacity, type of application, quality of water being treated and ultimate use for which the water is being treated (drinking, irrigation, recharge, among others) will determine scale up conditions for further implementation of desalination technologies. MD is a thermal membrane process that promises to be a low cost desalination technology due to its potential energy versatility by using both heat and electricity. Its true economics must be explored in order to find the cost advantages over competing desalination technologies and the applications where these advantages may be exploited.

\subsection{Capital and O\&M Costs for Desalination Systems}

The total cost of desalinating water includes the capital cost (or debt service), annual operation and maintenance costs. The capital cost is represented by the total construction and non-construction (engineering, commissioning, land acquisition, and legal and administrative fees) costs of the project and the interest on the capital over the loan payback period. The annual operation and maintenance costs are represented by the chemicals, power, equipment replacement and labor costs. For the particular case of MD, both capital and operational costs mainly depend on system parameters such as flux as a function of flow rates and feed inlet temperature [161]. Arroyo and Shirazi [341] calculated the total unit cost of desalinated water as follows:

$$
\text { Total unit cost of water }=\frac{\text { Annual debt service }}{365 X \text { design capacity }}+\frac{\text { Operation and Maintenance }}{\text { Production volume }}
$$

McGivney and Kawamura [342] developed cost curves for desalination processes as part of their "Cost Estimating Manual for Water Treatment Facilities". Their summarized work is presented in Table 13. Few cost models have been developed for MD, which is a relative new technology for water desalination applications. Recently, a cost estimate was made for solar-powered MD systems based on 
economic formulas utilizing both cost data and operational parameters [161]. The model was applied to DCMD, AGMD, and VMD configurations.

Table 13. Cost-curve equations for some desalination processes [342].

\begin{tabular}{|c|c|c|c|c|}
\hline \multirow{2}{*}{ Plant Capacity } & SWRO & MED & MVC & MSF \\
\hline & $\mathrm{Up}$ to $150 \mathrm{mgd}$ & $\mathrm{Up}$ to $80 \mathrm{mgd}$ & Up to $10 \mathrm{mgd}$ & $\mathrm{Up}$ to $50 \mathrm{mgd}$ \\
\hline $\begin{array}{l}\text { Total construction } \\
\text { cost }\left(\$ \times 10^{6}\right)\end{array}$ & $\begin{array}{c}9.3423 \times(\text { Plant } \\
\text { Capacity in mgd })^{0.7177}\end{array}$ & $\begin{array}{c}23 \times(\text { Plant Capacity } \\
\text { in mgd })^{0.6097}\end{array}$ & $\begin{array}{c}15.275 \times(\text { Plant } \\
\text { Capacity in mgd })^{0.907}\end{array}$ & $\begin{array}{c}32.28 \times(\text { Plant } \\
\text { Capacity in mgd })^{0.6739}\end{array}$ \\
\hline $\begin{array}{l}\text { Total capital cost } \\
\qquad\left(\$ \times 10^{6}\right)\end{array}$ & $\begin{array}{c}12.612 \times(\text { Plant } \\
\text { Capacity in mgd })^{0.7177}\end{array}$ & $\begin{array}{c}31.05 \times(\text { Plant } \\
\text { Capacity in mgd })^{0.6097}\end{array}$ & $\begin{array}{c}20.622 \times(\text { Plant } \\
\text { Capacity in mgd })^{0.907}\end{array}$ & $\begin{array}{c}43.577 \times(\text { Plant } \\
\text { Capacity in mgd })^{0.6739}\end{array}$ \\
\hline $\begin{array}{l}\text { O\&M cost } \\
\left(\$ \times 10^{6}\right)\end{array}$ & $\begin{array}{c}2.9129 \times(\text { Plant } \\
\text { Capacity in mgd })^{0.6484}\end{array}$ & $\begin{array}{c}1.2576 \times(\text { Plant } \\
\text { Capacity in mgd })^{1.0549}\end{array}$ & $\begin{array}{c}3.121 \times(\text { Plant } \\
\text { Capacity in mgd })^{0.9384}\end{array}$ & $\begin{array}{c}1.8653 \times(\text { Plant } \\
\text { Capacity in mgd })^{0.9808}\end{array}$ \\
\hline
\end{tabular}

Another proposed method for obtaining the cost of desalinating water is calculating the debt service load based on a life-cycle analysis by using an efficiency factor to estimate the actual production volume instead of the design production capacity; or by assigning the debt service cost to the actual production volume [341]. If the water demand is substantially less than the projected design capacity, the production of water results in a higher unit cost for the water produced by the desalination facility. In general, water from desalination facilities is the most expensive water a utility has access to (based on total per unit cost). However, from an operations perspective, membrane desalination facilities are better operated as base load plants with other resources such as fresh surface water and fresh groundwater, providing the balance and serving as support for peak demands. This is the opposite of what economic considerations alone would expect, where the most expensive sources are used during periods of peak demand or supply shortages. Using seawater RO to provide base load is not based on economic grounds but rather operational grounds, because membranes need to be preserved to maintain them in operational order.

Several factors affect the capital, operating and maintenance costs of desalination facilities. Some of them are included in Table 14. The capacity of the plants also impacts the capital cost; larger plants are generally more economical. Figure 36 shows the cost of treating brackish water and seawater as a function of the size of the facility [340].

The energy cost portion of the total annual O\&M cost greatly depends on the power/fuel pricing [340]. For an optimized desalination plant the cost of energy can represent $30 \%-40 \%$ of the total cost of the water [293]. Gray et al. [293] suggests that as compared to the grid, dedicated gas turbine power stations can reduce the cost of energy in desalination systems due to the fact that they are not exposed to fluctuations between day versus night and summer versus winter electricity demands. The use of renewable energy is another option to help reduce the energy cost for MD. For seawater RO the energy costs can vary from a third to more than half the cost of desalinating water [343]. Even though Wittholtz et al. [344] states that plant location may have little observable effect on the cost of the water, and that cost data from around the world may be applicable to any location [344], it is necessary to make cost adjustments based on site regulations, materials, construction, labor, and power. Currently the major obstacle to developing seawater desalination projects in China is the total cost of those facilities. By 2050 the water demands in China are projected to reach 800 billion cubic meters. 
Table 14. Factors affecting Capital and O\&M desalination costs [340,345].

\begin{tabular}{|c|c|}
\hline Costs & Factors \\
\hline Capital & $\begin{array}{l}\text { - Capacity of the plant } \\
\text { - Project location } \\
\text { - Quality and variability of the source water } \\
\text { - Co-location with existing power generation facilities } \\
\text { - Costs associated with intake and outfall design } \\
\text { - Configuration and permitting } \\
\text { - Concentrate management plan } \\
\text { - Environmental mitigation } \\
\text { - Required water quality }\end{array}$ \\
\hline O\&M & $\begin{array}{l}\text { - Energy consumption and cost } \\
\text { ○ Power/fuel pricing } \\
\text { - Water quality } \\
\circ \text { Chemical use for pre-treatment } \\
\circ \text { Post-treatment requirements } \\
\text { - Equipment replacement and frequency of replacement } \\
\circ \text { Membrane replacement } \\
\circ \text { Cartridge filter element replacement } \\
\circ \text { Pre-treatment membranes } \\
\circ \text { Filter media replacement } \\
\text { - Labor }\end{array}$ \\
\hline Other & $\begin{array}{l}\text { Type of post-treatment required } \\
\circ \text { Ancillary equipment selected } \\
\circ \text { Land costs } \\
\circ \text { Conveyance of the water to and from the plant }\end{array}$ \\
\hline
\end{tabular}

Figure 36. Typical operation and maintenance costs for brackish and seawater desalination plants. Reprint approved and authorized by the American Membrane Technology Association (AMTA). This figure has been adapted from [340].

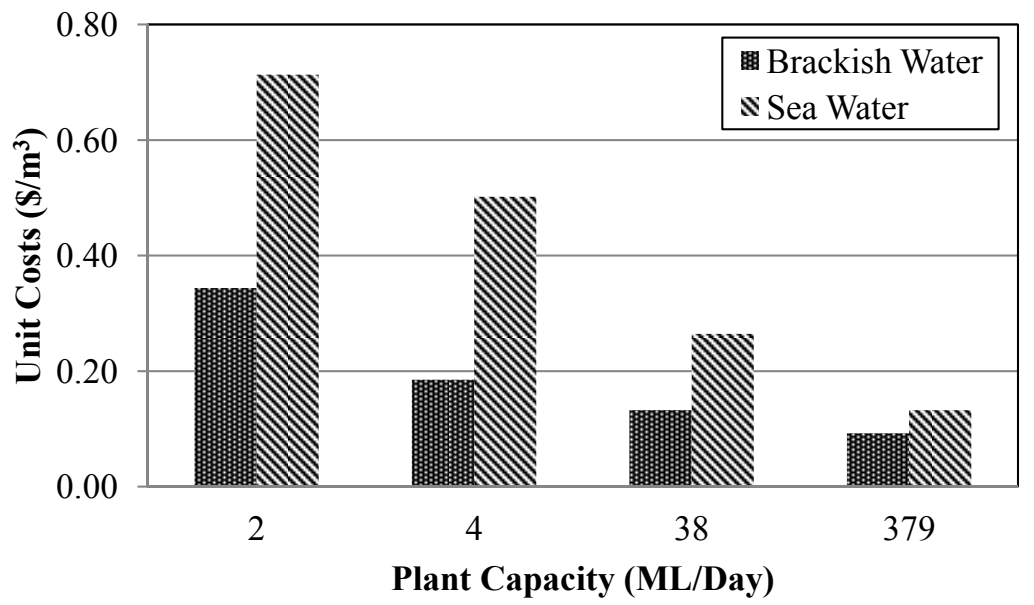

In the case of MD desalination plants, the cost and performance can be evaluated on the basis of heat recovery. Al-Obaidani et al. [11] conducted a study to compare the cost of a DCMD system without heat recovery and with heat recovery aiming to reuse the heat from the brine for pretreatment 
of the feed seawater. In the calculation researchers included total capital cost, annual fixed charge, membrane replacement, electricity, cost of steam, chemicals, labor, spares, brine disposal, total annual O\&M cost, total water cost, energy consumption, and primary energy. Economic evaluation was performed for a plant with a capacity of $24,000 \mathrm{~m}^{3} /$ day. The economic analysis reported that the unit cost of water produced by the heat recovery DCMD plant was $\$ 1.17 / \mathrm{m}^{3}$. This cost was $\$ 0.06$ lower than the water cost for a MD plant without heat recovery $\left(\$ 1.23 / \mathrm{m}^{3}\right)$. The cost contributed to a total savings of approximately $8 \%$ per year in the O\&M costs due to the savings in heating steam consumption. The total capital cost was approximately $4 \%$ higher than that of the MD plant without heat recovery due to the additional costs associated with heat exchangers for heat recovery. The performance ratio or proportion of mass flow of desalted water to mass flow of the heating steam was 13.7 with the heat recovery system. The energy supplied by fuel combustion to produce thermal energy was reduced by $11.7 \%$ in DCMD with heat recovery as compared to DCMD without heat recovery [11]. This work showed the value of heat recovery systems in terms of cost savings, justifying the need for heat recovery when high temperature heat is available.

The cost of $\$ 1.17 / \mathrm{m}^{3}$ reported by Al-Obaidani et al. [11] for DCMD with heat recovery was comparable to the cost of water produced by conventional thermal processes. The cost of water for multiple effect distillation (MED) was reported as $\$ 1.00 / \mathrm{m}^{3}$; for multi-stage flash it was reported as $\$ 1.40 / \mathrm{m}^{3}$. MD without heat recovery is still more expensive than its more mature non-membrane counterparts. However, MD is more sensitive to heat costs and for low cost heat cases, MD becomes the most economically viable thermal desalination technology.

\subsection{Cost of Competing Technologies}

There are many different types of desalination technologies. RO and ED are the most commonly utilized desalination processes for brackish water treatment [346]. RO is considered the most economic technology for large scale seawater desalination, followed by MSF and MED [8]. MSF desalination can be compared with other technologies only if seawater is considered as the feed to that process. RO is still the least energy intensive process [343]. It is estimated that the absolute minimum amount of energy required by RO to desalinate average seawater is approximately $1 \mathrm{kWh} / \mathrm{m}^{3}$ or $3.8 \mathrm{kWh} / \mathrm{kgal}$ of water produced. It is about $0.8 \mathrm{kWh} / \mathrm{m}^{3}$ for $0 \%$ recovery and about $1.2 \mathrm{kWh} / \mathrm{m}^{3}$ for $40 \%$ recovery. Presently, actual energy consumption for RO is in the order of $2.5-3.5 \mathrm{kWh} / \mathrm{m}^{3}(10-13 \mathrm{kWh} / \mathrm{kgal})$ [343]. Table 15 presents examples for total production cost of existing RO brackish groundwater and proposed seawater desalination facilities in the United States [341]. The WaterReuse Association [347] presents a comprehensive list of SWRO desalination facilities in the world including the cost trend as a function of production capacity.

In Table 15, additional cost due to salinity, distance and depth to the source, and increasing operation and maintenance cost from year to year are not included. Several cost analysis studies have been conducted for seawater desalination using RO and other technologies [348-352]. Unit costs between $\$ 0.06 / \mathrm{m}^{3}$ to $\$ 1.0 / \mathrm{m}^{3}$ for brackish water RO and between $\$ 0.40 / \mathrm{m}^{3}$ and $\$ 1.50 / \mathrm{m}^{3}$ for seawater RO have been reported [159,353-355]. Brackish water RO capital costs range from $\$ 240$ per $\mathrm{m}^{3} /$ day to $\$ 400$ per $\mathrm{m}^{3} /$ day while the capital cost for seawater RO range from $\$ 600 \mathrm{per}^{3} /$ day to $\$ 800$ per $\mathrm{m}^{3} /$ day [354]. The cost of power for a typical brackish water RO facility represents only $11 \%$ of the 
total cost as compared to the power cost for seawater RO (up to 44\%) [354]. Reduction in desalination costs has been possible as a result of improvements in pumps and membranes, and other equipment such as energy recovery systems that can regain a portion of the energy used.

Table 15. Example of total production cost for RO brackish and seawater desalination facilities (dollars of the year the facilities were built) [341,348].

\begin{tabular}{|c|c|c|c|c|c|c|c|c|}
\hline \multirow[t]{2}{*}{ Facility } & \multirow{2}{*}{$\begin{array}{c}\text { Start } \\
\text { date/ } \\
\text { (Year) }\end{array}$} & \multirow{2}{*}{$\begin{array}{l}\text { Construction } \\
\text { cost }(\$)\end{array}$} & \multirow{2}{*}{$\begin{array}{c}\text { Maximum } \\
\text { Design capacity } \\
\text { MGD (MLD) } \\
\end{array}$} & \multirow{2}{*}{$\begin{array}{c}\text { Power } \\
\text { cost } \\
(\$ / \mathbf{k W h})\end{array}$} & \multicolumn{3}{|c|}{$\begin{array}{l}\text { Production cost } \\
\text { (\$) per } 1000 \text { gallons }\end{array}$} & \multirow{2}{*}{$\begin{array}{c}\text { Total } \\
\text { cost } \\
\left(\$ / \mathbf{m}^{3}\right) \\
\end{array}$} \\
\hline & & & & & O\&M & Debt & Total cost & \\
\hline La Sara (brac & 2005 & 2,0 & $1.2(4.6)$ & 0.08 & 0.80 & 0.46 & 1.26 & 505,727 \\
\hline $\begin{array}{l}\text { Kay Bailey Hutchison } \\
\text { (brackish water) }\end{array}$ & 2006 & 0 & $27.5(1$ & 35 & 1.75 & 0.81 & 2.56 & 028,722 \\
\hline Lower RGV2 (seawater) & 2012 & 36,633 & $2.5(9.5)$ & 0.06 & 2.74 & 3.03 & 5.77 & $2,320,176$ \\
\hline Brownsville (Seawater) & 2050 & $170,229,000$ & $25(95)$ & 0.08 & 2.25 & 1.63 & 3.88 & $1,559,119$ \\
\hline
\end{tabular}

In Texas (United States), the total production cost of desalinated brackish groundwater ranges from $\$ 0.33 / \mathrm{m}^{3}$ to $\$ 0.69 / \mathrm{m}^{3}$, while the production cost of desalinated seawater ranges from $\$ 0.95 / \mathrm{m}^{3}$ to $\$ 1.52 / \mathrm{m}^{3}$ [341]. In China the unit cost is $\$ 0.6 / \mathrm{m}^{3}$ for RO brackish water and $\$ 1.0 / \mathrm{m}^{3}$ for seawater RO [356]. In Australia the product water cost per $\mathrm{kL}$ is mostly in the range of less than $\$ 1.25$ for potable water and $\$ 1.25-\$ 2.00$ for industrial water [305]. Lower costs have been reported in the Ashkelon (Israel) and Tuas (Singapore) plants $(\$ 0.47 / \mathrm{kL}-\$ 0.51 / \mathrm{kL})$ [305]. In the Middle East where seawater is the main water supply, MSF is leading the desalination market [346]. Coupling or collocating power generation and water generation is a priority due to the high demand of both electrical power and potable water.

A cost study of seawater desalination via reverse osmosis found that operating and total production costs increased linearly with increasing concentration, even though the capital costs was slightly affected by the increase in concentration. Energy costs represented the greatest part (70\%) of the operating cost [349]. The researchers suggested that more attention should be given to the energy consumption within the RO system.

\subsection{Cost of Stand Alone and Hybrid MD Systems}

For MD to be cost competitive as a water treatment technology, it is important to explore the typical costs expected for treatment of traditional and non-traditional waters and the energy cost related to their treatment. It is estimated that the treatment costs for a range of non-traditional waters including recycled, surface and produced water can range from $<\$ 0.26 / \mathrm{m}^{3}$ to in excess of $\$ 1 / \mathrm{m}^{3}$ (Figure 37) [357,358]. Additional sources of non-traditional waters include treated urban wastewater, stormwater, and mine drainage. A typical example of produced water is water from oil and gas exploration activities; surface water includes agricultural irrigation return flows [317,359].

Costs associated with treating produced waters with available technologies can be the largest component of the cost of water. However, advances in the ability to use produced water without extensive pretreatment may reduce the overall cost [357]. According to estimates cited by Freedman and Wolfe [357] the treatment cost of produced water from oil and gas exploration and agricultural 
irrigation return flows is of $\$ 1.06 / \mathrm{m}^{3}$ or more. Likewise the treatment cost for fresh water supplies is about $\$ 0.26 / \mathrm{m}^{3}$. Reducing the cost from $\$ 1.06 / \mathrm{m}^{3}$ to $\$ 0.26 / \mathrm{m}^{3}$ is not achievable at the current stage of research [357]. However, it is important to understand that moving from traditional water resources (e.g., surface water and fresh groundwater), mostly tapped out, to more expensive sources of water (e.g., reclamation, brackish groundwater, water importation, and seawater desalination) implies having to pay a higher total price for those new water resources or simply halting population growth, economic development and other activities in water short areas of the world. At the same time, research to help improving the efficiency and reducing the cost of new desalination technologies like MD needs to be done.

Figure 37. Example of water treatment cost per $\mathrm{m}^{3}$ per source. Adapted from [359].

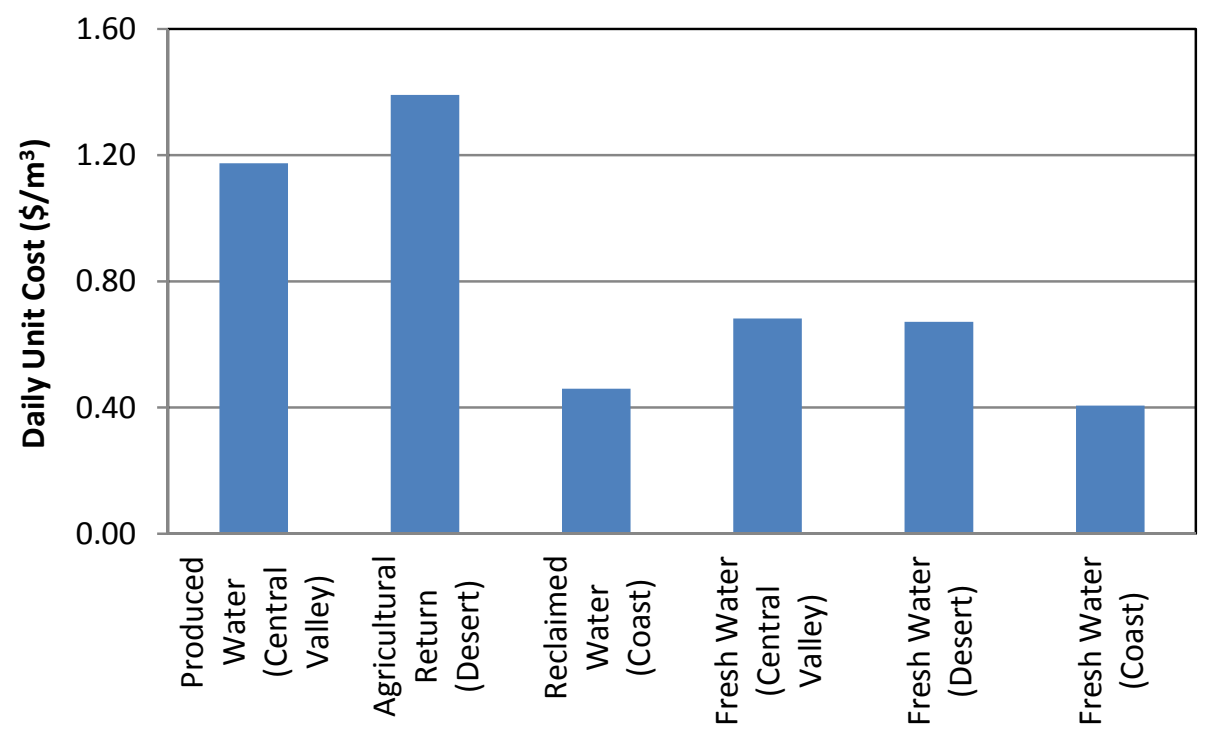

The power cost for electrodialysis treatment for processing produced waters containing up to $10,000 \mathrm{mg} / \mathrm{L}$ of TDS $\left(\$ 0.06 / \mathrm{m}^{3}\right)$ can be lower than the current cost for well disposal, which can exceed $\$ 0.31 / \mathrm{m}^{3}$. However, above $10,000 \mathrm{mg} / \mathrm{L}$ of TDS the power cost of electrodialysis can increase exponentially [360]. As an example, the cost to treat produced water with 15,000 mg/L TDS to below $2000 \mathrm{mg} / \mathrm{L}$ is about $\$ 2.52 / \mathrm{m}^{3}$, which according to the authors may be prohibitive for most field applications. Power costs required by electrodialysis systems to decrease the salinity of produced water from $5000 \mathrm{mg} / \mathrm{L}$ to $1000 \mathrm{mg} / \mathrm{L}$ TDS was reported as $\$ 0.06 / \mathrm{m}^{3}$ and $\$ 0.19 / \mathrm{m}^{3}$, respectively, based on an electricity price of $\$ 0.6 / \mathrm{kWh}[322]$.

The energy used for water desalination via RO is electricity (pumping to overcome pressure requirements) which may be more expensive than low-grade thermal energy, assuming the waste heat source is available and the cost of retrofitting the system is not significant [29]. Energy requirements for $\mathrm{RO}$ range from $3 \mathrm{kWh} / \mathrm{m}^{3}$ to $17 \mathrm{KWh} / \mathrm{m}^{3}$ depending on the scale, incoming salinity (fresh to brackish to seawater) and use of energy recovery devices. Average thermal energy use of MSF is 60 to $80 \mathrm{kWh} / \mathrm{m}^{3}$. For MED, approximately $30 \mathrm{kWh} / \mathrm{m}^{3}$ of thermal energy is required. Walton et al. [134] estimated that at the economy ratio of 15 , MD has a thermal energy requirement of $44 \mathrm{kWh} / \mathrm{m}^{3}$. The energy cost of MD is competitive as compared to RO and other thermal desalination technologies if an economy ratio of 15 is assumed and if $90 \%$ of the energy goes into desalination. The economy ratio is 
defined as the ratio of the heat energy theoretically required to distill the measured flux of water divided by the total heat energy used by the system. The maximum economy ratio of an MD module without latent heat recovery is one. Higher economy ratios implies that latent heat is recovered and therefore a higher efficiencies are reached [134].

This cost is still 2.5 times the energy requirement of the worst RO based processes. MD could, however, complement RO to help recover additional water from waste streams that will otherwise be disposed of. At an economic ratio of 15, MD is competitive energetically with other thermal desalination technologies. Table 16 shows water recovery rates for traditional desalination systems. It is been estimated that the product water recovery for MD is between $65 \%$ and $95 \%$ [143].

Table 16. Water recovery rates and operating parameters for traditional brine desalination systems $[134,361]$.

\begin{tabular}{cccccc}
\hline Operating Parameter & BWRO & SWRO & EDR & MED & MVC \\
\hline Recovery Rates $(\%)$ & $75-85$ & $30-60$ & $\geq 80$ & $20-65$ & $40-50$ \\
Thermal Energy Consumption $\left(\mathrm{kWh} / \mathrm{m}^{3}\right)$ & 3 & 17 & - & 30 & - \\
Electrical Energy Consumption $\left(\mathrm{kWh} / \mathrm{m}^{3}\right)$ & $0.5-2.0$ & $\leq 3.0-4.5$ & $\geq 0.6$ & $1.1-4.5$ & $8-14$ \\
\hline
\end{tabular}

MD has an electrical requirement of $2 \mathrm{kWh} / \mathrm{m}^{3}$ but can reduce to $<0.01 \mathrm{kWh} / \mathrm{m}^{3}$ in novel heat coupling arrangements and when thermal energy recovery is not needed (e.g., abundant low temperature waste heat) for example in the dairy industry [155]. This is one example of the versatility of MD compared to RO as a desalination technology, given its wider operational variables to enable optimal economic operation. In turn, MD requires thermal energy ranging from $120 \mathrm{kWh} / \mathrm{m}^{3}$ up to $1700 \mathrm{kWh} / \mathrm{m}^{3}$, depending on whether heat recovery is used and the heat recovery design. Similar tradeoffs and economic optimizations that are industry specific are already known to the thermal desalination industry (MED and MSF) [362]. It is estimated that in comparison to RO, when MD is fully developed at large scale it should be lower in capital cost and operating expenses. MD does not operate under pressure, therefore allowing for thinner piping made from cheaper materials (i.e., plastics versus stainless steel or expensive alloys) and reduced leaks and pump failure [134]. Seawater RO operates at around 70 bar, while MD at any salinity operates well below 1 bar.

Walton et al. [134]developed a cost estimate for MD as a function of thermal energy, assuming that the capital cost of the facility is the same as for seawater RO $\left(\$ 0.375 / \mathrm{m}^{3}\right)$, and compared it to RO assuming the energy cost of reverse osmosis to be $\$ 0.375 / \mathrm{m}^{3}$ as reported by Wangnick [363]. For example, assuming that the cost of thermal energy was $\$ 0.01 / \mathrm{kWh}$, the researcher calculated the total cost for MD to be $\$ 0.815 / \mathrm{m}^{3}$. Sirkar and Li [364] estimated that the total production cost of water by DCMD process using rectangular cross flow modules was $\$ 0.78 / \mathrm{m}^{3}$. Walton et al. [134] concluded that $\mathrm{MD}$ is competitive relative to RO when low cost heat energy is available and when the water chemistry of the source water is too difficult for treatment with RO. Al-Obaidani et al. [11] suggested that by using a low-grade thermal energy source, the cost of DCMD may be decreased to values approaching the cost of water produced by RO, which is about $\$ 0.50 / \mathrm{m}^{3}$. Nevertheless, having a diversified portfolio of water resources, competitive technologies, policies and business models will help reduce total cost for supplying water to a given geography. 
The production cost of small desalination plants with a production capacity of $<20 \mathrm{~m}^{3} / \mathrm{d}$ powered by renewable energy sources such as solar, photovoltaic collectors or wind turbines, are reported in the range of $\$ 1.5-\$ 18 / \mathrm{m}^{3}$ [161,357]. Yarlagadda et al. [324] summarize the energy requirements and cost of production per unit of distillate for MD as compared with other available technologies using renewable technologies (Table 17). Table 17 also includes costing from Al-Obaidani et al. [11] and $\mathrm{Wu}$ [365] for comparison. It also includes energy requirements for innovative desalination hybrid systems. Table 18 presents a comparison of desalination costs for different hybrid processes as function of plant capacity. Saffarini et al. [161] reported that solar heater costs accounted for over $70 \%$ of the total cost of solar-powered MD systems. He suggested using alternative sources of thermal energy, such as waste heat.

Table 17. Comparison of existing desalination technologies [11,324,365].

\begin{tabular}{|c|c|c|c|c|}
\hline Process & $\begin{array}{c}\text { Specific Energy } \\
\text { Consumption } \\
(\mathbf{K J} / \mathbf{K g}) \\
\end{array}$ & $\begin{array}{l}\text { Cost per unit of } \\
\text { permeate }\left(\$ / \mathbf{m}^{3}\right)\end{array}$ & Year & Reference \\
\hline MD-Geothermal water & 111 & $15-18$ & 2008 & {$[366,367]$} \\
\hline $\mathrm{RO}-\mathrm{PV}$ & 82 & 3.73 & 2002 & {$[366,367]$} \\
\hline MFD & 338 & 2.02 & 1996 & {$[366,368]$} \\
\hline MED & 240 & 2 & 1998 & {$[366,368]$} \\
\hline MED-solar still & 1500 & 12 & 2005 & {$[366,367]$} \\
\hline MD only & - & 1.17 & 2007 & [11] \\
\hline MD-low energy source & - & 0.64 & 2007 & {$[11]$} \\
\hline MD-cheap industrial waste heat & - & 0.26 & 2006 & {$[34]$} \\
\hline $\begin{array}{l}\text { NF-RO with energy recovery device-MD } \\
\text { with available heat energy }\end{array}$ & - & 0.56 & 2007 & [109] \\
\hline NF-RO-MD with available heat energy & - & 0.80 & 2007 & [109] \\
\hline $\begin{array}{l}\mathrm{NF}-\mathrm{RO} \text { and energy recovery device-MD } \\
\text { without available heat energy }\end{array}$ & - & 0.73 & 2007 & [109] \\
\hline $\mathrm{NF}+\mathrm{RO}-\mathrm{MD}$ without available heat energy & - & 0.97 & 2007 & [109] \\
\hline RO-MD & - & 1.25 & 2004 & {$[6]$} \\
\hline MD only & - & 1.32 & 2004 & {$[6]$} \\
\hline Nuclear desalination-MED & - & $0.72-0.76$ & 2006 & [365] \\
\hline Nuclear desalination-RO & - & 0.63 & - & [369] \\
\hline Nuclear desalination-MED & - & 0.70 & - & [369] \\
\hline DCMD-waste heat & - & $1.1-1.5$ & 2011 & [370] \\
\hline
\end{tabular}

Table 18. Comparison cost for MD hybrid processes [366,371].

\begin{tabular}{|c|c|c|c|}
\hline Process & Capacity $\left(\mathrm{m}^{3} / \mathrm{d}\right)$ & $\operatorname{Cost}\left(\$ / \mathbf{m}^{3}\right)$ & Reference \\
\hline Solar MED & $72-85$ & $2-10$ & {$[372,373]$} \\
\hline Solar MSF & 1 & 2.84 & [374] \\
\hline Solar PV-RO & 1 & 12.05 & [374] \\
\hline Geothermal MD & 17 & 13 & [367] \\
\hline Solar AGMD & 66 & 8.9 & {$[375]$} \\
\hline Solar MD & 0.1 & 15 & {$[366]$} \\
\hline Solar MD & 0.5 & 18 & {$[366]$} \\
\hline
\end{tabular}


In hybrid systems such as solar-powered AGMD, the water cost varies depending on the operating parameters used. Saffarini et al. [161] reported these variations as a function of effective membrane length, feed mass flow rate, air gap width, feed channel depth, and solar collector efficiency. From these parameters only the air gap width and solar collector efficiency have a linear effect on the water cost. Table 19 summarizes some of their results.

Similarly, the final cost of the solar MD system will be affected by the selected MD configuration. A single-point water cost comparison at constant recovery ratio of $4.4 \%$ when solar heaters were made for DCMD, AGMD, and VMD showed that AGMD is the most expensive configuration (Figure 38) [161].

Table 19. Effect of operation parameter on solar-powered AGMD water cost [161].

\begin{tabular}{ccc}
\hline Operating parameter & Operating range & Water Cost $\left(\mathbf{\$} / \mathbf{m}^{\mathbf{3}}\right)$ \\
\hline Effective membrane length $(\mathrm{m})$ & $10-140$ & $20-13$ \\
Feed mass flow rate $(\mathrm{kg} / \mathrm{s})$ & $0.2-1.2$ (laminar-turbulent) & $20-23$ \\
Air gap width $(\mathrm{m})$ & $0.0005-0.003$ & $15-46$ \\
Feed channel depth $(\mathrm{m})$ & $0.001-0.005$ & $20-24$ \\
Solar collector efficiency $(\%)$ & $35-60$ & $30-19$ \\
\hline
\end{tabular}

Figure 38. Cost for a solar panel MD configurations at a recovery ratio of $4.4 \%$ with solar heaters [161].

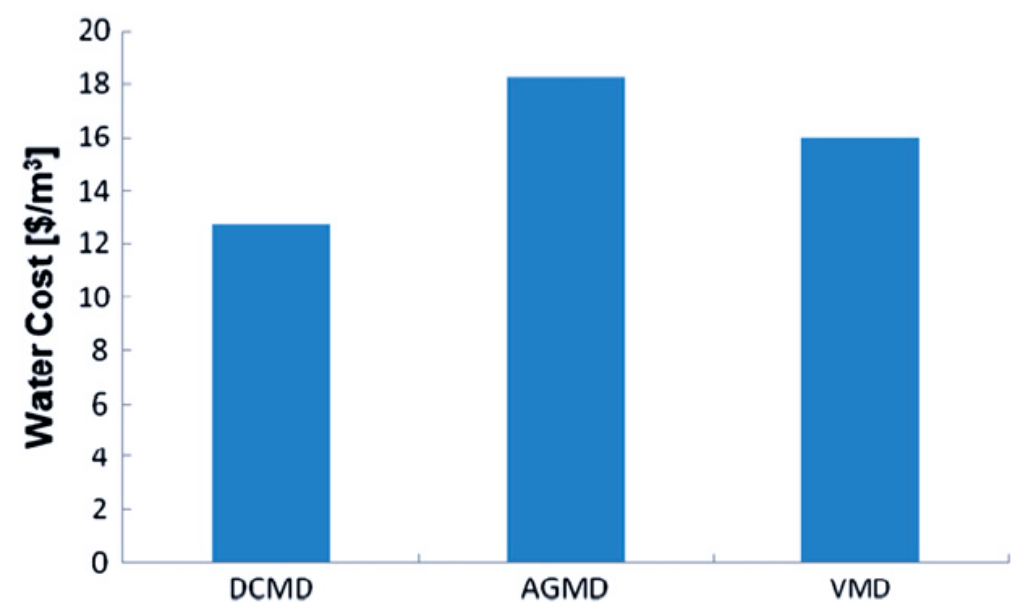

Capital and operating cost for DCMD can be lower compared with the costs for RO as demonstrated by Sirkar and Li [376] (Figure 39). The research conducted bench and pilot scale experiments for desalination of brine using rectangular cross flow hollow fiber modules, having membranes with plasmapolymerized coatings of silicone-fluoropolymers on the outside surface. Brine feed temperature ranged between 40 and $94{ }^{\circ} \mathrm{C}$. Experiments were carried out with $10 \%$ brine as feed. The cost of the RO was estimated by assuming an operating pressure of $1000 \mathrm{psi}, 30 \%$ recovery, feed flow rate of $0.15 \mathrm{~m}^{3} / \mathrm{s}$, and energy recovery of $30 \%$. For DCMD a shell operating pressure of $10 \mathrm{psi}$, $12 \%$ recovery, and feed flow rate of $0.36 \mathrm{~m}^{3} / \mathrm{s}$ was assumed. The cost of some capital items, such as site development, water, utilities, construction overhead and contingency, as well as some operating costs, such as membrane replacement, labor, spare parts, and filters in RO were the same as those in DCMD. The permeation flux of DCMD was assumed as 1.5 times higher than RO [376]. 
Estimated cost of water by DCMD was much lower than that by RO due to low-pressure operation, high water vapor flux, and good anti-fouling properties of the DCMD membrane and process. Total capital cost for DCMD was $\$ 0.85 / \mathrm{L}$ day compared to $\$ 1.19 / \mathrm{L}$ day for RO. Total production cost for DCMD was $\$ 0.96 / \mathrm{m}^{3}$ compared to $\$ 1.18 / \mathrm{m}^{3}$ for RO. The comparison was made assuming that both DCMD and RO desalination plants have a production rate of 3.7 MLD, and that industrial waste heat is available; therefore, the heat cost was neglected for DCMD. The salt content of water made from the DCMD system was less than $20 \mathrm{mg} / \mathrm{L}$ ). The salt content in water obtained from a single-stage RO system was greater than $200 \mathrm{mg} / \mathrm{L}$. The effect of salt concentration on the performance of the DCMD system was low since water vapour pressure is affected to a small extent by salt concentration [376]. Hot saline water, i.e., saline water from geothermal sources containing $3000-10,000 \mathrm{mg} / \mathrm{L}$ or higher TDS at $50-70{ }^{\circ} \mathrm{C}$, or RO reject which are not suitable for RO treatment can be used as the brine feed for DCMD. The high purity of water obtained from DCMD makes it suitable for use in high pressure boilers.

Figure 39. Comparison of capital and operating cost for DCMD and RO (adapted from [376]).

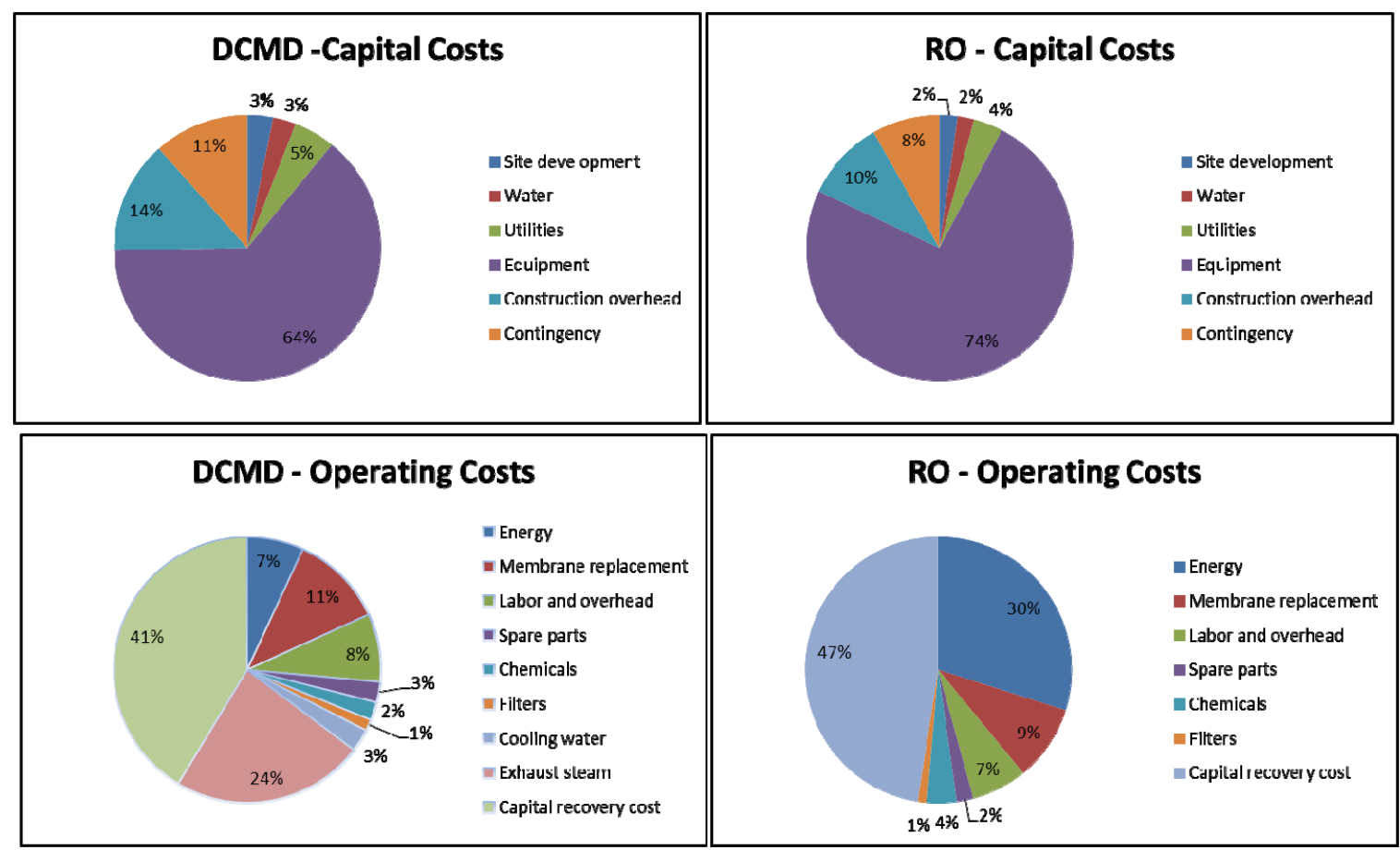

\subsection{Concentrate Management Cost for MD}

The cost of concentrate disposal can be significant. This is particularly valid for brackish water RO plants that use groundwater as the source water and have to dispose of the concentrate in either a different ground formation to ensure that it would not migrate and potentially contaminate a source of drinking water or in lined evaporation ponds. For these plants surface water outfall is not a disposal option. Even with advances in membrane production costs to have less expensive membranes, longer membrane life, and energy recovery improvements, the cost of concentrate management represents an increasing percentage of the total water treatment plant cost [377]. Table 20 shows that the cost 
for pretreatment and $\mathrm{RO}$ treatment of produced water increases as the concentration of the concentrate increases.

Several factors make difficult and costly the disposal of concentrate generated in desalination processes. Depending on local regulations and available lands, RO concentrate can be disposed of in surface water, evaporation ponds, deep injection wells or brine concentrators, among others. Disposal of concentrate in surface water can result in salt load buildup which eventually will reach a level that will limit additional discharges. Evaporation ponds are usually used only for small volumes of concentrate. Disposal to deep wells is usually restricted to larger volumes of concentrate where the cost of scaling up is affordable. Land applications depend on factors such as availability of land, percolation rates, irrigation needs and the ability to meet ground water quality standards [378]. In the case of deep well injection, finding a formation that can receive significant volumes of RO concentrate over a long period of time is part science and part art. Table 21 presents a cost comparison of concentrate disposal options with critical disposal factor as reported by Greenlee et al. [354]. The Colorado School of Mines report [328] presents a comprehensive summary of technical assessment of pre-treatment and post-treatment processes for produced water.

Table 20. Power cost of desalination of oil field brine [296].

\begin{tabular}{ccccc}
\hline \multirow{2}{*}{ Type of brine } & \multirow{2}{*}{$\begin{array}{c}\text { Concentration of feed } \\
\text { brine (TDS, ppm) }\end{array}$} & Pre-treatment & $\begin{array}{c}\text { RO } \\
\text { desalination }\end{array}$ & $\begin{array}{c}\text { Operating cost } \\
\text { per }^{\mathbf{3}}\end{array}$ \\
\cline { 3 - 5 } & $\sim 1,500$ & $\$ 0.17$ & $\$ 0.39$ & $\$ 0.50$ \\
\hline Contaminated surface water & $\sim 3,600$ & $\$ 0.66$ & $\$ 0.53$ & $\$ 1.19$ \\
\hline \multirow{2}{*}{ Gas well produced brine } & $\sim 35,000$ & $\$ 0.53$ & $\$ 1.11$ & $\$ 1.64$ \\
\cline { 2 - 5 } Oil well produced brine & $\sim 50,000$ & $\$ 2.20$ & $\$ 6.00$ & $\$ 8.20$ \\
\hline
\end{tabular}

Table 21. Cost comparison of concentrate disposal options for RO [354].

\begin{tabular}{lll}
\hline Concentrate disposal & Critical Factors & Cost $\mathbf{( \$ \mathbf { m } ^ { 3 } )}$ \\
\hline Surface water & Piping, pumping, outfall construction, permitting. & $0.03-0.30$ \\
\hline Evaporation pond & $\begin{array}{l}\text { Pond size and depth, salt concentration, evaporation rate, } \\
\text { disposal rate, pond liner cost, wildlife impacts, permitting, } \\
\text { land availability. }\end{array}$ & $1.18-10.40$ \\
\hline Deep well injection & $\begin{array}{l}\text { Casing diameter and depth, injection rate, chemical costs, } \\
\text { distance to plant. }\end{array}$ & $0.33-2.64$ \\
\hline Sewer & Disposal rate, salinity, sewer capacity, fees, permitting & $0.30-0.66$ \\
\hline $\begin{array}{l}\text { Mechanical evaporation (brine } \\
\text { concentrator, crystallizer) }\end{array}$ & $\begin{array}{l}\text { Disposal rate, energy costs, salinity, capacity, chemicals } \\
\text { for pretreatment }\end{array}$ & $0.66-26.41$ \\
\hline
\end{tabular}

Based on current concentrate disposal limitations, reclamation of effluents for irrigation and indirect potable water uses is rapidly developing as an alternative to seawater desalination [377]. Cote et al. [377] compared the total life cycle costs for treating water from secondary effluent using RO and seawater desalination, and found that they are $\$ 0.28 / \mathrm{m}^{3}$ and $\$ 0.62 / \mathrm{m}^{3}$, respectively.

An alternative disposal option for concentrate management is to treat the concentrate to recover potential economic products and have zero liquid discharge [316]. Zero liquid discharge presents an 
opportunity for MD in that, being a thermal process, it can concentrate saline water to the precipitation of salts with minimal drop in flux performance. By analyzing the cost of disposal in brine lagoons in Table 22, it is observed that technologies to reduce the disposal volume have good economic incentives. Capital cost included reductions estimated using RO or combined RO and MD desalination. Data in Table 22 assumes pond price at $\$ 1$ million/ha (including pond lining), evaporation rate of $1.0 \mathrm{~m} /$ year, and $75 \% \mathrm{RO}$ water recovery. Even with RO taking to 70,000 $\mathrm{mg} / \mathrm{L}$ at its limit, further concentrating the brine beyond this limit is worth a savings of $\$ 17$ million for a 5 MLD plant.

Table 22. Example of brine disposal pond capital costs for feed water stream of $5 \mathrm{ML} /$ day.

\begin{tabular}{cccccc}
\hline System & $\begin{array}{c}\text { Fresh water } \\
\text { recovery (\%) }\end{array}$ & $\begin{array}{c}\text { Fresh water } \\
\text { recovered (ML/day) }\end{array}$ & $\begin{array}{c}\text { Flow to be disposed } \\
\text { (ML/day) }\end{array}$ & $\begin{array}{c}\text { Disposal pond area } \\
\text { required (ha) }\end{array}$ & $\begin{array}{c}\text { Pond } \\
\text { cost }\end{array}$ \\
\hline Direct disposal & 0 & 0 & 5.0 & 183 & $\$ 183 \mathrm{M}$ \\
RO & 90 & 4.5 & 0.5 & 18 & $\$ 18 \mathrm{M}$ \\
RO + MD & 99.5 & 4.98 & 0.025 & 0.9 & $\$ 0.9 \mathrm{M}$ \\
\hline
\end{tabular}

Besides this financial incentive, environmental incentives likewise drive zero liquid discharge as brine disposal to lagoons may not be an acceptable practice due to risk of uncontrolled saline water release. MD is a potential treatment candidate for coupling with RO or ED to increase water recovery and to reduce the amount of concentrate requiring disposal to get closer to zero liquid discharge. Thermal desalination by MED would compete with MD in this space. However, when low cost thermal energy is available, MD can be an economical alternative to the established thermal processes in zero liquid discharge applications. MD is a technology that can be coupled with RO and/or others to reduce waste streams (i.e., RO concentrate). It could also be used for small-scale applications in which the water quality is not suitable for RO based processes. MD can also be co-located with power generation facilities or industrial facilities to take advantage of the waste heat to produce high quality water.

Additionally, MD can use a variety of membranes, which clearly presents a variation on the cost of the treated water [324]. While polypropylene (PP), polyvinylidenefluoride (PVDF) and polytetrafluoroethylene (PTFE) are the most widely used membrane materials, Their prices vary not only on the original material prices, but also in their design and performance. A survey of the materials has been conducted, and PTFE was found to offer best performance due to its highly hydrophobic character. Also, the support layer was found to greatly influence performance, with improved MD performance obtained by membranes supported on woven scrim materials [52]. Cost of membrane materials has been reported in the literature. For example, Al-Obaindani [11] proposed a cost of $\$ 90 / \mathrm{m}^{2}$, and explored price sensitivity in the range of $\$ 70$ to $\$ 100$ per $\mathrm{m}^{2}$. In general, membranes cost from $\$ 12$ to $\$ 40$ per $\mathrm{m}^{2}$ depending on the type (RO membranes are cheaper than UF). Presumably Al-Obaindani's [11] cost included the module. Low cost, high quality membranes emerging from China at present have a price less than $\$ 10$ per $\mathrm{m}^{2}$. Al-Obaindani [11] assumed $\$ 90$ per $\mathrm{m}^{2}$ and found that the membrane contributes to $50 \%$ of the capital cost and $30 \%$ of the operation and maintenance cost. So lower cost membranes, for example those emerging from China, will play a key role in making MD affordable. 


\section{Future Developments and Conclusions}

MD has been explored since the early 1960s, but only in the last decade has the interest grown substantially such that commercial systems are readily available, backed with pilot trial experience. Various MD providers offer solutions that are primarily focused on minimizing thermal energy demand, but there are also possibilities to reduce electrical energy demand.

MD has been used mainly trailed for removing salt for sea water and brackish water. It has also proven to be a suitable technology for removal of other contaminants, such as heavy metals, radionuclides, and organics from brackish, produced, industrial and other impaired water. While it is capable of treating many kinds of water, its ability to compete with established technologies such as RO, ED, MED and MSF is currently limited due to its high energy use. Consequently it is likely to find application where current established technologies are unable to operate or in applications that substantially favour its use. For instance, the treatment of brine streams that reverse osmosis finds difficult to treat may be a possible application, and integration of MD with RO to treat RO brine may be a suitable application where brine disposal is problematic. Treatment of CSG water brine is one such potential application, where reduction of brine pond areas has substantial capital cost benefits. Similarly, application in industries that have significant low grade waste heat sources, such as power stations and chemical plants, would also seem to be strong candidates for application of MD. The high quality of MD permeate compared to RO permeate may also provide advantages in these applications, particularly if purified water is required as boiler feed.

Finding suitable applications for MD currently seems to be the major impediment to its wider commercial use. The theory of its operation is well known, and models are available to allow design and scale up of MD systems using local heat sources. The ability to design MD processes using site specific heat flows is critical for its application, as it is dependent upon waste heat sources to achieve economic advantages, and the quality and available heat flows from such heat sources will vary from site to site. Efficient designs will be required to take this variability in available heat in to account.

Low fluxes and wetting have also been limitations for MD implementation. Having highly permeable membranes and suitable modules with improved hydrodynamics will allow increased permeate flux and overall performance of the MD process. Membrane hydrophobicity and pore geometry are critical parameters in reducing MD membrane wetting, and surface coatings are enabling reduced wetting to be achieved. For example, oleophobic coatings can reduce wetting and fouling from oily feeds. Membrane hydrophobicity also determines the largest possible membrane pore size for scale up as do process parameters such as feed water temperature, operating pressure, flow rate, and liquid composition.

A large variety of materials has been tested and investigated as MD membranes. It appears that although morphological features are critical to achieve high flux, improving the membrane performance is a complex issue involving a number of parameters. The variety of the MD configurations, membrane morphologies, module shape and size, as well as the testing conditions cause the large scatter that was visible in the Figures 24-34.

As defined by theory, pore size, porosity and thickness of the active layer matter, and the characteristics of the support are critical to achieving high flux. Controlling the thermal transfers across the different strata of the membrane is also critical and more efforts should be focused on 
improving the interfaces between the active layer and the supporting layer in order to reduce temperature polarization effects. Thermal conductivity measurements are often difficult to perform due to the difficulty in controlling the interfacial contact, but this should be an area of focus for researchers in order to better understand their structures. Although a few studies did investigate the long term performance of their membranes, it would also be interesting to investigate the long term flux and rejection stability of these novel membranes as very few groups investigated the impact of contaminants, such as chlorine, or chemical and thermal degradation on the process. MD induces strong temperature gradients across the membranes, and thermal degradation could occur over time depending on the composition of the feed. In addition, the compressibility of the membrane when stressed in the module under the pressure difference will likely affect flux and energy efficiency, particularly for DCMD.

To date commercial large pore size PTFE flat sheet membranes still show higher permeance than laboratory fabricated membranes when tested under similar conditions. A number of routes are open for researchers to improve the performance of membranes for MD. These routes include fabricating smaller pore size, but thinner active membrane layers with more hydrophilic materials. The smaller pore size will then lead to a larger LEP reducing the risk of liquid water penetration into pores while hydrophilic surfaces may reduce fouling. Research could also, on the other hand, be driven towards the processing of larger pore size hydrophobic membranes to achieve higher water vapor permeability in order to become more competitive with commercially available structures. Tuning the surface energy of the membrane is also critical, and novel approaches combining hydrophilic and hydrophobic materials have shown highly promising results. Other routes include the control of the support morphology by introducing large macro cavities to maximize the liquid water or vapor transport and reducing possible heat and concentration polarization effects.

Ceramic membranes are possible candidates in place of polymeric membranes in MD applications due to higher thermal resistance, mechanical strength, chemical stability and oxidant tolerance. Additional research is required to find optimal chemical modification candidates as well as optimal procedures to change the hydrophilic inorganic membranes to hydrophobic membranes without compromising the performance and permeate flux of the MD process. Nanoparticles are important emerging candidates to be used in the manufacturing of membranes for MD. They allow for control of membrane wetting and fouling. Graphene and carbon nanotubes are the most promising candidates due to their physico-chemical properties, which help engineering of desired structures and selectivity of the membrane separation process. Electro-spun webs, which are manufactured as affinity membranes for the study and growth of biological cells, may open opportunities for research in the area of membranes for MD.

MD appears to be poised for commercial implementation, and identification of opportunities that maximise the advantages of MD over competing technologies is emerging. In developing these opportunities, the energy consumption and desalted unit cost will decrease; therefore, competitive values with those of other desalination processes can be reached.

\section{References}

1. Lawson, K.W.; Lloyd, D.R. Membrane distillation. J. Membr. Sci. 1997, 124, 1-25. 
2. Lei, Z.; Chen, B.; Ding, Z. Membrane distillation. In Special Distillation Processes; Lei, Z., Chen, B., Ding, Z., Eds.; Elsevier Science: Amsterdam, the Netherlands, 2005; pp. 241-319.

3. Schneider, K.; van Gassel, T.J. Membran destillation. Chem. Ing. Tech. 1984, 56, 514-521.

4. Weyl, P.K. Recovery of Demineralized Water from Saline Waters. U.S. Patent 3,340,186, 9 May 1967.

5. Findley, M.E. Vaporization through porous membranes. Ind. Eng. Chem. Proc. Des. Dev. 1967, 6, 226-230.

6. Alklaibi, A.M.; Lior, N. Membrane-distillation desalination: Status and potential. Desalination 2005, 171, 111-131.

7. Hanbury, W.T.; Hodgkiess, T. Membrane distillation-An assessment. Desalination 1985, 56, 287-297.

8. Schofield, R.W.; Fane, A.G.; Fell, C.J.D. Heat and mass transfer in membrane distillation. J. Membr. Sci. 1987, 33, 299-313.

9. Carlsson, L. The new generation in sea water desalination su membrane distillation system. Desalination 1983, 45, 221-222.

10. Andersson, S.I.; Kjellander, N.; Rodesjö, B. Design and field tests of a new membrane distillation desalination process. Desalination 1985, 56, 345-354.

11. Alobaidani, S.; Curcio, E.; Macedonio, F.; Diprofio, G.; Alhinai, H.; Drioli, E. Potential of membrane distillation in seawater desalination: Thermal efficiency, sensitivity study and cost estimation. J. Membr. Sci. 2008, 323, 85-98.

12. Tomaszewska, M. Membrane distillation-examples of applications in technology and environmental protection. Environ. Studies 2000, 9, 27-36.

13. Smolders, K.; Franken, A.C.M. Terminology for membrane distillation. Desalination 1989, 72 , 249-262.

14. Khayet, M. Membranes and theoretical modelling of membrane distillation: A review. $A d v$. Colloid Interface Sci. 2011, 164, 56-88.

15. Martinez-Diez, L.; Florido-Diaz, F.J. Theoretical and experimental studies on desalination using membrane distillation. Desalination 2001, 139, 373-379.

16. Martinez-Diez, L.; Florido-Diaz, F.J.; Vazquez-Gonzalez, M.I. Study of evaporation efficiency in membrane distillation. Desalination 1999, 126, 193-198.

17. Phattaranawik, J.; Jiraratananon, R. Direct contact membrane distillation: Effect of mass transfer on heat transfer. J. Membr. Sci. 2001, 188, 137-143.

18. Calabro, V.; Jiao, B.L.; Drioli, E. Theoretical and experimental study on membrane distillation in the concentration of orange juice. Ind. Eng. Chem. Res. 1994, 33, 1803-1808.

19. Lawson, K.W.; Lloyd, D.R. Membrane distillation. I. Module design and performance evaluation using vacuum membrane distillation. J. Membr. Sci. 1996, 120, 111-121.

20. Josson, A.S.; Wimmerstedt, R.; Harrysson, A.C. Membrane distillation-A theoretical study of evaporation through microporous membranes. Desalination 1985, 56, 237-249.

21. Bandini, S.; Gostoli, C.; Sarti, G.C. Separation efficiency in vacuum membrane distillation. J. Membr. Sci. 1992, 73, 217-229.

22. Sarti, G.C.; Gostoli, C.; Bandini, S. Extraction of organic components from aqueous streams by vacuum membrane distillation. J. Membr. Sci. 1993, 80, 21-33. 
23. Garcia-Payo, M.C.; Rivier, C.A.; Marison, I.W.; von Stockar, U. Separation of binary mixtures by thermostatic sweeping gas membrane distillation: II. Experimental results with aqueous formic acid solutions. J. Membr. Sci. 2002, 198, 197-210.

24. Basini, L.; D’Angelo, G.; Gobbi, M.; Sarti, G.C.; Gostoli, C. A desalination process through sweeping gas membrane distillation. Desalination 1987, 64, 245-257.

25. Khayet, M.; Godino, P.; Mengual, J.I. Theory and experiments on sweeping gas membrane distillation. J. Membr. Sci. 2000, 165, 261-272.

26. Khayet, M.; Godino, P.; Mengual, J.I. Nature of flow on sweeping gas membrane distillation. J. Membr. Sci. 2000, 170, 243-255.

27. Rivier, C.A.; Garcia-Payo, M.C.; Marison, I.W.; von Stockar, U. Separation of binary mixtures by thermostatic sweeping gas membrane distillation: I. Theory and simulations. J. Membr. Sci. 2002, 201, 1-16.

28. Chernyshov, M.N.; Meindersma, G.W.; de Haan, A.B. Comparison of spacers for temperature polarization reduction in air gap membrane distillation. Desalination 2005, 183, 363-374.

29. Meindersma, G.W.; Guijt, C.M.; de Haan, A.B. Desalination and water recycling by air gap membrane distillation. Desalination 2006, 187, 291-301.

30. García-Payo, M.C.; Izquierdo-Gil, M.A.; Fernández-Pineda, C. Air gap membrane distillation of aqueous alcohol solutions. J. Membr. Sci. 2000, 169, 61-80.

31. Chouikh, R.; Bouguecha, S.; Dhahbi, M. Modelling of a modified air gap distillation membrane for the desalination of seawater. Desalination 2005, 181, 257-265.

32. Liu, G.L.; Zhu, C.; Cheung, C.S.; Leung, C.W. Theoretical and experimental studies on air gap membrane distillation. Heat Mass Transf. 1998, 34, 329-335.

33. Curcio, E.; Drioli, E. Membrane distillation and related operations: A review. Sep. Purif. Rev. 2005, 34, 35-86.

34. Hanemaaijer, J.H.; van Medevoort, J.; Jansen, A.E.; Dotremont, C.; van Sonsbeek, E.; Yuan, T.; de Ryck, L. Memstill membrane distillation-A future desalination technology. Desalination 2006, 199, 175-176.

35. Operation and evaluation of memstill pilot plant. Avaliable online: http:/www.pub.gov.sg/ research/Key_Projects/Pages/Membrane3.aspx (accessed on 14 January 2013).

36. Gryta, M. Long-term performance of membrane distillation process. J. Membr. Sci. 2005, 265, 153-159.

37. Schneider, K.; Hölz, W.; Wollbeck, R.; Ripperger, S. Membranes and modules for transmembrane distillation. J. Membr. Sci. 1988, 39, 25-42.

38. Guo, H.; Wyart, Y.; Perot, J.; Nauleau, F.; Moulin, P. Low-pressure membrane integrity tests for drinking water treatment: A review. Water Res. 2010, 44, 41-57.

39. Johnson, W.T. Predicting log removal performance of membrane systems using in situ integrity testing. Filtr. Sep. 1998, 35, 26-29.

40. Banat, F.; Jwaied, N.; Rommel, M.; Koschikowski, J.; Wieghaus, M. Desalination by a "compact smades" autonomous solarpowered membrane distillation unit. Desalination 2007, 217, 29-37.

41. Song, L.; Ma, Z.; Liao, X.; Kosaraju, P.B.; Irish, J.R.; Sirkar, K.K. Pilot plant studies of novel membranes and devices for direct contact membrane distillation-based desalination. J. Membr. Sci. 2008, 323, 257-270. 
42. Winter, D.; Koschikowski, J.; Wieghaus, M. Desalination using membrane distillation: Experimental studies on full scale spiral wound modules. J. Membr. Sci. 2011, 375, 104-112.

43. Chang, H.; Wang, G.-B.; Chen, Y.-H.; Li, C.-C.; Chang, C.-L. Modelling and optimization of a solar driven membrane distillation desalination system. Renew. Energy 2010, 35, 2714-2722.

44. Song, L.; Li, B.; Sirkar, K.K.; Gilron, J.L. Direct contact membrane distillation-based desalination: Novel membranes, devices, larger-scale studies, and a model. Ind. Eng. Chem. Res. 2007, 46, 2307-2323.

45. Teoh, M.M.; Chung, T.-S. Membrane distillation with hydrophobic macrovoid-free PVDF-PTFE hollow fiber membranes. Sep. Purif. Technol. 2009, 66, 229-236.

46. Gryta, M.; Tomaszewska, M.; Morawski, A.W. A capillary module for membrane distillation process. Chem. Pap. 2000, 54, 370-374.

47. Bonyadi, S.; Chung, T.S. Flux enhancement in membrane distillation by fabrication of dual layer hydrophilic-hydrophobic hollow fiber membranes. J. Membr. Sci. 2007, 306, 134-146.

48. Cheng, L.-H.; Wu, P.-C.; Chen, J. Modelling and optimization of hollow fiber demd module for desalination. J. Membr. Sci. 2008, 318, 154-166.

49. Bonyadi, S.; Chung, T.-S. Highly porous and macrovoid-free pvdf hollow fiber membranes for membrane distillation by a solvent-dope solution co-extrusion approach. J. Membr. Sci. 2009, 331, 66-74.

50. Bonyadi, S.; Chung, T.S.; Rajagopalan, R. A novel approach to fabricate macrovoid-free and highly permeable pvdf hollow fiber membranes for membrane distillation. AIChE J. 2009, 55, $828-833$.

51. Zhang, J.; Li, J.-D.; Duke, M.; Xie, Z.; Gray, S. Performance of asymmetric hollow fiber membranes in membrane distillation under various configurations and vacuum enhancement. J. Membr. Sci. 2010, 362, 517-528.

52. Zhang, J.; Dow, N.; Duke, M.; Ostarcevic, E.; Li, J.-D.; Gray, S. Identification of material and physical features of membrane distillation membranes for high performance desalination. J. Membr. Sci. 2010, 349, 295-303.

53. Jiao, B.; Cassano, A.; Drioli, E. Recent advances on membrane processes for the concentration of fruit juices: A review. J. Food Eng. 2004, 63, 303-324.

54. Dumée, L.F.; Sears, K.; Schütz, J.; Finn, N.; Huynh, C.; Hawkins, S.; Duke, M.; Gray, S. Characterization and evaluation of carbon nanotube bucky-paper membranes for direct contact membrane distillation. J. Membr. Sci. 2010, 351, 36-43.

55. Suk, D.E.; Matsuura, T.; Park, H.B.; Lee, Y.M. Development of novel surface modified phase inversion membranes having hydrophobic surface-modifying macromolecule (NSMM) for vacuum membrane distillation. Desalination 2010, 261, 300-312.

56. Suk, D.E.; Matsuura, T.; Park, H.B.; Lee, Y.M. Synthesis of a new type of surface modifying macromolecules (NSMM) and characterization and testing of NSMM blended membranes for membrane distillation. J. Membr. Sci. 2006, 277, 177-185.

57. Mulder, M. Basic Principles of Membrane Technology, 2nd ed.; Kluwer: Dordrecht, the Netherlands, 1996.

58. Lloyd, D.R.; Kinzer, K.E.; Tseng, H.S. Microporous membrane formation via thermally induced phase separation. I. Solid-liquid phase separation. J. Membr. Sci. 1990, 52, 239-261. 
59. Tomaszewska, M. Preparation and properties of flat-sheet membranes from poly(vinylidene fluoride) for membrane distillation. Desalination 1996, 104, 1-11.

60. Drioli, E.; Calabrd, V.; Wu, Y. Microporous membranes in membrane distillation. Pure Appl. Chem. 1986, 58, 1657-1662.

61. Khayet, M.; Matsuura, T.; Mengual, J.I.; Qtaishat, M. Design of novel direct contact membrane distillation membranes. Desalination 2006, 192, 105-111.

62. Criscuoli, A.; Carnevale, M.C.; Drioli, E. Evaluation of energy requirements in membrane distillation. Chem. Eng. Process. Process Intensif. 2008, 47, 1098-1105.

63. Peña, L.; Paz Godino, M.; Mengual, J.I. A method to evaluate the net membrane distillation coefficient. J. Membr. Sci. 1998, 143, 219-233.

64. Khayet, M.; Matsuura, T. Application of surface modifying macromolecules for the preparation of membranes for membrane distillation. Desalination 2003, 158, 51-56.

65. Huang, J.; Zhang, J.; Hao, X.; Guo, Y. Study of a new novel process for preparing and co-stretching ptfe membrane and its properties. Eur. Polym. J. 2004, 40, 667-671.

66. Strathmann, H.; Kock, K.; Amar, P.; Baker, R.W. The formation mechanism of asymmetric membranes. Desalination 1975, 16, 179-203.

67. Khayet, M.; Matsuura, T. Preparation and characterization of polyvinylidene fluoride membranes for membrane distillation. Ind. Eng. Chem. Res. 2001, 40, 5710-5718.

68. Zhang, J.; Li, J.-D.; Gray, S. Effect of applied pressure on performance of ptfe membrane in dcmd. J. Membr. Sci. 2011, 369, 514-525.

69. Zhang, J.H.; Gray, S.; Li, J.D. Modelling heat and mass transfers in demd using compressible membranes. J. Membr. Sci. 2012, 387, 7-16.

70. Schäfer, A.I.; Fane, A.G.; Waite, T.D. Nanofiltration: Principles and Applications; Elsevier Advanced Technology: Oxford, UK, 2005.

71. Scott, K. Handbook of Industrial Membranes; Elsevier Advanced Technology: Oxford, UK, 1995.

72. He, F.; Gilron, J.; Lee, H.; Song, L.; Sirkar, K.K. Potential for scaling by sparingly soluble salts in crossflow demd. J. Membr. Sci. 2008, 311, 68-80.

73. He, F.; Sirkar, K.K.; Gilron, J. Effects of antiscalants to mitigate membrane scaling by direct contact membrane distillation. J. Membr. Sci. 2009, 345, 53-58.

74. He, F.; Sirkar, K.K.; Gilron, J. Studies on scaling of membranes in desalination by direct contact membrane distillation: $\mathrm{CaCO}_{3}$ and mixed $\mathrm{CaCO}_{3} / \mathrm{CaSO}_{4}$ systems. Chem. Eng. Sci. 2009, 64, $1844-1859$.

75. Dow, N.; Zhang, J.; Duke, M.; Li, J.; Gray, S.R.; Ostarcervic, E. Membrane Distillation of Brine Wastes; CRC for Water Quality and Treatment: Adelaide, Australia, 2008.

76. Gryta, M. Concentration of nacl solution by membrane distillation integrated with crystallization. Sep. Sci. Technol. 2002, 37, 3535-3558.

77. Franken, A.C.M.; Nolten, J.A.M.; Mulder, M.H.V.; Bargeman, D.; Smolders, C.A. Wetting criteria for the applicability of membrane distillation. J. Membr. Sci. 1987, 33, 315-328.

78. Qtaishat, M.; Matsuura, T.; Kruczek, B.; Khayet, M. Heat and mass transfer analysis in direct contact membrane distillation. Desalination 2008, 219, 272-292. 
79. Schofield, R.W.; Fane, A.G.; Fell, C.J.D. Gas and vapour transport through microporous membranes. II. Membrane distillation. J. Membr. Sci. 1990, 53, 173-185.

80. Gryta, M.; Tomaszewska, M. Heat transport in the membrane distillation process. J. Membr. Sci. 1998, 144, 211-222.

81. Guijt, C.M.; Meindersma, G.W.; Reith, T.; de Haan, A.B. Air gap membrane distillation: 1. Modelling and mass transport properties for hollow fiber membranes. Sep. Purif. Technol. 2005, 43, 233-244.

82. Guijt, C.M.; Meindersma, G.W.; Reith, T.; de Haan, A.B. Air gap membrane distillation: 2. Model validation and hollow fiber module performance analysis. Sep. Purif. Technol. 2005, 43, 245-255.

83. Ding, Z.; Ma, R.; Fane, A.G. A new model for mass transfer in direct contact membrane distillation. Desalination 2003, 151, 217-227.

84. Kast, W.; Hohenthanner, C.R. Mass transfer within the gas-phase of porous media. Int. J. Heat Mass Transf. 2000, 43, 807-823.

85. Kuhn, H.; Forstering, H.-D. Principles of Physical Chemistry; Wiley: New York, NY, USA, 2000.

86. Albert, R.A.; Silbey, R.J. Physical Chemistry, 2nd ed.; Wiley: New York, NY, USA, 1997.

87. Cussler, E.L. Diffusion: Mass transfer in fluid system, 2nd ed.; Cambridge University Press: New York, NY, USA, 1997.

88. Schofield, R.W.; Fane, A.G.; Fell, C.J.D. Gas and vapour transport through microporous membranes. I. Knudsen-poiseuille transition. J. Membr. Sci. 1990, 53, 159-171.

89. Mason, E.A.; Malinauskas, A.P. Gas Transport in Porous Media: The Dusty-Gas Model; Elsevier: Amsterdam, the Netherlands, 1983.

90. Fernandez-Pineda, C.; Izquierdo-Gil, M.A.; Garcia-Payo, M.C. Gas permeation and direct contact membrane distillation experiments and their analysis using different models. J. Membr. Sci. 2002, 198, 33-49.

91. Mason, E.A.; Malinauskas, A.P.; Evans, R.B. Flow and diffusion of gases in porous media. J. Chem. Phys. 1967, 46, 3199-3216.

92. Phattaranawik, J.; Jiraratananon, R.; Fane, A.G.; Halim, C. Mass flux enhancement using spacer filled channels in direct contact membrane distillation. J. Membr. Sci. 2001, 187, 193-201.

93. Martinez-Diez, L.; Vazquez-Gonzalez, M.I.; Florido-Diaz, F.J. Study of membrane distillation using channel spacers. J. Membr. Sci. 1998, 144, 45-56.

94. Yao, Y. Principle of Chemical Engineering, 1st ed.; Tianjin Science Technology Press: Tianjin, China, 1992; p. 225.

95. Towler, G.; Sinnott, R.K. Chemical Engineering Design: Principles, Practice and Economics of Plant and Process Design; Elsevier/Butterworth-Heinemann: Burlington, MA, USA, 2007.

96. Da Costa, A.R.; Fane, A.G.; Wiley, D.E. Spacer characterization and pressure drop modelling in spacer-filled channels for ultrafiltration. J. Membr. Sci. 1994, 87, 79-98.

97. Schwinge, J.; Wiley, D.E.; Fane, A.G.; Guenther, R. Characterization of a zigzag spacer for ultrafiltration. J. Membr. Sci. 2000, 172, 19-31. 
98. Phattaranawik, J.; Jiraratananon, R.; Fane, A.G. Effects of net-type spacers on heat and mass transfer in direct contact membrane distillation and comparison with ultrafiltration studies. J. Membr. Sci. 2003, 217, 193-206.

99. Da Costa, A.R.; Fane, A.G.; Fell, C.J.D.; Franken, A.C.M. Optimal channel spacer design for ultrafiltration. J. Membr. Sci. 1991, 62, 275-291.

100. Schock, G.; Miquel, A. Mass transfer and pressure loss in spiral wound modules. Desalination 1987, 64, 339-352.

101. He, K.; Hwang, H.J.; Woo, M.W.; Moon, I.S. Production of drinking water from saline water by direct contact membrane distillation (DCMD). J. Ind. Eng. Chem. 2011, 17, 41-48.

102. Phattaranawik, J.; Jiraratananon, R.; Fane, A.G. Heat transport and membrane distillation coefficients in direct contact membrane distillation. J. Membr. Sci. 2003, 212, 177-193.

103. Suárez, F.; Tyler, S.W.; Childress, A.E. A theoretical study of a direct contact membrane distillation system coupled to a salt-gradient solar pond for terminal lakes reclamation. Water Res. 2010, 44, 4601-4615.

104. Dow, N.; Duke, M.; Zhang, J.; O’Rielly, T.; Li, J.-D.; Gray, S.; Ostarcevic, E.; Atherton, P. Demonstration of solar driven membrane distillation in remote victoria. In Australian Water Association, Ozwater10, Brisbane, Queensland, Australia, 8-10 March, 2010.

105. Gore, D.W. Gore-tex membrane distillation. In Proceedings of 10th Annual Conference Water, Honolulu, HI, USA, 25-29 July, 1982; pp. 25-29.

106. Kjellander, N. Design and field tests of a membrane distillation system for seawater desalination. Desalination 1987, 61, 237-243.

107. Godino, M.P.; Peña, L.; Rincón, C.; Mengual, J.I. Water production from brines by membrane distillation. Desalination 1997, 108, 91-97.

108. Banat, F.A.; Simandl, J. Desalination by membrane distillation: A parametric study. Sep. Sci. Technol. 1998, 33, 201-226.

109. Macedonio, F.; Curcio, E.; Drioli, E. Integrated membrane systems for seawater desalination: Energetic and exergetic analysis, economic evaluation, experimental study. Desalination 2007, 203, 260-276.

110. Fane, A.G. Solar Heated Membrane Distillation; Energy Research and Development Corporation, University of New South: Canberra, Australia, 1992.

111. Banat, F.; Jumah, R.; Garaibeh, M. Exploitation of solar energy collected by solar stills for desalination by membrane distillation. Renew. Energy 2002, 25, 293-305.

112. Drioli, E.; Laganà, F.; Criscuoli, A.; Barbieri, G. Integrated membrane operations in desalination processes. Desalination 1999, 122, 141-145.

113. Zolotarev, P.P.; Ugrozov, V.V.; Volkina, I.B.; Nikulin, V.M. Treatment of waste water for removing heavy metals by membrane distillation. J. Hazard. Mater. 1994, 37, 77-82.

114. Tomaszewska, M.; Gryta, M.; Morawski, A.W. Recovery of hydrochloric acid from metal pickling solutions by membrane distillation. Sep. Purif. Technol. 2001, 22-23, 591-600.

115. Tomaszewska, M. Concentration of the extraction fluid from sulfuric acid treatment of phosphogypsum by membrane distillation. J. Membr. Sci. 1993, 78, 277-282. 
116. Zakrzewska-Trznadel, G.; Harasimowicz, M.; Chmielewski, A.G. Concentration of radioactive components in liquid low-level radioactive waste by membrane distillation. J. Membr. Sci. 1999, 163, 257-264.

117. Banat, F.A.; Simandl, J. Removal of benzene traces from contaminated water by vacuum membrane distillation. Chem. Eng. Sci. 1996, 51, 1257-1265.

118. Semmens, M.J.; Qin, R.; Zander, A. Using a microporous hollow-fiber membrane to separate vocs from water. J. Am. Water Works Assoc. 1989, 81, 162-167.

119. Lagana, F.; Barbieri, G.; Drioli, E. Direct contact membrane distillation: Modelling and concentration experiments. J. Membr. Sci. 2000, 166, 1-11.

120. Nene, S.; Kaur, S.; Sumod, K.; Joshi, B.; Raghavarao, K.S.M.S. Membrane distillation for the concentration of raw cane-sugar syrup and membrane clarified sugarcane juice. Desalination 2002, 147, 157-160.

121. Sakai, K.; Koyano, T.; Muroi, T.; Tamura, M. Effects of temperature and concentration polarization on water vapour permeability for blood in membrane distillation. Chem. Eng. J. 1988, 38, B33-B39.

122. Sakai, K.; Muroi, T.; Ozawa, K.; Takesawa, S.; Tamura, M.; Nakane, T. Extraction of solute-free water from blood by membrane distillation. ASAIO J. 1986, 32, 397-400.

123. Capuano, A.; Memoli, B.; Andreucci, V.E.; Criscuoli, A.; Drioli, E. Membrane distillation of human plasma ultrafiltrate and its theoretical applications to haemodialysis techniques. Int. J. Artif. Organs 2000, 23, 415-422.

124. Gryta, M.; Morawski, A.W.; Tomaszewska, M. Ethanol production in membrane distillation bioreactor. Catal. Today 2000, 56, 159-165.

125. Bodell, B.R. Distillation of Saline Water Using Silicone Rubber Membrane. U.S. Patent 3,361,645, 2 January 1968.

126. Çakmakce, M.; Kayaalp, N.; Koyuncu, I. Desalination of produced water from oil production fields by membrane processes. Desalination 2008, 222, 176-186.

127. Gryta, M. Influence of polypropylene membrane surface porosity on the performance of membrane distillation process. J. Membr. Sci. 2007, 287, 67-78.

128. Perego, C.; Bagatin, R.; Tagliabue, M.; Vignola, R. Zeolites and related mesoporous materials for multi-talented environmental solutions. Microporous Mesoporous Mater. 2013, 166, 37-49.

129. Hausmann, A.; Sanciolo, P.; Vasiljevic, T.; Ponnampalam, E.; Quispe-Chavez, N.; Weeks, M.; Duke, M. Direct contact membrane distillation of dairy process streams. Membranes 2011, 1 , 48-58.

130. Koschikowski, J.; Wieghaus, M.; Rommel, M.; Ortin, V.S.; Suarez, B.P.; Betancort Rodríguez, J.R. Experimental investigations on solar driven stand-alone membrane distillation systems for remote areas. Desalination 2009, 248, 125-131.

131. Jansen, A.; Hanemaaijer, J.H.; Assink, J.W.; Sonsbeek, E.V.; Dotremont, C.; Medevoort, J.V. Pilot plants prove feasibility of a new desalination technique. Asian Water 2010, 26, 22-26.

132. Nijskens, P.; Cools, B.; Kregersman, B. Seawater desalination with memstill technology-A sustainable solution for the industry. In Proceedings of International Workshop on Membrane Distillation and Related Technologies, Ravello, Italy, 9-12 October 2011; pp. 83-85. 
133. Tarnacki, K.; Meneses, M.; Melin, T.; van Medevoort, J.; Jansen, A. Environmental assessment of desalination processes: Reverse osmosis and memstill ${ }^{\circledR}$. Desalination 2012, 296, 69-80.

134. Walton, J.; Lu, H.; Turner, C.; Solis, S.; Hein, H. Solar and Waste Heat Desalination by Membrane Distillation; Desalination and Water Purification Research and Development Program Report No. 81; Bureau of Reclamation: Denver, CO, USA, 2004.

135. Lu, H.; Walton, J.C.; Swift, A.H.P. Desalination coupled with salinity-gradient solar ponds. Desalination 2001, 136, 13-23.

136. Blanco Gálvez, J.; García-Rodríguez, L.; Martín-Mateos, I. Seawater desalination by an innovative solar-powered membrane distillation system: The medesol project. Desalination 2009, 246, 567-576.

137. Guillén-Burrieza, E.; Blanco, J.; Zaragoza, G.; Alarcón, D.-C.; Palenzuela, P.; Ibarra, M.; Gernjak, W. Experimental analysis of an air gap membrane distillation solar desalination pilot system. J. Membr. Sci. 2011, 379, 386-396.

138. Kullab, A.; Martin, A. Membrane distillation and applications for water purification in thermal cogeneration plants. Sep. Purif. Technol. 2011, 76, 231-237.

139. Martin, A.R. In air gap membrane distillation and applications in water purification and desalination. In Proceedings of International Workshop on Membrane Distillation and Related Technologies, Ravello, Italy, 9-12 October, 2011; pp. 67-68.

140. Heinzl, W.; Büttner, S.; Lange, G. Industrialized modules for MED desalination with polymer surfaces. Desalin. Water Treat. 2012, 42, 177-180.

141. Memsys-NTU partnership aims to enhance water desalination technology. Membr. Technol. 2011, doi:10.1016/S0958-2118(11)70042-8.

142. Cipollina, A.; di Sparti, M.G.; Tamburini, A.; Micale, G. Development of a membrane distillation module for solar energy seawater desalination. Chem. Eng. Res. Des. 2012, 90, 2101-2121.

143. Martinetti, C.R.; Childress, A.E.; Cath, T.Y. High recovery of concentrated ro brines using forward osmosis and membrane distillation. J. Membr. Sci. 2009, 331, 31-39.

144. Karakulski, K.; Gryta, M. Water demineralisation by NF/MD integrated processes. Desalination 2005, 177, 109-119.

145. Cath, T.Y.; Childress, A.E.; Martinetti, C.R. Combined Membrane-Distillation-Forward-Osmosis Systems and Methods of Use. U.S. Patent 8,029,671, 4 October 2011.

146. Wang, K.Y.; Teoh, M.M.; Nugroho, A.; Chung, T.-S. Integrated forward osmosis-membrane distillation (FO-MD) hybrid system for the concentration of protein solutions. Chem. Eng. Sci. 2011, 66, 2421-2430.

147. Cath, T.Y.; Adams, D.; Childress, A.E. Membrane contactor processes for wastewater reclamation in space: II. Combined direct osmosis, osmotic distillation, and membrane distillation for treatment of metabolic wastewater. J. Membr. Sci. 2005, 257, 111-119.

148. Turek, M.; Dydo, P. Hybrid membrane-thermal versus simple membrane systems. Desalination 2003, 157, 51-56.

149. Tun, C.M.; Fane, A.G.; Matheickal, J.T.; Sheikholeslami, R. Membrane distillation crystallization of concentrated salts-Flux and crystal formation. J. Membr. Sci. 2005, 257, 144-155. 
150. Ji, X.; Curcio, E.; Al Obaidani, S.; Di Profio, G.; Fontananova, E.; Drioli, E. Membrane distillation-crystallization of seawater reverse osmosis brines. Sep. Purif. Technol. 2010, 71, 76-82.

151. Gryta, M. Direct contact membrane distillation with crystallization applied to nacl solutions. Chem. Pap. 2002, 56, 14-19.

152. Creusen, R.; van Medevoort, J.; Roelands, M.; Renesse, V.; van Duivenbode, A. Approach for a combined membrane distillation-crystallization (MDC) concept. In Proceedings of International Workshop on Membrane Distillation and Related Technologies, Ravello, Italy, 9-12 October 2011; pp. 121-124.

153. Caridi, A.; Profio, G.D.; Curcio, E.; Drioli, E. Carbamazepine-saccharin cocrystals formulation from solvent mixtures by means of membranecrystallization technique. In Proceedings of International Workshop on Membrane Distillation and Related Technologies, Ravelo, Italy, 9-12 October 2011; pp. 131-134.

154. Guillen-Burrieza, E.; Zaragoza, G.; Miralles-Cuevas, S.; Blanco, J. Experimental evaluation of two pilot-scale membrane distillation modules used for solar desalination. J. Membr. Sci. 2012, 409, 264-275.

155. Hausmann, A.; Sanciolo, P.; Vasiljevic, T.; Weeks, M.; Duke, M. Membrane distillation in the dairy industry: Process integration and membrane performance. In Proceedings of International Workshop on Membrane Distillation and Related Technologies, Ravello, Italy, 9-12 October 2011; pp. 93-96.

156. Hausmann, A.; Sanciolo, P.; Vasiljevic, T.; Weeks, M.; Duke, M. Integration of membrane distillation into heat paths of industrial processes. Chem. Eng. J. 2012, 211-212, 378-387.

157. Yu, H.; Yang, X.; Wang, R.; Fane, A.G. Analysis of heat and mass transfer by CFD for performance enhancement in direct contact membrane distillation. J. Membr. Sci. 2012, 405-406, $38-47$.

158. Susanto, H. Towards practical implementations of membrane distillation. Chem. Eng. Process. Process Intensif. 2011, 50, 139-150.

159. Qtaishat, M.R.; Banat, F. Desalination by solar powered membrane distillation systems. Desalination 2013, 308, 186-197.

160. Guillen, E.; Blanco, J.; Alarcón, D.; Zaragoza, G.; Palenzuela, P.; Ibarra, M. Comparative evaluation of two membrane distillation modules. Desalin. Water Treat. 2011, 31, 226-234.

161. Saffarini, R.B.; Summers, E.K.; Arafat, H.A.; Lienhard, V.J.H. Economic evaluation of stand-alone solar powered membrane distillation systems. Desalination 2012, 299, 55-62.

162. Koschikowski, J.; Wieghaus, M.; Rommel, M. Solar thermal-driven desalination plants based on membrane distillation. Desalination 2003, 156, 295-304.

163. Raluy, R.G.; Schwantes, R.; Subiela, V.J.; Peñate, B.; Melián, G.; Betancort, J.R. Operational experience of a solar membrane distillation demonstration plant in pozo izquierdo-gran canaria island (spain). Desalination 2012, 290, 1-13.

164. Rommel, M.; Koschikowsly, J.; Wieghaus, M. Solar driven desalination systems based on membrane distillation. In Solar Desalination for the 21st Century; Springer: Dordrecht, the Netherlands, 2007; pp. 247-257. 
165. Banat, F.; Jwaied, N. Autonomous membrane distillation pilot plant unit driven solar energy: Experiences and lessons learned. Int. J. Sustain. Water Environ. Syst. 2010, 1, 21-24.

166. Palenzuela, P.; Zaragoza, G.; Padilla, D.; Guillen, E.; Ibarra, M.; Blanco, J. Assessment of different configurations for combined parabolic-trough (PT) solar power and desalination plants in arid regions. Energy 2011, 36, 4950-4958.

167. Deng, S. Solar Desalination of Brackish Water Using Membrane Distillation Process; WRRI Technical Completion Report No. 342; New Mexico Water Resources Research Institute: Las Cruces, NM, USA, 2008; pp. 1-31.

168. Hogan, P.A.; Sudjito; Fane, A.G.; Morrison, G.L. Desalination by solar heated membrane distillation. Desalination 1991, 81, 81-90.

169. Thomas, K. Overview of Village Scale, Renewable Energy Powered Desalination; National Renewable Energy Laboratory: Golden, CO, USA, 1997; pp. 1-31.

170. Rommel, M.; Wieghaus, M.; Koschikowski, J. Solar powered desalination: An autonomous water supply. Desalination 2008, 3, 22-24.

171. Wang, X.; Zhang, L.; Yang, H.; Chen, H. Feasibility research of potable water production via solar-heated hollow fiber membrane distillation system. Desalination 2009, 247, 403-411.

172. Galveza, J.; Garcia-Rodriguez, L.; Martin-Mateos, I. Seawater desalination by an innovative solar-powered membrane distillation system. Renew. Energy 2009, 25, 293-305.

173. Alatiqi, I.; Ettouney, H.; El-Dessouky, H. Process control in water desalination industry: An overview. Desalination 1999, 126, 15-32.

174. Banat, F.; Jwaied, N.; Rommel, M.; Koschikowski, J.; Wieghaus, M. Performance evaluation of the "large smades" autonomous desalination solar-driven membrane distillation plant in aqaba, jordan. Desalination 2007, 217, 17-28.

175. Bouguecha, S.; Dhahni, M. Fluidised bed crystallizer and air gap membrane distillation as a solution to geothermal water desalination. Desalination 2002, 152, 237-244.

176. El Amali, A.; Bouguecha, S.; Maalej, M. Experimental study of air gap and direct contact membrane distillation configurations: Application to geothermal and seawater desalination. Desalination 2004, 168, 357.

177. Jaafar, S.; Sarbatly, R. Geothermal water desalination by using nanofiber membrane. In Proceedings of International Conference on Chemical, Environmental and Biological Sciences, Penang, Malasya, 11-12 February 2012.

178. Singh, D.; Sirkar, K.K. Desalination of brine and produced water by direct contact membrane distillation at high temperatures and pressures. J. Membr. Sci. 2012, 389, 380-388.

179. Wang, P.; Chung, T.S. A conceptual demonstration of freeze desalination-membrane distillation (fd-md) hybrid desalination process utilizing liquefied natural gas (lng) cold energy. Water Res. 2012, 46, 4037-4052.

180. Zakrzewska-Trznadel, G.; Harasimowicz, M.; Chmielewski, A.G. Membrane processes in nuclear technology-application for liquid radioactive waste treatment. Sep. Purif. Technol. 2001, 22-23, 617-625.

181. Zakrzewska-Trznadel, G.; Chmielewski, A.G.; Miljević, N.R. Separation of protium/deuterium and oxygen-16/oxygen-18 by membrane distillation. J. Membr. Sci. 1996, 113, 337-342. 
182. Khayet, M.; Godino, M.P.; Mengual, J.I. Possibility of nuclear desalination through various membrane distillation configurations: A comparative study. Int. J. Nucl. Desalin. 2003, 1, 30-46.

183. Khayet, M.; Mengual, J.I.; Zakrzewska-Trznadel, G. Direct contact membrane distillation for nuclear desalination, part II: Experiments with radioactive solutions. Int. J. Nucl. Desalin. 2006, 2, 56-73.

184. Ambashta, R.D.; Sillanpaa, M.E. Membrane purification in radioactive waste management: A short review. J. Environ. Radioact. 2012, 105, 76-84.

185. Criscuoli, A.; Zhong, J.; Figoli, A.; Carnevale, M.C.; Huang, R.; Drioli, E. Treatment of dye solutions by vacuum membrane distillation. Water Res. 2008, 42, 5031-5037.

186. Van der Bruggen, B.; Curcio, E.; Drioli, E. Process intensification in the textile industry: The role of membrane technology. J. Environ. Manag. 2004, 73, 267-274.

187. Grzechulska-Damszel, J.; Tomazewska, M.; Morawski, A.W. Integration of photocatalysis with membrane processes for purification of water contaminated with organic dyes. Desalination 2009, 241, 118-126.

188. Banat, F.; Al-Asheh, S.; Qtaishat, M. Treatment of waters colored with methylene blue dye by vacuum membrane distillation. Desalination 2005, 174, 87-96.

189. Mariah, L.; Buckley, C.A.; Brouckaert, C.J.; Curcio, E.; Drioli, E.; Jaganyi, D.; Ramjugernath, D. Membrane distillation of concentrated brines-Role of water activities in the evaluation of driving force. J. Membr. Sci. 2006, 280, 937-947.

190. Curcio, E.; Criscuoli, A.; Drioli, A. Membrane crystallizers. Ind. Eng. Chem. Resour. 2001, 40, 2679-2684.

191. Drioli, E.; Curcio, E.; Criscuoli, A.; Profio, G.D. Integrated system for recovery of $\mathrm{CaCO}_{3}, \mathrm{NaCl}$ and $\mathrm{MgSO}_{4} \cdot 7 \mathrm{H}_{2} \mathrm{O}$ from nanofiltration retentate. J. Membr. Sci. 2004, 239, 27-38.

192. Gryta, M. Calcium sulphate scaling in membrane distillation process. Chem. Pap. 2008, 63, 146-151.

193. Gryta, M. Application of membrane distillation process for tap water purification. Membr. Water Treat. 2010, 1, 1-12.

194. Alkhudhiri, A.; Darwish, N.; Hilal, N. Treatment of high salinity solutions: Application of air gap membrane distillation. Desalination 2012, 287, 55-60.

195. Zeng, L.; Gao, C. The prospective application of membrane distillation in the metallurgical industry. Membr. Technol. 2010, 2010, 6-10.

196. Li, Q.; Zhang, Q.X.; Zhang, G.Q.; Zhou, K.G. Study on direct concentration of waste sulphuric acid from titanium oxide hydrolysis by vacuum membrane distillation. Rare Met. Cem. Carbides 2001, 146, 1-4.

197. Tang, J.J.; Zhou, K.G.; Zhang, Q.X. Study on hydrochloric acid recovery from chloride solutions of rare earth by vacuum membrane distillation. Membr. Sci. Technol. 2002, 22, 38-42.

198. Tang, J.; Zhou, K. Hydrochloric acid recovery from rare earth chloride solutions by continuous vacuum membrane distillation. J. Rare Earths 2005, 23, 117-120.

199. Tang, J.J.; Zhang, W.; Zhou, K.G.; Li, R.X.; Zhang, Q.X. Sulphuric acid recovery from rare earth sulfate solutions by integrated membrane distillation. Membr. Sci. Technol. 2005, 25, 54-60.

200. Adiche, C.; Sundmacher, K. Experimental investigation on a membrane distillation based micro-separator. Chem. Eng. Process. Process Intensif. 2010, 49, 425-434. 
201. Koonaphapdeelert, S.; Tan, X.; Wu, Z.; Li, K. Solvent distillation by ceramic hollow fiber membrane contactors. J. Membr. Sci. 2008, 314, 58-66.

202. Chanachai, A.; Meksup, K.; Jiraratananon, R. Coating of hydrophobic hollow fiber PVDF membrane with chitosan for protection against wetting and flavor loss in osmotic distillation process. Sep. Purif. Technol. 2010, 72, 217-224.

203. Kozák, Á.; Békássy-Molnár, E.; Vatai, G. Production of black-currant juice concentrate by using membrane distillation. Desalination 2009, 241, 309-314.

204. Bandini, S.; Sarti, G.C. Concentration of must through vacuum membrane distillation. Desalination 2002, 149, 253-259.

205. Varming, C.; Andersen, M.L.; Poll, L. Influence of thermal treatment on black currant (ribes nigrum 1.) juice aroma. J. Agric. Food Chem. 2004, 52, 7628-7636.

206. Gunko, S.; Verbych, S.; Bryk, M.; Hilal, N. Concentration of apple juice using direct contact membrane distillation. Desalination 2006, 190, 117-124.

207. Deshmukh, S.K.; Tajane, M.M. Distillation process in fruit juice concentration by membrane surface modification. Int. J. Chem. Biol. Eng. 2010, 3, 147-152.

208. Izquierdo-Gil, M.A.; García-Payo, M.C.; Fernández-Pineda, C. Air gap membrane distillation of sucrose aqueous solutions. J. Membr. Sci. 1999, 155, 291-307.

209. Diban, N.; Voinea, O.C.; Urtiaga, A.; Ortiz, I. Vacuum membrane distillation of the main pear aroma compound: Experimental study and mass transfer modelling. J. Membr. Sci. 2009, 326, 64-75.

210. Christensen, K.; Andresen, R.; Tandskov, I.; Norddahl, B.; du Preez, J.H. Using direct contact membrane distillation for whey protein concentration. Desalination 2006, 200, 523-525.

211. Pouliot, Y. Membrane processes in dairy technology_From a simple idea to worldwide panacea. Int. Dairy J. 2008, 18, 735-740.

212. Sarti, G.C.; Gostoli, C.; Bandini, S. Extraction of organic-components from aqueous streams by vacuum membrane distillation. Presented at International Conference on Engineering of Membrane Processes, Garmisch Partenkir, Germany, 13-15 May 1992; pp. 21-33.

213. Izquierdo-Gil, M.A.; Jonsson, G. Factors affecting flux and ethanol separation performance in vacuum membrane distillation (VMD). J. Membr. Sci. 2003, 214, 113-130.

214. Dumée, L.; Sears, K.; Schütz, J.; Finn, N.; Duke, M.; Gray, S. Carbon nanotube based composite membranes for water desalination by membrane distillation. Desalin. Water Treat. 2010, 17, $72-79$.

215. Criscuoli, A.; Drioli, E.; Capuano, A.; Memoli, B.; Andreucci, V.E. Human plasma ultrafiltrate purification by membrane distillation: Process optimisation and evaluation of its possible application on-line. Desalination 2002, 147, 147-148.

216. Gryta, M.; Tomaszewska, M.; Karakulski, K. Wastewater treatment by membrane distillation. Desalination 2006, 198, 67-73.

217. Babu, B.R.; Rastogi, N.K.; Raghavarao, K.S.M.S. Mass transfer in osmotic membrane distillation of phycocyanin colorant and sweet-lime juice. J. Membr. Sci. 2006, 272, 58-69. 
218. Cabassud, C.; Wirth, D. Membrane distillation for water desalination: How to chose an appropriate membrane? In Proceedings of Conference on Desalination and the Environment-Fresh Water for All, Malta, Italy, 4-8 May 2003; Elsevier Science B.V.: Malta, Italy, 2003; pp. 307-314.

219. Wirth, D.; Cabassud, C. Water desalination using membrane distillation: Comparison between inside/out and outside/in permeation. Desalination 2002, 147, 139-145.

220. Hernández, A.; Calvo, J.I.; Prádanos, P.; Tejerina, F. Pore size distributions in microporous membranes. A critical analysis of the bubble point extended method. J. Membr. Sci. 1996, 112, $1-12$.

221. Martínez, L.; Florido-Díaz, F.J.; Hernández, A.; Prádanos, P. Characterisation of three hydrophobic porous membranes used in membrane distillation: Modelling and evaluation of their water vapour permeabilities. J. Membr. Sci. 2002, 203, 15-27.

222. El-Bourawi, M.S.; Ding, Z.; Ma, R.; Khayet, M. A framework for better understanding membrane distillation separation process. J. Membr. Sci. 2006, 285, 4-29.

223. Burgoyne, A.; Vahdati, M.M., Direct contact membrane distillation. Sep. Sci. Technol. 2000, 35, $1257-1284$.

224. Garcia-Payo, M.C.; Izquierdo-Gil, M.A.; Fernández-Pineda, C. Wetting study of hydrophobic membranes via liquid entry pressure measurements with aqueous alcohol solutions. J. Colloid Interface Sci. 2000, 230, 420-431.

225. Kim, B.-S.; Harriott, P. Critical entry pressure for liquids in hydrophobic membranes. J. Colloid Interface Sci. 1987, 115, 1-8.

226. Alklaibi, A.M.; Lior, N. Heat and mass transfer resistance analysis of membrane distillation. J. Membr. Sci. 2006, 282, 362-369.

227. Rodríguez-Maroto, J.M.; Martínez, L. Bulk and measured temperatures in direct contact membrane distillation. J. Membr. Sci. 2005, 250, 141-149.

228. Zhang, H.; Lamb, R.; Lewis, J. Engineering nanoscale roughness on hydrophobic surface-Preliminary assessment of fouling behaviour. Sci. Technol. Adv. Mater. 2005, 6, 236-239.

229. Ramón-Torregrosa, P.J.; Rodríguez-Valverde, M.A.; Amirfazli, A.; Cabrerizo-Vílchez, M.A. Factors affecting the measurement of roughness factor of surfaces and its implications for wetting studies. Colloids Surf. A Physicochem. Eng. Asp. 2008, 323, 83-93.

230. Netz, R.R.; Andelman, D. Roughness-induced wetting. Phys. Rev. E 1997, 55, 687-700.

231. Quéré, D. Wetting and roughness. Annu. Rev. Mater. Res. 2008, 38, 71-99.

232. Callies, M.; Chen, Y.; Marty, F.; Pépin, A.; Quéré, D. Microfabricated textured surfaces for super-hydrophobicity investigations. Microelectron. Eng. 2005, 78-79, 100-105.

233. Quéré, D. Rough ideas on wetting. Phys. A Stat. Mech. Appl. 2002, 313, 32-46.

234. Boussu, K.; van der Bruggen, B.; Volodin, A.; Snauwaert, J.; van Haesendonck, C.; Vandecasteele, C. Roughness and hydrophobicity studies of nanofiltration membranes using different modes of afm. J. Colloid Interface Sci. 2005, 286, 632-638. 
235. Ladavos, A.K.; Katsoulidis, A.P.; Iosifidis, A.; Triantafyllidis, K.S.; Pinnavaia, T.J.; Pomonis, P.J. The bet equation, the inflection points of $\mathrm{N}_{2}$ adsorption isotherms and the estimation of specific surface area of porous solids. Microporous Mesoporous Mater. 2012, 151, $126-133$.

236. Arnault, J.C.; Knoll, A.; Smigiel, E.; Cornet, A. Roughness fractal approach of oxidised surfaces by afm and diffuse X-ray reflectometry measurements. Appl. Surf. Sci. 2001, 171, 189-196.

237. Persson, U. In-process measurement of surface roughness using light scattering. Wear 1998, 215, 54-58.

238. Hashino, M.; Katagiri, T.; Kubota, N.; Ohmukai, Y.; Maruyama, T.; Matsuyama, H. Effect of surface roughness of hollow fiber membranes with gear-shaped structure on membrane fouling by sodium alginate. J. Membr. Sci. 2011, 366, 389-397.

239. Zhang, S.; Hodgson, P.D.; Duncan, J.L.; Cardew-Hall, M.J.; Kalyanasundaram, S. Effect of membrane stress on surface roughness changes in sheet forming. Wear 2002, 253, 610-617.

240. Zhong, Z.; Li, D.; Zhang, B.; Xing, W. Membrane surface roughness characterization and its influence on ultrafine particle adhesion. Sep. Purif. Technol. 2012, 90, 140-146.

241. Cot, L.; Ayral, A.; Durand, J.; Guizard, C.; Hovnanian, N.; Julbe, A.; Larbot, A. Inorganic membranes and solid state sciences. Solid State Sci. 2000, 2, 313-334.

242. Khemakhem, S.; Amar, R.B. Modification of tunisian clay membrane surface by silane grafting: Application for desalination with air gap membrane distillation process. Colloids Surf. A Physicochem. Eng. Asp. 2011, 387, 79-85.

243. Koonaphapdeelert, S.; Li, K. Preparation and characterization of hydrophobic ceramic hollow fiber membrane. J. Membr. Sci. 2007, 291, 70-76.

244. Cerneaux, S.; Struzynska, I.; Kujawski, W.M.; Persin, M.; Larbot, A. Comparison of various membrane distillation methods for desalination using hydrophobic ceramic membranes. $J$. Membr. Sci. 2009, 337, 55-60.

245. Gazagnes, L.; Cerneaux, S.; Persin, M.; Prouzet, E.; Larbot, A. Desalination of sodium chloride solutions and seawater with hydrophobic ceramic membranes. Desalination 2007, 217, 260-266.

246. Hendren, Z.D.; Brant, J.; Wiesner, M.R. Surface modification of nanostructured ceramic membranes for direct contact membrane distillation. J. Membr. Sci. 2009, 331, 1-10.

247. Krajewski, S.R.; Kujawski, W.; Bukowska, M.; Picard, C.; Larbot, A. Application of fluoroalkylsilanes (FAS) grafted ceramic membranes in membrane distillation process of nacl solutions. J. Membr. Sci. 2006, 281, 253-259.

248. Larbot, A.; Gazagnes, L.; Krajewski, S.; Bukowska, M.; Wojciech, K. Water desalination using ceramic membrane distillation. Desalination 2004, 168, 367-372.

249. Duke, M.C.; O’Brien-Abraham, J.; Milne, N.; Zhu, B.; Lin, J.Y.S.; Diniz da Costa, J.C. Seawater desalination performance of MFI type membranes made by secondary growth. Sep. Purif. Technol. 2009, 68, 343-350.

250. Duke, M.C.; Mee, S.; Diniz da Costa, J.C. Performance of porous inorganic membranes in non-osmotic desalination. Water Res. 2007, 41, 3998-4004.

251. Wijaya, S.; Duke, M.C.; Diniz da Costa, J.C. Carbonised template silica membranes for desalination. Desalination 2009, 236, 291-298. 
252. Drobek, M.; Yacou, C.; Motuzas, J.; Julbe, A.; Ding, L.; Diniz da Costa, J.C. Long term pervaporation desalination of tubular mfi zeolite membranes. J. Membr. Sci. 2012, 415-416, 816-823.

253. Sears, K.; Dumée, L.; Schütz, J.; She, M.; Huynh, C.; Hawkins, S.; Duke, M.; Gray, S. Recent developments in carbon nanotube membranes for water purification and gas separation. Materials 2010, 3, 127-149.

254. Dumée, L.; Sears, K.; Schütz, J.; Finn, N.; Duke, M.; Gray, S. Carbon nanotube based composite membranes for water desalination by membrane distillation. Desalin. Water Treat. 2010, 17, $72-79$.

255. Dumée, L.; Germain, V.; Sears, K.; Schütz, J.; Finn, N.; Duke, M.; Cerneaux, S.; Cornu, D.; Gray, S. Enhanced durability and hydrophobicity of carbon nanotube bucky paper membranes in membrane distillation. J. Membr. Sci. 2011, 376, 241-246.

256. Dumée, L.; Campbell, J.L.; Sears, K.; Schütz, J.; Finn, N.; Duke, M.; Gray, S. The impact of hydrophobic coating on the performance of carbon nanotube bucky-paper membranes in membrane distillation. Desalination 2011, 283, 64-67.

257. Kong, Y.; Lin, X.; Wu, Y.; Chen, J.; Xu, J. Plasma polymerization of octafluorocyclobutane and hydrophobic microporous composite membranes for membrane distillation. J. Appl. Polym. Sci. 1992, 46, 191-199.

258. García-Payo, M.C.; Essalhi, M.; Khayet, M. Preparation and characterization of PVDF-HFP copolymer hollow fiber membranes for membrane distillation. Desalination 2009, 245, 469-473.

259. Peng, P.; Fane, A.G.; Li, X.D. Desalination by membrane distillation adopting a hydrophilic membrane. Desalination 2005, 173, 45-54.

260. Alkhudhiri, A.; Darwish, N.; Hilal, N. Membrane distillation: A comprehensive review. Desalination 2012, 287, 2-18.

261. Corporation, P. Emflon ${ }^{\circledR}$ PTFE Membrane. Avaliable online: http://www.pall.com/main/ Laboratory/Literature-Library-Details.page?id=28704 (acessed on 14 January 2013).

262. Tension, S. Solid surface energy data (SFE) for common polymers. Avaliable online: http://www.surface-tension.de/solid-surface-energy.htm (acessed on 14 January 2013).

263. Qtaishat, M.; Khayet, M.; Matsuura, T. Novel porous composite hydrophobic/hydrophilic polysulfone membranes for desalination by direct contact membrane distillation. J. Membr. Sci. 2009, 341, 139-148.

264. Qtaishat, M.; Rana, D.; Khayet, M.; Matsuura, T. Preparation and characterization of novel hydrophobic/hydrophilic polyetherimide composite membranes for desalination by direct contact membrane distillation. J. Membr. Sci. 2009, 327, 264-273.

265. Gryta, M. Fouling in direct contact membrane distillation process. J. Membr. Sci. 2008, 325, 383-394.

266. Edwie, F.; Teoh, M.M.; Chung, T.-S. Effects of additives on dual-layer hydrophobic-hydrophilic pvdf hollow fiber membranes for membrane distillation and continuous performance. Chem. Eng. Sci. 2012, 68, 567-578.

267. Su, M.; Teoh, M.M.; Wang, K.Y.; Su, J.; Chung, T.-S. Effect of inner-layer thermal conductivity on flux enhancement of dual-layer hollow fiber membranes in direct contact membrane distillation. J. Membr. Sci. 2010, 364, 278-289. 
268. Teoh, M.M.; Chung, T.-S.; Yeo, Y.S. Dual-layer pvdf/ptfe composite hollow fibers with a thin macrovoid-free selective layer for water production via membrane distillation. Chem. Eng. J. 2011, 171, 684-691.

269. Wang, P.; Teoh, M.M.; Chung, T.-S. Morphological architecture of dual-layer hollow fiber for membrane distillation with higher desalination performance. Water Res. 2011, 45, 5489-5500.

270. Wei, X.; Zhao, B.; Li, X.-M.; Wang, Z.; He, B.-Q.; He, T.; Jiang, B. CF 4 plasma surface modification of asymmetric hydrophilic polyethersulfone membranes for direct contact membrane distillation. J. Membr. Sci. 2012, 407-408, 164-175.

271. Razmjou, A.; Arifin, E.; Dong, G.; Mansouri, J.; Chen, V. Superhydrophobic modification of $\mathrm{TiO}_{2}$ nanocomposite pvdf membranes for applications in membrane distillation. J. Membr. Sci. 2012, 415-416, 850-863.

272. Teoh, M.M.; Peng, N.; Chung, T.-S.; Koo, L.L. Development of novel multichannel rectangular membranes with grooved outer selective surface for membrane distillation. Ind. Eng. Chem. Res. 2011, 50, 14046-14054.

273. Gethard, K.; Sae-Khow, O.; Mitra, S. Carbon nanotube enhanced membrane distillation for simultaneous generation of pure water and concentrating pharmaceutical waste. Sep. Purif. Technol. 2012, 90, 239-245.

274. Behler, K.; Havel, M.; Gogotsi, Y. New solvent for polyamides and its application to the electrospinning of polyamides 11 and 12. Polymer 2007, 48, 6617-6621.

275. Feng, C.; Khulbe, K.C.; Matsuura, T.; Gopal, R.; Kaur, S.; Ramakrishna, S.; Khayet, M. Production of drinking water from saline water by air-gap membrane distillation using polyvinylidene fluoride nanofiber membrane. J. Membr. Sci. 2008, 311, 1-6.

276. Huang, Z.-M.; Zhang, Y.Z.; Kotaki, M.; Ramakrishna, S. A review on polymer nanofibers by electrospinning and their applications in nanocomposites. Compos. Sci. Technol. 2003, 63, 2223-2253.

277. Peining, Z.; Nair, A.S.; Shengyuan, Y.; Shengjie, P.; Elumalai, N.K.; Ramakrishna, S. Rice grain-shaped $\mathrm{TiO}_{2}-\mathrm{MWCNT}$ composite-A functional material with a novel morphology for dye-sensitized solar cells. J. Photochem. Photobiol. A Chem. 2012, 231, 9-18.

278. Ioannis S, C. Novel nanocomposites and nanoceramics based on polymer nanofibers using electrospinning process-A review. J. Mater. Process. Technol. 2005, 167, 283-293.

279. Yun, K.M.; Suryamas, A.B.; Iskandar, F.; Bao, L.; Niinuma, H.; Okuyama, K. Morphology optimization of polymer nanofiber for applications in aerosol particle filtration. Sep. Purif. Technol. 2010, 75, 340-345.

280. Zhao, Z.; Zheng, J.; Wang, M.; Zhang, H.; Han, C.C. High performance ultrafiltration membrane based on modified chitosan coating and electrospun nanofibrous pvdf scaffolds. J. Membr. Sci. 2012, 394-395, 209-217.

281. Kaur, S.; Barhate, R.; Sundarrajan, S.; Matsuura, T.; Ramakrishna, S. Hot pressing of electrospun membrane composite and its influence on separation performance on thin film composite nanofiltration membrane. Desalination 2011, 279, 201-209. 
282. Prince, J.A.; Singh, G.; Rana, D.; Matsuura, T.; Anbharasi, V.; Shanmugasundaram, T.S. Preparation and characterization of highly hydrophobic poly(vinylidene fluoride)-clay nanocomposite nanofiber membranes (pvdf-clay nnms) for desalination using direct contact membrane distillation. J. Membr. Sci. 2012, 397-398, 80-86.

283. Lai, C.-L.; Liou, R.-M.; Chen, S.-H.; Huang, G.-W.; Lee, K.-R. Preparation and characterization of plasma-modified ptfe membrane and its application in direct contact membrane distillation. Desalination 2011, 267, 184-192.

284. Ge, Z.; Cahill, D.G.; Braun, P.V. Thermal conductance of hydrophilic and hydrophobic interfaces. Phys. Rev. Lett. 2006, 96, 186101:1-186101:4.

285. Martínez-Díez, L.; Vázquez-González, M.I. Temperature and concentration polarization in membrane distillation of aqueous salt solutions. J. Membr. Sci. 1999, 156, 265-273.

286. Beasley, J.K.; Penn, R.E. Hollow fine fiber vs. Flat sheet membranes-A comparison of structures and performance. Desalination 1981, 38, 361-372.

287. International Desalination Association (IDA). Desalting Inventory: Desalination Stabilized on a Higher Level; IDA: Topsfield, MA, USA, 2004; pp. 14-17.

288. International Desalination Association (IDA). Desalination Yearbook 2010-2011; IDA: Topsfield, MA, USA, 2010; pp.1-216.

289. International Desalination Association (IDA). Desalination Yearbook 2011-2012; IDA: Topsfield, MA, USA, 2011; pp. 1-231.

290. Mickley, M. Concentration Management: State-of-the-Science Report; Joint Water Reuse \& Desalination Task Force: Bolder, CO, USA, 2005.

291. Afonso, M.D.; Jaber, J.O.; Mohsen, M.S. Brackish groundwater treatment by reverse osmosis in jordan. Desalination 2004, 164, 157-171.

292. Khawaji, A.D.; Kutubkhanah, I.K.; Wie, J.-M. Advances in seawater desalination technologies. Desalination 2008, 221, 47-69.

293. Gray, S.; Semiat, R.; Duke, M.; Rahardianto, A.; Cohen, Y. Seawater use and desalination technology. In: Treatise on Water Science; Wilderer, P., Ed.; Academic Press: Oxoford, UK, 2011; Volume 4, pp. 73-109.

294. Global Water Intelligence (GWI). Desalination Market 2010: Global Forecast and Analysis; GWI: Oxford, UK, 2010; pp. 1-610.

295. LBG-Guyton Associates. Brackish Groundwater Manual for Texas Region Water Planning Groups; Texas Water Development Board: Austin, TX, USA, 2003; pp. 1-187.

296. Vavra, C.J. Desalination of Oil Field Brine; D.B. Burnett Global Petroleum Research Institute: College Station, TX, USA, 2006; pp. 1-34.

297. NRS Consulting Engineers. Guidance Manual for Brackish Groundwater Desalination in Texas; Texas Water Development Board: Austin, TX, USA, 2008; pp. 1-96.

298. Florida Department of Environmental Protection (FDEP). Desalination in Florida: Technology, Implementation, and Environmental Issues; Division of Water Resources Management, FDEP: Tallahassee, FL, USA, 2010; pp. 1-123.

299. Younos, T. Desalination: Supplementary freswater spplies approaches and challenges. J. Contemp. Water Res. Educ. 2005, 132, 1-2. 
300. Sessions, B.; Shih, W.-Y.; MacHarg, J.; Dundorf, S.; Arrollo, J.A. Optimizing Brackish Water Reverse Osmosis for Affordable Desalination; Carollo Engineers: Boise, ID, USA, 2011; pp. $1-10$.

301. Hernández Leal, L.; Temmink, H.; Zeeman, G.; Buisman, C.J.N. Characterization and anaerobic biodegradability of grey water. Desalination 2011, 270, 111-115.

302. Al-Ruwaih, F.M. Chemistry of groundwater in the dammam aquifer, kuwait. J. Hydrogeol. 1995, 3, 42-55.

303. Macedonio, F.; Drioli, E. Pressure-driven membrane operations and membrane distillation technology integration for water purification. Desalination 2008, 223, 396-409.

304. Jacques, G. and Herron, C. Arab Countries Regional Report WWF5; World Water Forum: Istambul, Turkey, 14-15 March 2009; pp. 1-88

305. Hoang, M.; Bolto, B.; Haskard, C.; Barron, O.; Gray, S.; Leslie, G. Desalination plants: An Australia survey. Desalin. Techn. Featur. 2009, 92-98.

306. Balaban, M. Desalination in maghreb. In Euromed Conference on Desalination Strategies in South Mediterranean Countries; European Desalination Society: The Dead Sea, Jordan, 2008.

307. Jagannathan, N.V.; Mohamed, A.S.; Kremer, A. Water in the Arab World: Management Perspectives and Innovations; World Bank: Washington, DC, USA, 2009.

308. Shea, A.L. Status and challenges for desalination in the united states. In Proceedings of Japan-U.S. Joint Conference On Drinking Water Quality Management and Wastewater Control, Las Vegas, NV, USA, March 2009; pp. 1-31.

309. Pangarkar, B.L.; Sane, M.G.; Guddad, M. Reverse osmosis and membrane distillation for desalination of groundwater: A review. ISRN Mater. Sci. 2011, 2011, 1-9.

310. Adham, S.; Hussain, A.; Matar, L.M.; Dores, R.; Katebah, M.; Janson, A. Evaluation and application of membrane distillation for seawater desalination. In Proceedings of Qatar Foundation Annual Research Forum, Doha, Qatar, 20 November 2011.

311. Stuyfzand, P.J.; Raat, K.J. Benefits and hurdles of using brackish groundwater as a drinking water source in the netherlands. Hydrogeol. J. 2010, 18, 117-130.

312. Salahi, A.; Mohammadi, T.; Rekabdar, F.; Mahdavi, H. Reverse osmosis of refinery oily wastewater effluents. Iran J. Environ. Health Sci. Eng. 2010, 7, 413-422.

313. Mace, R.E.; Nicot, J.P.; Chowdhury, A.H.; Dutton, A.R.; Kalaswad, S. Please Pass the Salt: Using Oil Fields for The Disposal of Concentrate from Desalination Plants; Texas Water Development Board: Austin, TX, USA, 2006; pp. 1-198.

314. Alley, B.; Beebe, A.; Rodgers, J., Jr.; Castle, J.W. Chemical and physical characterization of produced waters from conventional and unconventional fossil fuel resources. Chemosphere 2011, $85,74-82$.

315. Benko, K.L.; Drewes, J.E. Produced water in the western united states: Geographical distribution, occurrence, and composition. Environ. Eng. Sci. 2008, 25, 239-246.

316. National Research Council (NRC). Desalination: A national perspective; The National Academies Press: Washingtong, DC, USA, 2008; pp. 1-316.

317. Clark, C.E.; Veil, J.A. Produced Water Volumes and Management Practices in the United States; Argonne National Laboratory: Argonne, IL, USA, 2009. 
318. Veil, A.V. Water Management Technologies Used by Marcellus Shale Gas Producers; Argonne National Laboratory: Argonne, IL, USA, 2010.

319. Utvik, T.I.R. Chemical characterisation of produced water from four offshore oil production platforms in the north sea. Chemosphere 1999, 39, 2593-2606.

320. Johnson, B.M.; Kanagy, L.E.; Rodgers, J.H.; Castle, J.W. Chemical, physical, and risk characterization of natural gas storage produced waters. Water Air Soil Pollut. 2008, 191, 33-54.

321. Licensable Technologies Home Page. Avaliable online: http:/www.lanl.gov/partnerships/ license/technologies/ (accessed on 14 January 2013).

322. Hayes, T.; Arthur, D. Overview of emerging produced water treatment technologies. In Proceedings of The 11th Annual International Petroleum Environmental Conference, Albuquerque, NM, USA, 12-15 October 2004.

323. Camacho, L.M.; Gude, V.G.; Deng, S. Membrane Distillation for Brackish Water Desalination; Final Report; New Mexico State University-ConocoPhillips: Las Cruces, NM, USA, 2010; pp. 1-86.

324. Yarlagadda, S.; Gude, V.G.; Camacho, L.M.; Pinappu, S.; Deng, S.G. Potable water recovery from as, $\mathrm{u}$, and $\mathrm{f}$ contaminated ground waters by direct contact membrane distillation process. J. Hazard. Mater. 2011, 192, 1388-1394.

325. Dahm, K.G.; Guerra, K.L.; Xu, P.; Drewes, J.E. Composite geochemical database for coalbed methane produced water quality in the rocky mountain region. Environ. Sci. Technol. 2011, 45, 7655-7663.

326. United States Geological Survey (USGS). Water Produced with Coal-Bed Methane; USGS Fact Sheet FS-156-00; USGS: Denver, CO, USA, 2000.

327. Orem, W.H.; Tatu, C.A.; Lerch, H.E.; Rice, C.A.; Bartos, T.T.; Bates, A.L.; Tewalt, S.; Corum, M.D. Organic compounds in produced waters from coalbed natural gas wells in the powder river basin, wyoming, USA. Appl. Geochem. 2007, 22, 2240-2256.

328. Colorado School of Mines. An Integral Framework for Treatment and Management of Produced Water; Colorado School of Mines: Golden, CO, USA, 2009; pp. 1-157.

329. Ali, I.; Morin, S.; Barrington, S.; Whalen, J.; Bonnell, R.; Martinez, J. Surface irrigation of dairy farm effluent, part I: Nutrient and bacterial load. Biosyst. Eng. 2006, 95, 547-556.

330. Luostarinen, S.A.; Rintala, J.A. Anaerobic on-site treatment of black water and dairy parlour wastewater in uasb-septic tanks at low temperatures. Water Res. 2005, 39, 436-448.

331. Reimann, W. Influence of organic matter from waste water on the permeability of membranes. Desalination 1997, 109, 51-55.

332. Reimann, W. Ultrafiltration of agricultural waste waters with organic and inorganic mambranes. Desalination 1997, 109, 263-267.

333. Das, M.; Kumar, A. Effluent characterization and different modes of reuse in agriculture-A model case study. Environ. Sci. Pollut. Res. Int. 2009, 16, 466-473.

334. Botalova, O.; Schwarzbauer, J.; Frauenrath, T.; Dsikowitzky, L. Identification and chemical characterization of specific organic constituents of petrochemical effluents. Water Res. 2009, 43, $3797-3812$. 
335. Andres, C.; Eklund, B.; Gravenfors, E.; Kukulska, Z.; Tarkpea, M. A multivariate biological and chemical characterization of industrial eflluents connected to municipal sewage treatment plants. Environ. Toxicol. Chem. 1998, 17, 228-233.

336. Humbolt State University. What Industries/Products are the Most Water-Intensive within the United States? Research Summary; Humbolt State University: Arcata, CA, 28 October 2009.

337. Dow, N.; Gray, S.; Li, J.-D.; Ostarcevic, E.; Barron, R.; Liubinas, A.; Atherton, P.; Halliwell, D.; Mikel, D. Membrane distillation of industrial wastewater. In Australian Water Association Ozwater 11, Adelaide, Australia, 9-11 May 2011.

338. Srinivasamoorthy, K.; Chidambaram, S.; Sarma, V.S.; Vasanthavigar, M.; Vijayaraghavan, K.; Rajivgandhi, R.; Anandhan, P.; Manivannan, R. Hidrogeochemical characterisation of groundwater in salem distric of tamilnadu, india. Res. J. Environ. Earth Sci. 2009, 1, 22-33.

339. Morikawa, M.; Morrison, J.; Gleick, P. Corporate Reporting on Water: A Review of Eleven Global Industries; Pacific Institute for Studies in Development, Environment, and Security: Oakland, CA, USA, 2007; pp. 1-50.

340. American Membrane Technology Association (AMTA). Membrane desalination costs. In Fact Sheets; AMTA: Stuart, FL, USA, 2007.

341. Arrollo, J.A.; Shirazi, S. Cost of Water Desalination in Texas; Texas Water Development Board: Austin, TX, USA, 2002; pp. 1-7.

342. Kawamura, S.; McGivney, W. Cost Estimating Manual for Water Treatment Facilities; Wiley: Hoboken, NJ, USA, 2008.

343. American Membrane Technology Association (AMTA). Membrane desalination power usage put in perspective. In Fact Sheets; AMTA: Stuart, FL, USA, 2009.

344. Wittholz, M.K.; O'Neill, B.K.; Colby, C.B.; Lewis, D. Estimating the cost of desalination plants using a cost database. Desalination 2008, 229, 10-20.

345. Younos, T. The economics of desalination. J. Contemp. Water Res. Educ. 2005, 132, 39-45.

346. Borsani, R.; Rebagliati, S. Fundamentals and costing of msf desalination plants and comparison with other technologies. Desalination 2005, 182, 29-37.

347. Water Reuse Association (WRA). Seawater Desalination Costs. White Paper; WRA: Alexandria, VA, USA, September 2011; p. 26.

348. Texas Water Development Board (TWDB). The Future of Desalination in Texas; Biennial Report on Seawater Desalination; TWDB: Austin, TX, USA, 2010; pp. 1-26.

349. Akgul, D.; Çakmakcı, M.; Kayaalp, N.; Koyuncu, I. Cost analysis of seawater desalination with reverse osmosis in turkey. Desalination 2008, 220, 123-131.

350. Wade, N.M. Energy and cost allocation in dual-purpose power and desalination plants. Desalination 1999, 123, 115-125.

351. Hafez, A.; El-Manharawy, S. Economics of seawater ro desalination in the red sea region, Egypt. Part 1. A case study. Desalination 2003, 153, 335-347.

352. Shrestha, E.; Ahmad, S.; Johnson, W.; Shrestha, P.; Batista, J.R. Carbon footprint of water conveyance versus desalination as alternatives to expand water supply. Desalination 2011, 280, 33-43.

353. Texas Water Development Board (TWDB). The Future of Desalination in Texas; Biennial Report on Seawater Desalination; TWDB: Austin, TX, USA, 2004; Volume 1, pp. 1-51. 
354. Greenlee, L.F.; Lawler, D.F.; Freeman, B.D.; Marrot, B.; Moulin, P. Reverse osmosis desalination: Water sources, technology, and today's challenges. Water Res. 2009, 43, 2317-2348.

355. Karagiannis, I.C.; Soldatos, P.G. Water desalination cost literature: Review and assessment. Desalination 2008, 223, 448-456.

356. Zhou, Y.; Tol, R.S.J. Evaluating the costs of desalination and water transport. Water Resour. Res. 2005, 41, 1-16.

357. Freedman, P.L.; Wolfe, J.R. Thermal Electric Power Plant Water Uses; Improvements Promote Sustainability and Increase Profits. Presented at the Canadian-US Water Policy Workshop, Washington, DC, USA, 2 October 2007; pp. 1-11.

358. Electric Power Research Institute (EPRI). Use of Degraded Water Sources as Cooling Water in Power Plants; Consultant Report 1005359; EPRI: Palo Alto, CA, USA, 2003, pp. 1-168.

359. Electric Power Research Institute (EPRI). Program on Technology Innovation: An Energy/Water Sustainability Research Program for The Electric Power Industry; Topical Report 1015371, EPRI: Palo Alto, CA, USA, 2007; pp. 1-96.

360. Hayes, T. The electrodialysis alternative for produced water management. Gas Tips 2004, 10, $15-20$.

361. Burgess, G.; Lovegrove, K. Solar Thermal Powered Desalination: Membrane versus Distillation Technologies; Australian National University: Canberra, Australia, 2005.

362. Tonner, J. Barriers to Thermal Desalination in the United States; Desalination and Water Purification Research and Development Program Report No. 144; Bureau of Reclamation: Denver, CO, USA, 2008.

363. Wangnick, K. Present status of thermal seawater desalination techniques. Desalin. Water Reuse Q. 2000, 10, 14-21.

364. Sirkar, K.K.; Li, B. Novel Membrane and Device for Direct Contact Membrane Distillation-Based Desalination Process: Phase II; Desalination and Water Purification Research and Development Program Report No. 96; Bureau of Reclamation: Denver, CO, USA, 2003; pp. 1-76.

365. Wu, S. Analysis of water production costs of a nuclear desalination plant with a nuclear heating reactor coupled with med processes. Desalination 2006, 190, 287-294.

366. Banat, F.; Jwaied, N. Economic evaluation of desalination by small-scale autonomous solar-powered membrane distillation units. Desalination 2008, 220, 566-573.

367. Bouguecha, S.; Hamrouni, B.; Dhahbi, M. Small scale desalination pilots powered by renewable energy sources: Case studies. Desalination 2005, 183, 151-165.

368. Gude, V.G.; Nirmalakhandan, N.; Deng, S.G.; Maganti, A. Feasibility study of a new two-stage low temperature desalination process. Energy Convers. Manag. 2012, 56, 192-198.

369. Nisan, S.; Benzarti, N. A comprehensive economic evaluation of integrated desalination systems using fossil fuelled and nuclear energies and including their environmental costs. Desalination 2008, 229, 125-146.

370. Zuo, G.; Wang, R.; Field, R.; Fane, A.G. Energy efficiency evaluation and economic analyses of direct contact membrane distillation system using aspen plus. Desalination 2011, 283, 237-244. 
371. Gude, V.G.; Nirmalakhandan, N. Combined desalination and solar-assisted air-conditioning system. Energy Convers. Manag. 2008, 49, 3326-3330.

372. Milow, B.; Zarza, E. Advanced med solar desalination plants. Configurations, costs, future-Seven years of experience at the plataforma solar de almeria (Spain). Desalination 1997, 108, 51-58.

373. El-Nashar, A.; Samad, M. The solar desalination plant in abu dhabi: 13 years of performance and operating history. Renew. Energy 1998, 14, 236-274.

374. Suri, R.K.; Al-Marafie, A.M.R.; Al-Homoud, A.A.; Maheshwari, G.P. Cost-effectiveness of solar water production. Desalination 1989, 71, 165-175.

375. Kullab, A.; Liu, C.; Martin, A. Solar desalination using membrane distallation-Technical evaluation case study. In Proceedings of International Solar Energy Society Conference, Orlando, Fl, USA, 6-12 August 2005.

376. Sirkar, K.K.; Li, B. Novel Membrane and Device for Direct Contact Membrane Distillation-Based Desalination Process: Phase III; Desalination and Water Purification Research and Development Program Report No. 99; Bureau of Reclamation: Denver, CO, USA, 2008; pp. 1-62.

377. Côté, P.; Siverns, S.; Monti, S. Comparison of membrane-based solutions for water reclamation and desalination. Desalination 2005, 182, 251-257.

378. Mickley, M. Review of concentrate management options; In The Future of Desalination in Texas, Volume II: Technical Papers, Case Studies and Desalination Technology Resources; Report No. 363; Texas Water Development Board: Austin, TX, USA, 2004; pp. 1-14.

(C) 2013 by the authors; licensee MDPI, Basel, Switzerland. This article is an open access article distributed under the terms and conditions of the Creative Commons Attribution license (http://creativecommons.org/licenses/by/3.0/). 